UNIVERSIDADE DE SÃO PAULO

FACULDADE DE FILOSOFIA, CIÊNCIAS E LETRAS DE RIBEIRÃO PRETO

DEPARTAMENTO DE FÍSICA

PROGRAMA DE PÓS-GRADUAÇÃO EM FÍSICA APLICADA À MEDICINA E BIOLOGIA

AIRTON MONTE SERRAT BORIN JUNIOR

Avaliação de Métodos de Análises não Lineares Alternativos à Entropia Multi-escala em Séries Fisiológicas Curtas

Ribeirão Preto-SP 



\title{
Avaliação de Métodos de Análises não Lineares Alternativos à Entropia Multi-escala em Séries Fisiológicas Curtas
}

\author{
Versão Corrigida \\ Versão original encontra-se na FFCLRP/USP.
}

Tese apresentada à Faculdade de Filosofia, Ciências e Letras de Ribeirão Preto (FFCLRP) da Universidade de São Paulo (USP), como parte das exigências para a obtenção do título de Doutor em Ciências.

Área de Concentração: Ciências.

Orientador: Luiz Otávio Murta Junior

Coorientador: Luiz Eduardo Virgílio da Silva

Ribeirão Preto-SP 

Borin Jr, Airton Monte Serrat

Avaliação de Métodos de Análises não Lineares Alternativos à Entropia Multiescala em Séries Fisiológicas Curtas. Ribeirão Preto-SP, 2021.

101p. : il.; $30 \mathrm{~cm}$.

Tese apresentada à Faculdade de Filosofia, Ciências e Letras de Ribeirão Preto da USP, como parte das exigências para a obtenção do título de Doutor em Ciências.

Orientador: Luiz Otávio Murta Junior

Coorientador: Luiz Eduardo Virgílio da Silva

1. Entropia Multi-escala. 2. Séries Temporais Fisiológicas Curtas. 3. Lógica Fuzzy. 

Airton Monte Serrat Borin Junior

Avaliação de Métodos de Análises não Lineares Alternativos à Entropia Multi-escala em Séries Fisiológicas Curtas

Trabalho aprovado. Ribeirão Preto-SP, 18 de junho de 2021:

Orientador:

Orientador

Professor

Convidado 1

Professor

Convidado 2

Professor

Convidado 3

Professor

Convidado 4

Professor

Convidado 5

Ribeirão Preto-SP

2021 

Dedico este trabalho aos meus orientadores e meus familiares. Sem eles nada seria possível. 



\section{Agradecimentos}

Em primeiro lugar, devo agradecer aos meus orientadores de pesquisa, Prof. Dr Luiz Otávio Murta Junior e Dr Luiz Eduardo Virgílio da Silva. Sem suas assistências e envolvimento dedicado em todas as etapas do processo, esta tese nunca teria sido realizada. Gostaria de agradecer muito ao apoio e compreensão que me deram ao longo dos últimos quatro anos.

Em junho de 2016, fui para a Universidade de São Paulo. Meu tempo no CSIM foi altamente produtivo e trabalhar com meus colegas de laboratório foi uma experiência extraordinária. Sou grato pela convivência nesse tempo em que compartilhamos nossos estudos.

Terminar minha tese exigiu mais do que apoio acadêmico, e tenho muitas, muitas pessoas a agradecer por me ouvir e, às vezes, por ter que me tolerar nos últimos anos. Não posso começar a expressar minha gratidão e apreço por sua amizade. Antônio Alberto de Sousa, Leonardo Ferreira, Juliano Jinzenji, amigos que foram imprescindíveis em seu apoio pessoal e profissional durante o tempo que passei na Universidade.

Mais importante ainda, nada disso poderia ter acontecido sem minha família. Minha esposa, que me encorajava todas as vezes que me sentia incapaz de resolver alguma situação e toda vez que eu estava pronto para desistir, você jamais me deixou. Aos meus filhos, minha razão de viver. Para meus pais e irmãos - seria um eufemismo dizer que, como família, passamos por altos e baixos nessa vida, mas sempre que precisei estiveram ao meu lado e por isso serei eternamente grato. Esta tese é uma prova do amor e incentivo incondicional de vocês. 

"Por vezes sentimos que aquilo que fazemos não é senão uma gota de água no mar. Mas o mar seria menor se lhe faltasse uma gota."

(Madre Teresa de Calcutá) 



\section{Resumo}

O estudo de ritmos fisiológicos (por exemplo, respiração, ciclos cardíacos) e sua regulação, pode ser feito por meio de métodos que caracterizam a complexidade da regulação fisiológica. Os mecanismos fisiológicos subjacentes às variações cardiorrespiratórias incluem múltiplos ciclos de feedback "determinísticos"que regulam o sistema cardiorrespiratório, bem como processos "estocásticos"nos níveis celular e molecular (por exemplo, canais iônicos, liberação de neurotransmissores, etc.). A natureza estocástica dos sistemas reais impede o uso de modelos determinísticos para descrever variações fisiológicas. Assim, os métodos estocásticos podem fornecer informações úteis sobre a complexidade dos ritmos fisiológicos e descobrir mecanismos que estão associados a patologias complexas, como arritmia cardíaca por exemplo. Uma maneira de abordar a complexidade por métodos estocásticos é procurando a presença da propriedade fractais, que pode ser detectado em sistemas naturais acima de uma determinada escala de tempo.

A introdução do método de entropia multi-escala (MSE) foi um marco no campo da análise de sinais fisiológicos complexos, de forma que a MSE se tornou uma abordagem fundamental para acessar a complexidade de uma série de temporal, estimando sua criação de informações em uma gama de escalas temporais. No entanto, a MSE pode não ser precisa ou válida para séries temporais curtas. Por isso que estudos anteriores aplicaram diferentes tipos de derivações de seu algoritmo a séries temporais de curto prazo. Contudo, nenhum estudo analisou e comparou sistematicamente suas confiabilidades. Uma das variantes mais importantes da MSE é a entropia multi-escala modificada (MMSE), embora ainda possa produzir estimativas enviesadas devido aos critérios de similaridade rígidos da entropia amostral.

Aproveitando as vantagens do MMSE e do conceito de entropia fuzzy, propomos nessa tese a entropia multi-escala fuzzy modificada (MMFE) como refinamento da MMSE para séries temporais fisiológicas de curto prazo. Avaliamos a robustez da MMSE e MMFE usando ruídos estocásticos segmentados e séries de variabilidade da frequência cardíaca real, comparadas com os resultados da MSE clássica obtidos com os sinais completos. Os resultados mostram que o MMFE é muito mais robusta do que o MMSE para um série temporal fisiológica curta, assemelhando-se a MSE para amostras da séries com 400 batimentos. Também mostramos a existência de uma relação exponencial entre o parâmetro fuzzy da MMFE e o tamanho do sinal. Sugerimos o uso dessa relação para escolher o parâmetro MMFE ideal como parte do método.

Nessa tese também são comparadas as mais importantes variações do algoritmo MSE adaptadas a séries temporais curtas em séries temporais de variabilidade da frequência cardíaca (VFC) humana e de rato. São estudadas as variações mais utilizadas de MSE: MSE composta (CMSE), MSE composta refinada (RCMSE), além da MSE modificado 
(MMSE) e suas versões fuzzy. Também analisamos os erros nas estimativas de MSE para uma gama de expoentes fuzzy incorporados. Os resultados mostram que as versões fuzzy MSE, em função do comprimento da série temporal, apresentam erros mínimos em comparação com os algoritmos não fuzzy. O algoritmo da MSE tradicional com contagem fuzzy (MFE) tem precisão semelhante a algoritmos alternativos com melhor desempenho computacional. Para a melhor precisão, os resultados sugerem diferentes expoentes fuzzy de acordo com o comprimento da série temporal.

Palavras-chave: Entropia Multi-escala. Séries Temporais Fisiológicas Curtas. Lógica Fuzzy. 


\section{Abstract}

The study of physiological rhythms (for example, breathing, cardiac cycles) and their regulation, can be done through methods that characterize the complexity of physiological regulation. The physiological mechanisms underlying cardiorespiratory variations include multiple "deterministic"feedback loops that regulate the cardiorespiratory system, as well as "stochastic"processes at the cellular and molecular levels (for example, ion channels, neurotransmitter release, etc.). The stochastic nature of real systems prevents the use of deterministic models to describe physiological variations. Thus, stochastic methods can provide useful information on the complexity of physiological rhythms and discover mechanisms that are associated with complex pathologies, such as cardiac arrhythmia for example. One way to approach complexity by stochastic methods is to look for the presence of the fractals property, which can be detected in natural systems above a certain time scale.

The introduction of the multiscale entropy method (MSE) was a milestone in the field of complex physiological signal analysis, so that the MSE has become a fundamental approach to access the complexity of a time series, estimating its creation of information in a range of time scales. However, the MSE may not be accurate or valid for short time series. That is why previous studies have applied different types of derivations of its algorithm to short-term time series. Nevertheless, , no study has systematically analyzed and compared its reliability. One of the most important variants of the MSE is the modified multiscale entropy (MMSE), although it can still produce skewed estimates due to the strict similarity criteria of the sample entropy.

Taking advantage of the MMSE and the fuzzy entropy concept, we propose in this thesis the modified multi-scale fuzzy entropy (MMFE) as a refinement of the MMSE for short-term physiological time series. We evaluated the robustness of the MMSE and MMFE using segmented stochastic noises and series of variability of the real heart rate, compared with the results of the classical MSE obtained with the complete signals. The results show that the MMFE is much more robust than the MMSE for a short physiological temparl series, similar to the MSE for samples from the series with 400 beats. We also show the existence of an exponential relationship between the MMFE fuzzy parameter and the size of the signal. We suggest using this relationship to choose the ideal MMFE parameter as part of the method.

In this thesis, the most important variations of the MSE algorithm adapted to short time series in human and rat heart rate variability (HRV) time series are also compared. The most used variations of MSE are studied: composite MSE (CMSE), refined composite MSE (RCMSE), in addition to the modified MSE (MMSE) and its fuzzy versions. We also analyzed the errors in the MSE estimates for a range of embedded fuzzy exponents. 
The results show that the fuzzy MSE versions, as a function of the length of the time series, have minimal errors compared to the non-fuzzy algorithms. The traditional MSE algorithm with fuzzy counting (MFE) has precision similar to alternative algorithms with better computational performance. For the best precision, the results suggest different fuzzy exponents according to the length of the time series.

Keywords: Multiscale Entropy. Short Physiological Time Series. Fuzzy Logic. 


\section{Lista de figuras}

Figura 1 - Na figura acima o painel a) ilustra a definição binária da função Degrau e sua descontinuidade. O painel b) ilustra o fato de uma função exponencial ser contínua. . . . . . . . . . . . . . . . . . . 35

Figura 2 - Um exemplo de uma estrutura fractal gerada por computador, ilustrando auto-similaridade em múltiplas escalas usando algoritmos modificados com base na chamada matriz de Kantor. Fonte: Figura gerada pelo autor. . . . . 39

Figura 3 - Evolução da curva logística para (a) $a=2,8$ (regime constante), (b) $a=$ 3,2 (período igual a 2), (c) $a=3,5$ (período igual a 4) e (d) $a=4,0$ ( comportamento caótico). Em todos os casos a condição inicial foi definida por $\mathrm{x} 0=0 ; 1$, os 60 primeiros valores foram descartados para garantir a estabilização e os 100 pontos seguintes foram plotados. Fonte: Figura gerada pelo autor. . . . . . . . . . . . . . . . . . . . . .

Figura 4 - Diagrama de bifurcação do mapa logístico. Para cada valor de r, foram obtidos 2000 pontos sequenciais do mapa logístico, desprezando-se os primeiro 500 pontos para estabilização. O diagrama de bifurcação para a equação 2.6. Fonte: Figura gerada pelo autor. . . . . . . . . . . . . . . . . . . . . 42

Figura 5 - Série temporal de frequência cardíaca para um sujeito do sexo feminino de 22 anos (painel superior) e um sujeito do sexo masculino de 73 anos (painel inferior). A média de batimentos cardíacos por minuto para o jovem foi de 64,7; desvio padrão, 3,9; e entropia aproximada, 1,09. A média de batimentos cardíacos por minuto para o idoso era de 64,5 ; desvio padrão, 3,8 ; e entropia aproximada, 0,48. A entropia aproximada é uma medida de "complexidade não linear". Apesar das medias e desvios padrão da frequência cardíaca quase idênticas para as duas séries temporais, a "complexidade"do sinal do sujeito mais velho é significativamente menor. Figura adaptada Lewis, Lipsitz,Ary e Goldberger $(1) \quad \ldots \ldots \ldots$. . . . . . . . . . . . . . 44

Figura 6 - Variabilidade da frequência cardíaca: registros representativos de eletrocardiograma (ECG) de um cão consciente que ilustram as variações batimento a batimento no intervalo RR e na frequência cardíaca. Figura adaptada Billman (2) . . . . . . . . . . . . . . . . . . . . . 4 4 
Figura 7 - Exemplo de contagem de padrões (match) conforme a equação 3.3. Nesse exemplo, considerando $m=3$, e tendo $x_{3}(i)=\{u(6), u(7), u(8)\}$ como o primeiro padrão. As linhas tracejadas horizontais indicam a tolerância $(r)$ para cada um dos três pontos do padrão que segundo a equação 3.4 é $x_{m}(i) \pm r$. Os pontos em verde estão no intervalo de tolerância do ponto u(6), em azul do $u(2)$ e em vermelho, do $u(3)$. Podemos notar que apenas a sequência $\{u(47), u(48), u(49)\}$ é um padrão no qual os três pontos reaparecem em sequência dentro das tolerâncias definidas. Para o caso de $m=2$, e tomando $x_{2}(i)=\{u(6), u(7)\}$ teremos 5 padrões considerados iguais $(\{u(9), u(10)\}$, $\{u(21), u(22)\},\{u(36), u(37)\},\{u(47), u(48)\}$ e $\{u(61), u(62)\}) \ldots \ldots 1$

Figura 8 - SampEn e ApEn como funções de $N(m=2, r=0,2)$ calculadas para ruídos branco simulados. Os intervalos de confiança para estatísticas SampEn são exibidos como barras de erro. A linha reta é o valor teoricamente do

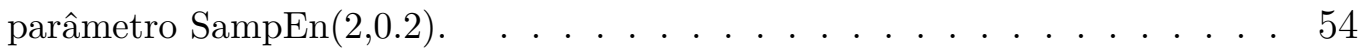

Figura 9 - MSE calculada para ruídos simulados de distribuição gaussiana branco (média zero e variância 1), e para série temporal de ruído $1 / f$, de comprimento 30000 pontos cada. Os símbolos representam valores médios de entropia para 30 séries temporais e barras de erro do desvio padrão. As linhas representam a avaliação numérica do cálculo analítico da SampEn. Adaptado de (3). . 56

Figura 10 - Ilustração do processo de construção de séries temporais coarse-grained para fatores de escala $\tau=2$ e $\tau=3$ segundo o método da MSE, onde cada ponto na escala $\tau$ da série coarse-grained é obtido pela média móvel sem sobreposição de $\tau$ pontos da série original. Adaptado de (4) . . . . . . . . . . . . . . . 56

Figura 11 - Ilustração esquemática do procedimento coarse-grained segundo a CMSE para a escala $\tau=2$ e $\tau=3$ (5).Para cada fator de escala $\tau$, são consideradas $\tau$ séries, duas séries na escala $\tau=2$, três séries na escala $\tau=3$ e assim sucessivamente. Figura adaptada de (5) . . . . . . . . . . . . . . . 58

Figura 12 - O coarse-grained segundo a MMSE (6), ilustrando a média móvel com sobreposição para os fatores de escala $\tau=2$ e $\tau=3$. Fonte: figura gerada pelo autor. . . . . . . . . . . . . . . . . . . 6 61 
Figura 13 - Entropia multi-escala (MSE), MSE modificada (MMSE) e a entropia fuzzy multi-escala modificada proposta (MMFE) calculada para os conjuntos de dados VFC. Os valores representam a entropia média, ou seja, MSE, MMSE e MMFE, \pm SD plotado como uma função de escalas de tempo $(\tau)$. Os resultados para ratos (painéis superiores) e humanos (painéis inferiores) são mostrados. Os gráficos mostram que as curvas MMFE estão mais próximas para a MSE quando comparadas ao MMSE, para séries segmentadas em janelas de 400 (plotagens à esquerda) e 1200 pontos (plotagens à direita). O MMSE não pode estimar valores de entropia para escalas maiores que $\tau=11$ (ratos) ou $\tau=14$ (humanos) para séries RR com 400 pontos. Observe que o MSE original é o mesmo nos gráficos da esquerda e da direita, pois é sempre calculado a partir da série RR completa. . . . . . . . . . . . . . .

Figura 14 - Entropia multi-escala (MSE), MSE modificada (MMSE) e a proposta da entropia fuzzy multi-escala modificada (MMFE) calculada para os ruídos estocásticos. Os valores representam a entropia média, ou seja, MSE, MMSE e MMFE, \pm desvio padrão plotado como uma função de escalas de tempo $(\tau)$. Os resultados para ruído branco (painéis superiores) e ruído rosa (painéis inferiores) são mostrados. Os gráficos mostram que as curvas MMSE virtualmente se sobrepõem ao MSE para ruído branco, para segmentos de $N=400$ (gráficos à esquerda) e $N=1200$ pontos (gráficos à direita). Para ruído rosa, MMFE está mais próximo de MSE do que MMSE para $N=400$, mas o oposto acontece para $N=1200$. Além disso, o MMSE não pode estimar os valores de entropia do ruído rosa para escalas maiores que $\tau=15$. Observe que o MSE original é o mesmo nos gráficos da esquerda e da direita, pois é sempre calculado a partir da série RR completa. . . . . . . . . . . .

Figura 15 - Erro quadrático médio de conjuntos de dados VFC calculados para MMSE (linhas cinzas) e MMFE (linhas azuis e pretas), tomando o MSE original, calculado usando a série temporal completa, como padrão ouro. Os painéis da esquerda mostram os resultados para ratos e os painéis da direita mostram os resultados para humanos. O gráfico na parte superior mostra o erro para diferentes expoentes $n$ de MMFE, indicando que, para séries curtas, MMFE apresentou estimativas muito mais precisas em relação a toda a dinâmica. Os gráficos no canto inferior esquerdo são uma ampliação do anterior. O gráfico no canto inferior direito mostra o erro mínimo obtido com MMFE ( $n$ diferente para cada tamanho de segmento) em comparação com o erro obtido com MMSE. O erro do MMFE está sempre abaixo do erro do MMSE para um comprimento de série de até $N=11200$ (ratos) ou $N=13600$ (humanos) amostras quando escolhemos o $n$ adequado. . . . . . . . . . . . . 73 
Figura 16 - Erro quadrático médio dos ruídos estocásticos calculados para MMSE (linhas cinzas) e MMFE (linhas vermelhas), tomando o MSE original, calculado usando a série temporal completa, como padrão ouro. O painel esquerdo mostra os resultados para o ruído branco e o painel direito mostra os resultados para o ruído rosa. O expoente fuzzy MF que retorna o menor erro para MMFE é $n=0,5$ para ruídos brancos e rosa. No entanto, mesmo para o melhor expoente, MMSE retorna os erros mais baixos, exceto para $N=400$ no ruído rosa. Diferentemente dos resultados para conjuntos de dados VFC, o melhor expoente MF do MMFE não depende do tamanho do segmento para ruídos estocásticos. . . . . . . . . . . . . . . . . . . . . . 74

Figura 17 - Melhores expoentes de funções fuzzy MMFE e exemplos ilustrativos de funções de pertinência (MF). O gráfico à esquerda e ao centro mostra os melhores expoentes para cada tamanho de segmento, ou seja, os valores de $n$ que resultam no erro inferior, para os conjuntos de dados VFC de ratos e humanos, respectivamente. (ver figura 16). As linhas pretas mostram o ajuste exponencial sugerido para ser usado na escolha do melhor $n$. À direita, o contraste entre a função de passo de Degrau usada em MSE convencional e MMSE (linha preta), e a função fuzzy exponencial contínua, definida como $\exp \left[-\left(\frac{d}{r}\right)^{n}\right]$, usada em MMFE (linhas azuis). Usamos $r=0,15$ para o exemplo da ilustração. . . . . . . . . . . . . . . . . . . . . . . . . . 74

Figura 18 - Erros médios quadrados de MMFE (curvas com símbolos) e MMSE (curvas sem símbolos) em função do tamanho do segmento. Apenas erros ótimos para MMFE são mostrados, obtidos com os expoentes fuzzy ótimos para cada tamanho de segmento. As linhas tracejadas mostram os resultados para $m=1$, enquanto as linhas sólidas mostram os resultados para $m=2$. Os erros foram calculados usando duas referências diferentes: o MSE original (MSE cg, gráficos à esquerda) e o MSE com o procedimento de coarse-graining substituído por um filtro Butterworth de $6^{\mathrm{a}}$ ordem (MSE bw, gráficos à direita). Os resultados para conjuntos de dados de ratos (primeira linha) e humanos (segunda linha) são mostrados. Detalhes sobre os conjuntos de dados podem ser encontrados no artigo original $(7) \ldots \ldots . \ldots 76$ 
Figura 19 - Erro Quadrático Médio de MFE em função do tamanho do segmento. Os erros foram obtidos para expoentes fuzzys variando no intervalo $n=0,8$ a $n=1,5$ (ratos) e $n=0,85$ a $n=0,92$ (humanos). Os gráficos superiores mostram todas as curvas de erro, enquanto os gráficos inferiores mostram a ampliação dos erros de tamanhos de segmentos curtos. Pode-se notar que o expoente fuzzy que dá a melhor precisão (menor erro) varia de acordo com o tamanho do segmento. O erro mais baixo para todos os tamanhos de segmento é ilustrado nos gráficos à direita dos gráficos de ampliação (MFE mínimo). . . . . . . . . . . . . 79

Figura 20 - Erros médios quadrados de CMFE e CMSE em função do tamanho do segmento. Os erros de CMFE foram obtidos para expoentes fuzzy variando no intervalo $n=0,8$ a $n=1,5$ (ratos, à esquerda) e $n=0,85$ a $n=0,92$ (humanos, à direita). Os gráficos superiores mostram as curvas de erro completas de CMFE (linhas sólidas) e CMSE (linhas tracejadas), enquanto os gráficos inferiores mostram uma ampliação dos erros para tamanhos de segmento curtos. Pode-se notar que o expoente fuzzy que dá a melhor precisão (menor erro) para o CMFE varia de acordo com o tamanho do segmento. O erro mais baixo para CMFE (linhas pretas) e CMSE (linhas cinza) para todos os tamanhos de segmento são ilustrados nos gráficos à direita dos gráficos de ampliação. 80

Figura 21 - Erros quadrados médios de RCMFE e RCMSE em função do tamanho do segmento. Os erros de RCMFE foram obtidos para expoentes fuzzys variando na faixa de $n=0,8$ a $n=1,5$ (ratos, à esquerda) e $n=0,85$ a $n=0,92$ (humanos, à direita). Os gráficos superiores mostram as curvas de erro completas de RCMFE (linhas sólidas) e RCMSE (linhas tracejadas), enquanto os gráficos inferiores mostram a ampliação dos erros de tamanho de segmento curto. Pode-se notar que o expoente fuzzy que dá a melhor precisão (menor erro) para o RCMFE varia de acordo com o tamanho do segmento. O menor erro para RCMFE (linhas pretas) e RCMSE (linhas cinzas) para todos os tamanhos de segmento são ilustrados nos gráficos à direita dos gráficos de ampliação. . . . . . . 81 
Figura 22 - Erros quadrados médios de MMFE e MMSE em função do tamanho do segmento. Os erros de MMFE foram obtidos para expoentes fuzzys variando na faixa de $n=0,8$ a $n=1,5$ (ratos, à esquerda) e $n=0,85$ a $n=0,92$ (humanos, à direita). Os gráficos superiores mostram as curvas de erro completas de MMFE (linhas sólidas) e MMSE (linhas tracejadas), enquanto os gráficos inferiores mostram uma ampliação dos erros para tamanhos de segmento curtos. Pode-se notar que o expoente fuzzy que dá a melhor precisão (menor erro) para o MMFE varia de acordo com o tamanho do segmento. O menor erro para MMFE (linhas pretas) e MMSE (linhas cinzas) para todos os tamanhos de segmento são ilustrados nos gráficos à direita dos gráficos de ampliação. . . . . . . 82

Figura 23 - Erro quadrático médio para todas as abordagens consideradas, ou seja, CMSE, RCMSE, MMSE, CMFE, RCMFE, MMFE e MFE. Para abordagens baseadas em entropia fuzzy, apenas o erro mínimo é mostrado, obtido com o expoente fuzzy ótimo para cada tamanho de segmento. Os resultados são mostrados para bancos de dados de ratos (esquerda) e humanos (direita). Observe que os erros são calculados em relação ao MSE de séries temporais de comprimento total, ou seja, 15892 batimentos. 82

Figura 24 - Os melhores expoentes fuzzy encontrados para cada tamanho de segmento em conjuntos de dados VFC de ratos e humanos. As linhas sólidas representam as funções de melhor ajuste, ou seja, uma função exponencial decrescente $y=1,64-0,75 \times \exp \left(-3 \times x / 10^{4}\right)$ para ratos e um exponencial crescente $y=0,82-0,10 \times \exp \left(-4 \times x / 10^{4}\right)$ para humanos. Essas funções podem ser usadas para escolher o melhor expoente fuzzy desses conjuntos de dados de acordo com o comprimento da série.

Figura 25 - Erros quadrados médios de MFE em função do tamanho do segmento, obtidos com a função fuzzy alternativa, ou seja, $\exp \left(-0,6931 \times(d / r)^{n}\right)$. Os erros são ilustrados para o expoente fuzzy variando no intervalo $n=1,3$ a $n=3,0$ (ratos) e $n=2,0$ a $n=5,5$ (humanos). Os gráficos superiores mostram todas as curvas de erro, enquanto os gráficos inferiores mostram a ampliação dos erros de tamanhos de segmentos curtos. Pode-se notar que o expoente fuzzy que dá a melhor precisão (menor erro) varia de acordo com o tamanho do segmento, embora os expoentes ótimos sejam diferentes daqueles obtidos com a função fuzzy original. O erro mais baixo para todos os tamanhos de segmento é ilustrado nos gráficos ampliados à direita (MFE mínimo). Para referência, o MMSE também é ilustrado nos gráficos (linhas cinza). . . 84 
Figura 26 - Tempo de computação das variantes baseadas em entropia fuzzy de MSE, ou seja, MFE, CMFE, RCMFE e MMFE. O gráfico mostra o tempo médio consumido (em segundos) para calcular as variantes de MSE para três séries de VFC de humanos até segmentos de 12.000 pontos. É importante notar que o CMFE e o RCMFE levam praticamente o mesmo tempo para serem calculados e, portanto, essas curvas são sobrepostas. . . . . . . . . . . . . . . . . . 85 



\section{Lista de abreviaturas e siglas}

\begin{tabular}{|c|c|}
\hline ApEn & Entropia Aproximada \\
\hline ASR & Arritmia Sinusal Respiratória \\
\hline bw & Filtro Butterworth \\
\hline $\mathrm{cg}$ & Média Móvel \\
\hline CMFE & Entropia Fuzzy Multi-escala Composta \\
\hline CMSE & Entropia multi-escala Composta \\
\hline ECG & Eletrocardiograma \\
\hline $\exp$ & Função Exponencial \\
\hline $\mathrm{HRV}$ & Heart Rate Variability \\
\hline $\mathrm{KS}$ & Kolmogorov-Sinai \\
\hline $\mathrm{MF}$ & Funções de Pertinência \\
\hline MFE & Entropia Multi-escala Fuzzy \\
\hline MMFE & Entropia Multi-escala Fuzzy modificada \\
\hline MMSE & Entropia Multi-escala Fuzzy modificada \\
\hline MSE & Entropia Multi-escala Fuzzy \\
\hline $\mathrm{RCMFE}$ & Entropia Multi-escala Fuzzy Composta Refinada \\
\hline RCMSE & Entropia Multi-escala Composta Refinada \\
\hline $\mathrm{RR}$ & Período Cardíaco \\
\hline SampEn & Entropia Amostral \\
\hline SD & Desvio Padrão \\
\hline $\mathrm{VFC}$ & Variabilidade da Frequência Cardíaca \\
\hline
\end{tabular}





\section{Lista de símbolos}

$\Gamma$

$\delta$

$\epsilon$

$\Theta$

$\mu$

$\pi$

$\sigma$

$\tau$

$\phi$

$\Phi$
Letra grega maiúscula gama

Letra grega minúscula delta

Letra grega minúscula epsilon

Letra grega maiúscula Teta

Letra grega minúscula mi

Letra grega minúscula pi

Letra grega minúscula sigma

Letra grega minúscula tau

Letra grega minúscula phi

Letra grega maiúscula phi 



\section{Sumário}

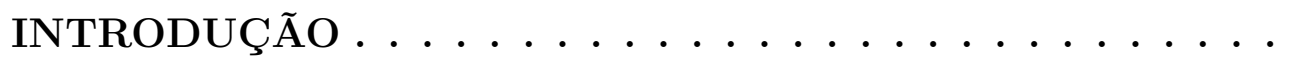

COMPLEXIDADE FISIOLÓGICA . . . . . . . . . . 37

2.0.1 Dinâmica não Linear, Fractais e Caos _ . . . . . . . . . . . . 37

2.0.2 Dinâmica não Linear em Sistemas Fisiológicos . . . . . . . . . . . . 43

2.0.3 Dinâmica Cardíaca . . . . . . . . . . . . . . 46

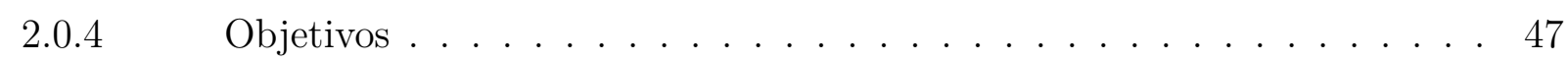

ANÁLISE NÃO LINEAR DE SÉRIES TEMPORAIS CURTAS POR MEIO DE ENTROPIA . . . . . . . . . . . . . 49

$3.1 \quad$ Entropia Aproximada - ApEn . . . . . . . . . . . . 50

$3.2 \quad$ Entropia Amostral - SampEn . . . . . . . . . . . . . 52

3.3 Métodos Variantes da Entropia Amostral . . . . . . . . . . . 54

3.3.1 Entropia Multi-escala - MSE . . . . . . . . . . . . . 55

3.3.2 Entropia Multi-escala Composta - CMSE . . . . . . . . . . . 57

3.3.3 Entropia Multi-escala Composta Redefinida - RCMSE . . . . . . . . . 59

3.3.4 Entropia Multi-escala Modificada - MMSE . . . . . . . . . . . . 60

3.4 Entropia Fuzzy - FuzzyEn . . . . . . . . . . . . 61

3.5 Métodos Variantes da Entropia Fuzzy . . . . . . . . . . . . 63

3.5.1 Multiscale Fuzzy Entropy - MFE . . . . . . . . . . . . . 63

3.5.2 Entropia Fuzzy Multi-escala Composta - CMFE . . . . . . . . . . 63

3.5.3 Entropia Fuzzy Multi-escala Composta Refinida - RCMFE . . . . . . . 64

3.5.4 Entropia Multi-escala Fuzzy Modificada - MMFE . . . . . . . . . . 65

4 CONJUNTO DE DADOS E EXPERIMENTOS . . . . . 67

4.1 Teste de Robustez da MMFE . . . . . . . . . . . . 67

4.1.1 Conjuntos de Dados . . . . . . . . . . . . . . 67

$4.1 .2 \quad$ Ruídos Estocásticos . . . . . . . . . . . . . . 68

4.1.3 Substituição do Filtro Média Móvel pelo Filtro Butterworf . . . . . . . . 68

4.1.4 Teste de Robustez . . . . . . . . . . . . . . . . . . . 69

4.1.5 Resultados e Discussão do Teste de Robustez da MMFE . . . . . . . . 70

4.2 Testes de Robustez de Variantes da MSE Baseadas em Entropia Fuzzy ........................ 77

4.2.1 Conjunto de Dados . . . . . . . . . . . . . 77

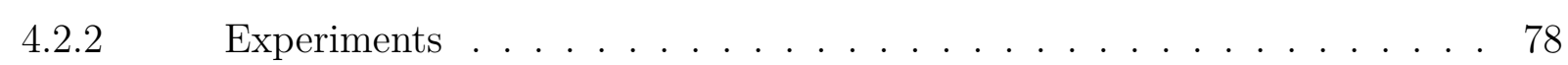


4.2.3 Resultados e Discussão dos Testes de Robustez de Variantes da MSE Baseadas em Entropia Fuzzy . . . . . . . . . . . . . . . . . 79

5

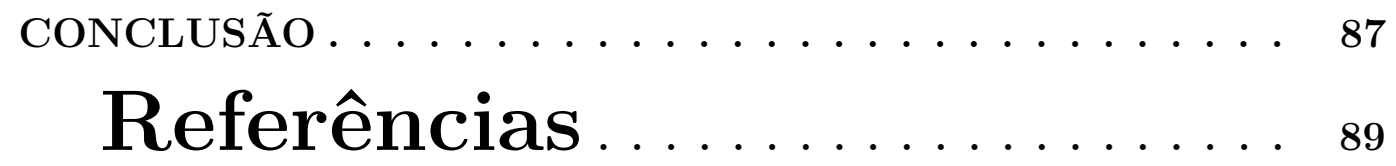

$\begin{array}{ll}\text { APENNICES } & 97\end{array}$

APÊNDICE A - ARTIGO: "MODIFIED MULTISCALE FUZZY ENTROPY: A ROBUST METHOD FOR SHORTTERM PHYSIOLOGIC SIGNALS"HTTPS://DOI.ORG/10.1063/5.0

APÊNDICE B - ARTIGO: "RESPONSE TO "COMMENT ON 'MODIFIED MULTISCALE FUZZY ENTROPY:

A ROBUST METHOD FOR SHORT-TERM PHYSIOLOGIC SIGNALS" HTTPS://DOI.ORG/10.1063/5.0040708101 


\section{Introdução}

Pode-se acessar a taxa de criação de informação das séries temporais de diferentes maneiras. Uma das formas mais consistentes é a entropia de Kolmogorov-Sinai (KS), que não é realmente uma entropia, mas uma entropia por unidade de tempo, ou uma "taxa de entropia". Toda via, quando olhamos para a sua definição, mais precisamente na equação 3.1 , vemos que, numericamente, apenas entropias para $d$ finito podem ser calculadas. Assim que $d$ se torna grande em relação ao comprimento de uma determinada série temporal, a entropia $K$ é subestimada e tende a zero. Portanto, a entropia $K S$ para séries temporais de comprimento finito geralmente não pode ser estimada com precisão razoável.

Para a análise dessas séries temporais relativamente curtas e ruidosas, Pincus introduziu entropia aproximada (ApEn), uma família de parâmetros que pode ser aplicada em séries fisiológicas (8). Posteriormente, uma modificação no algoritmo da ApEn, chamada entropia amostral (SampEn) (9), foi proposta com a vantagem de ser menos dependente do comprimento da série temporal. Esses algoritmos, no entanto, atribuem um maior valor de entropia para certas séries temporais patológicas que se presume representar uma dinâmica menos complexa do que a séries temporais derivadas de função saudável (10). A possível razão para que esses resultados ocorram está atrelada ao fato de que essas medidas são baseadas em uma única escala temporal. Tanto a entropia $K S$ quanto os parâmetros ApEn dependem da diferença de um passo de uma função e refletem a incerteza do próximo ponto, dado o história passada da série, de forma que tais medidas não levam em consideração características relacionadas à estrutura em diferentes escalas mais curtas (4).

Zhang $(11,12)$ propôs uma abordagem geral para levar em consideração as múltiplas escalas de tempo em sistemas físicos. Sua medida, baseada em uma soma ponderada de entropias dependentes da escala, de fato, produz valores mais altos para ruídos correlacionados em comparação com os não correlacionados. No entanto, uma vez que é baseado na definição de entropia de Shannon, o método de Zhang requer uma grande quantidade de dados quase sem ruído, a fim de mapear um sinal para uma sequência simbólica discreta 
com precisão estatística suficiente. Portanto, apresenta limitações óbvias quando aplicado a sinais fisiológicos típicos que variam continuamente e têm comprimento finito (4).

Em 2002 Costa et al., propôs a abordagem da entropia multi-escala (MSE) para representar a complexidade de um sinal (4). A MSE basicamente calcula a entropia amostral (SampEn) em uma faixa de escalas. A SampEn é uma medida de probabilidade condicional que quantifica a probabilidade de que dada uma sequência de $m$ pontos consecutivos correspondem a outra sequência do mesmo comprimento, dentro de uma tolerância $r$, ainda corresponderá à outra sequência quando seu comprimento for aumentado de comprimento para $m+1$. Logo, $m$ define o comprimento dos padrões que são comparados entre si (9). A distância entre dois vetores é calculada como a diferença máxima absoluta de seus componentes escalares correspondentes (ver equação 3.4).

Costa et al. define em seu algoritmo as séries temporais coarse-grained (ver seção 3.3.1 ), as quais representam a dinâmica do sistema em diferentes escalas o que permite analisar com o algoritmo de entropia amostral (SampEn) diferentes escalas temporais. Desde a sua introdução, o MSE tornou-se um método predominante para quantificar a complexidade dos sinais (13). Embora tenha sido usado com sucesso em diferentes campos de pesquisa e se mostrado como um método robusto em discriminar diferentes dinâmicas complexas, ele apresenta viés ao lidar com séries temporais de curta duração, o algoritmo da MSE pode dar uma estimativa imprecisa de entropia ou mesmo induzir valores de entropia indefinidos para séries temporais curtas (ver, por exemplo, (5)). O fato de que o cálculo do MSE requer, como primeira etapa, a construção de séries coarse-grained em escala, utilizando um filtro de média móvel sem sobreposição, reduz drasticamente o comprimento de cada série temporal escalonada por um fator $\tau$, resultando em uma série de comprimento $N / \tau$. Como consequência, o MSE torna-se inviável para ser aplicada na análise de séries temporais curtas.

O algoritmo para contagem de repetição de padrão e cálculo de entropia é responsável pelo viés da MSE. A repetição do padrão diminui à medida que a série temporal encurta, originando o viés e a instabilidade numérica. A MSE prova ser imprecisa em análises de séries temporais curtas $(6,14)$, perdendo significativamente sua sensibilidade (15).

Desde que a MSE foi introduzida, uma série de modificações e refinamentos foram propostos, alguns visando aumentar o precisão das estimativas de entropia como a substituição da função degrau, que considera somente os valores 0 e 1 na contagem de similaridade entre padrões por funções exponenciais como entropia Fuzzy (FuzzyEn) que incorpora o conceito de conjuntos fuzzy, onde a similaridade dos vetores é definida com base na função exponencial e suas formas (16). Em uma função Degrau, o limite é rígido de forma que todos os pontos de dados dentro da tolerância são tratadas igualmente, enquanto os pontos de dados fora dela são descartados. O limite rígido causa descontinuidade, 
o que pode levar a mudanças abruptas dos valores de entropia quando a tolerância muda ligeiramente, e até mesmo à falha na definição no cálculo da entropia se nenhuma correspondência for encontrada. Em uma função exponencial, ao contrário, não há limite rígido. O valor da função exponencial em torno de determinado vetor pode ser visto como a associação Fuzzy (17) para indicar a similaridade entre ele e seu vizinho. Quanto mais próximo estiver da tolerância, mais semelhante serão, e a semelhança entre eles será quase zero caso contrário (16). Nessa abordagem todos os pontos são considerados como membros da função exponencial fuzzy, os valores de entropia FuzzyEn mudarão continuamente e não há limitação para a definição de parâmetros. A figura 1 ilustra a transição binária da função Degrau (painel a)) e transição suave e contínua da função fuzzy (painel b))
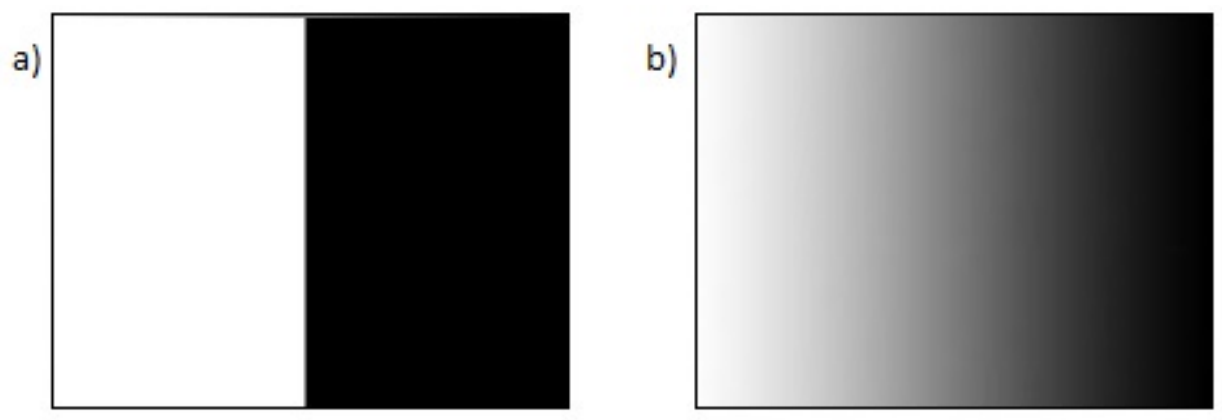

Figura 1 - Na figura acima o painel a) ilustra a definição binária da função Degrau e sua descontinuidade. O painel b) ilustra o fato de uma função exponencial ser contínua.

A entropia fuzzy multi-escala (MFE) usa contagem Fuzzy para as repetições de padrão como forma de evitar contagens zero ou instabilidades numéricas no cálculo de entropia $(18,19)$.

Outros métodos exploram procedimentos alternativos para a construção das séries coarse-grained. A entropia multi-escala composta (CMSE) (5) e a entropia multi-escala composta refinada (RCMSE) (20) empregam um conjunto de coarse-graining em tamanho real das séries temporais coarse-graining, evitando séries temporais curtas únicas. Outro método importante é a entropia multi-escala modificada (MMSE), cujo algoritmo propõe gerar a série temporal coarse-graining substituindo a média aritmética pelo procedimento de média móvel (6).

As combinações são possíveis com as técnicas relativas ao coarse-graining e contagem padrão de similaridade. A entropia Fuzzy multi-escala composta e a refinada (CMFE e RCMFE) apresentam uma abordagem em conjunta com CMSE, RCMSE, respectivamente, assim como a MFE em relação a MSE original. Ambos CMFE e RCMFE foram avaliados no contexto de sinais mecânicos e biomédicos $(19,21)$.

Nessa tese propomos a entropia Fuzzy multi-escala modificada (MMFE) para séries 
temporais fisiológicas de curto prazo, a qual avaliamos em séries de variabilidade da frequência cardíaca (VFC) (ver seção 2.0.3) e no contexto de dinâmica simulada (7). Comparamos sistematicamente as abordagens para melhorar a precisão da estimativa de MSE com MFE e suas combinações, ou seja, CMFE, RCMFE e MMFE para séries temporais curtas além de investigar a dependência do expoente fuzzy conforme o comprimento da série temporal diminui. Sendo assim, nosso objetivo principal é investigar a abordagem mais precisa e eficaz para analisar séries temporais curtas baseadas na entropia multi-escala. No capítulo 1 dessa tese trataremos do conceito de complexidade em fisiologia, apresentando uma breve introdução dos conceitos de dinâmica não Linear, fractais e caos. Falaremos da dinâmica não linear em sistemas fisiológicos com ênfase na dinâmica cardíaca. No capítulo 2, sobre análise não linear de séries temporais curtas por meio de entropia iremos descrever com detalhes os métodos que foram usados nesse estudo. Na capítulo 3 descrevemos os experimentos, apresentamos nossos resultados e faremos a discussão dos mesmos. No capítulo 4 encerramos o trabalho apresentando nossas conclusões. 


\section{Complexidade Fisiológica}

A capacidade de se prever o estado futuro de um sistema, dado o atual, está na base do conhecimento científico com implicações relevantes do ponto de vista conceitual e também em suas aplicações (22). O conhecimento da lei de evolução do sistema pode induzir alguém a concluir que esse objetivo foi alcançado. Este é o ponto de vista determinístico clássico, conforme afirmado por Laplace (23): "uma vez que as leis de evolução do sistema são conhecidas, o estado em um determinado instante $t_{0}$ determina completamente os estados subsequentes para cada tempo $t>t_{0}{ }^{11}$. No entanto, é bem estabelecido agora que isso não pode ser realizado na prática.

\subsubsection{Dinâmica não Linear, Fractais e Caos}

Em matemática uma equação linear significa que seu valor de saída é uma soma ponderada dos valores de entrada, ou seja, uma equação linear em $n$ variáveis (desconhecidas) $x_{1}, \ldots, x_{n}$ tem a forma

$$
a_{1} x_{1}+a_{2} x_{2}+\ldots+a_{n} x_{n}=b .
$$

onde $a_{1}, a_{2}, \ldots, a, b$ são números reais. Para números reais $s_{1}, s_{2}, \ldots, s_{n}$ se

$$
a_{1} s_{1}+a_{2} s_{2}+\ldots+a_{n} s_{n}=b .
$$

nós dizemos que $x_{1}=s_{1}, x_{2}=s_{2}, \ldots, x_{n}=s_{n}$ é uma solução desta equação.

Quando falamos em sistema de equações lineares em $n$ variáveis $x_{1}, \ldots, x_{n}$ queremos dizer uma coleção de equações lineares nessas variáveis. Um sistema de $m$ equações lineares

1 Considerar o cenário usual onde um sistema é estudado por um observador externo,evitando o problema da auto-predição 
nessas $n$ variáveis podem ser escritas como

$$
\left\{\begin{array}{c}
a_{11} x_{1}+a_{12} x_{2}+a_{13} x_{3}+\ldots+a_{1 n} x_{n}=b_{1} \\
a_{21} x_{1}+a_{22} x_{2}+a_{23} x_{3}+\ldots+a_{2 n} x_{n}=b_{2} \\
a_{31} x_{1}+a_{32} x_{2}+a_{33} x_{3}+\ldots+a_{3 n} x_{n}=b_{3} \\
\ldots \\
\ldots \\
a_{m 1} x_{1}+a_{m 2} x_{2}+a_{m 3} x_{3}+\ldots+a_{m n} x_{n}=b_{m}
\end{array}\right.
$$

onde $a_{i j}$ e $b_{i}$ são todos números reais

A palavra dinâmica está relacionada a variação, mudança. Um sistema dinâmico é qualquer coisa que se move, muda ou evolui com o tempo. Geralmente não é razoável supor que existe algum forma de fluxo de energia envolvida em tal sistema. Um sistema dinâmico não linear é, como o nome indica, um sistema cuja melhor descrição (comportamento) não é linear (24). Em outras palavras, os valores de um sistema em um momento não são iguais à soma ponderada dos valores anteriores. Uma definição alternativa e uma espécie de "recusa"é que não linear se refere a qualquer coisa que não seja linear (25).

Existem definições matemáticas mais formais, rígidas e complexas, mas não precisaremos desses detalhes, embora o significado de "não linear"seja intuitivamente claro, os especialistas ainda não chegaram a uma definição abrangente e aceitável para todos. Curiosamente, o mesmo se aplica a outros termos matemáticos comuns, como número, sistema, conjunto, ponto, infinito, aleatório, caos e também complexidade.

Independentemente de nossa especialidade, geralmente estamos interessados em compreender esse movimento. Temos interesse também em prever como algo se comportará ao longo do tempo e seu resultado final.

A dinâmica não linear, como o próprio nome diz, estuda sistemas nos quais a saída não é igual à soma ponderada dos valores anteriores, como por exemplo o que ocorre nos sistemas fisiológicos (1). Dois conceitos centrais na dinâmica não linear são fractais e caos. O termo fractal é um conceito geométrico que se aplica a uma ampla classe de formas complexas. A geometria fractal inicialmente desenvolvida por Mandelbrot (26) teve um grande impacto na modelagem e análise nas ciências naturais e físicas. Os fractais fornecem uma estrutura matemática apropriada para estudar as formas complexas e irregulares encontradas na natureza. Mandelbrot demonstrou que muitas superfícies fractais são generalizações de passos aleatórios e movimento browniano, ou seja, eles resultam como o limite de processos que modificam aleatoriamente a forma localmente em cada estágio. Mandelbrot demonstrou também diversos casos em que detalha a utilidade da geometria fractal (26). Pentland (27) apresentou evidências de que a maioria das superfícies naturais são fractais espacialmente isotrópicos e que as imagens de intensidade dessas superfícies também são fractais. Este trabalho fornece a base para o uso de recursos derivados de modelos fractais na análise de imagens (28). 
A principal característica desse padrão fractal é chamada de auto-similaridade. Quanto mais de perto um objeto fractal é observado, mais a estrutura é revelada. Além disso, os detalhes vistos sob ampliação lembram o contorno da estrutura maior (Figura 2). O interesse do estudo da fisiológico na geometria fractal vem da arquitetura de ramificação com propriedade auto-similar de muitas anatomias, incluindo certas redes nervosas, fibras de His-Purkinje, dobras gastrointestinais, e sistemas vasculares $(26,29)$.

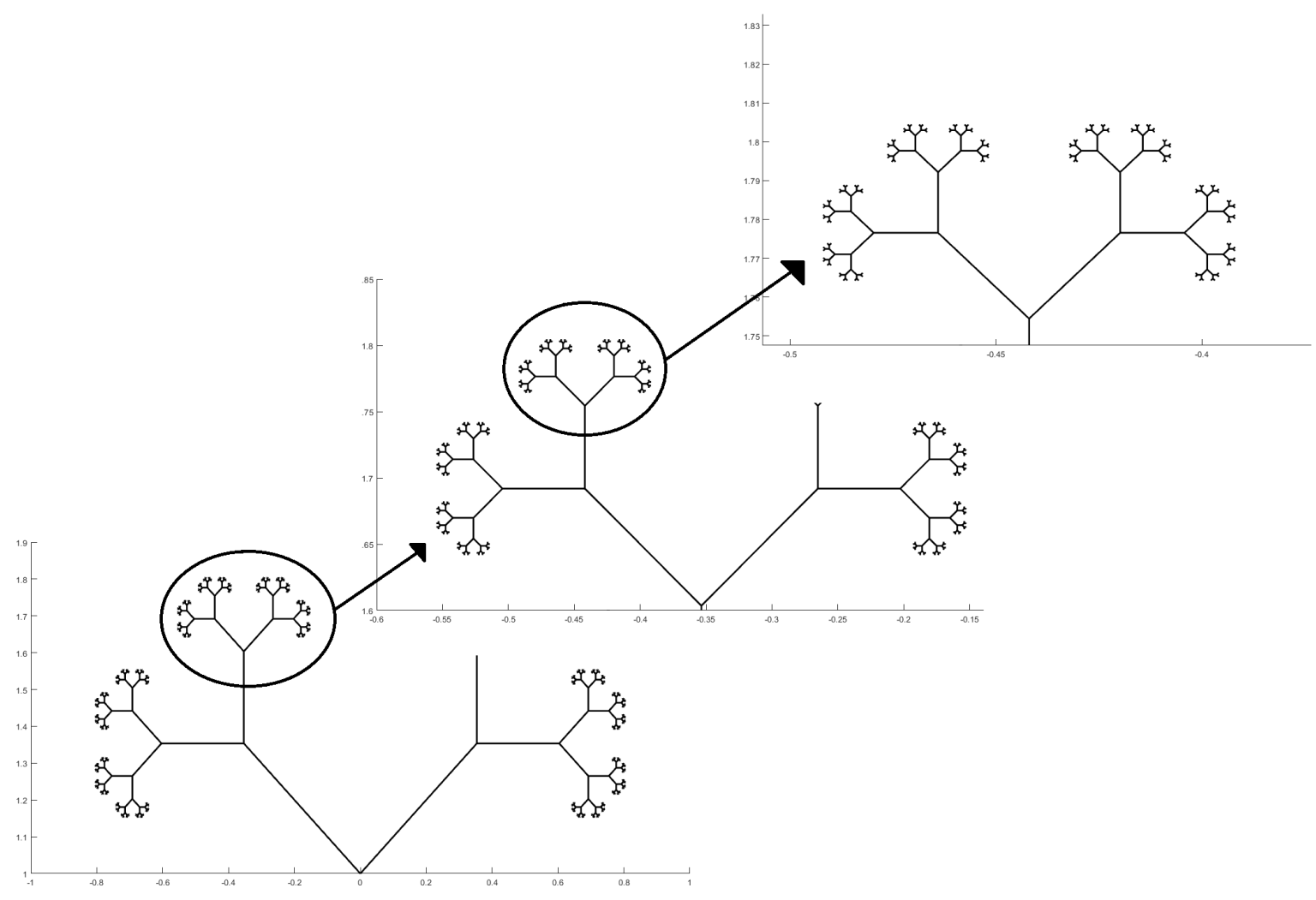

Figura 2 - Um exemplo de uma estrutura fractal gerada por computador, ilustrando autosimilaridade em múltiplas escalas usando algoritmos modificados com base na chamada matriz de Kantor. Fonte: Figura gerada pelo autor.

Os sistemas dinâmicos se enquadram em uma de duas categorias, dependendo se o sistema perde energia. Um sistema dinâmico conservador não tem atrito; não perde energia com o tempo. Em contraste, um sistema dinâmico dissipativo tem atrito; ele perde energia com o tempo e, portanto, sempre se aproxima de alguma condição assintótica ou limitante. Esse estado assintótico ou limitante, sob certas condições, é onde ocorre o caos. O termo caos descreve um comportamento aparentemente imprevisível que pode surgir dos loops de feedback interno de certos sistemas não lineares(26, 29, 30, 31, 32). O caos lida com a evolução a longo prazo, ou seja, como algo muda ao longo do tempo. Há processos aleatórios, às vezes chamados de processos estocásticos, que implica em uma coleção de variáveis aleatórias, representando a evolução de algum sistema de valores 
aleatórios ao longo do tempo (33). Em vez de descrever um processo que só pode evoluir de uma maneira (como, por exemplo, as soluções de uma equação diferencial ordinária), em um processo estocástico há alguma indeterminação: mesmo que a condição inicial seja conhecida, existem várias (muitas vezes infinitamente muitas) direções nas quais o processo pode evoluir. Existe uma evolução probabilística dos estados iniciais. Por outro lado, temos sistemas caóticos determinísticos cuja evolução temporal tem uma dependência muito forte das condições iniciais. O modelo determinístico sempre produzirá a mesma saída de uma determinada condição inicial ou estado inicial (34). Um exemplo específico é fornecido pela equação

$$
N_{t+1}=N_{t}\left(a-b N_{t}\right)
$$

A equação 2.4 é chamada de equação de diferença "logística" (35). No limite $b=0$, descreve uma população crescendo de modo exponencialmente (para $a>1$ ); para $b \neq 0$, a não linearidade quadrática produz uma curva de crescimento com uma saliência, cuja inclinação é ajustada pelo parâmetro $a$. Ao escrever $X=b N / a$, a equação pode ser trazida para a forma canônica $(35,36,37)$

$$
X_{t+1}=a X_{t}\left(1-X_{t}\right) .
$$

O parâmetro $a$ da sua equação 2.5 é uma constante que determina o regime de evolução no tempo. Dependendo do valor escolhido, sua série pode apresentar regime periódico, com a possibilidade de diversos períodos diferentes, ou mesmo regime caótico. A Figura mostra a dinâmica do mapa logístico para quatro valores diferentes de r. Como podemos observar na figura 3 , para $a=2,8$, a evolução do mapa logístico atinge um valor constante após algumas iterações. Já para os valores $a=3,2$ e $a=3,5$, o regime é periódico com período 2 e 4, respectivamente. Porém, quando temos $a=4,0$, a dinâmica deixa de ser periódica e torna-se caótica. Assim, percebe-se que a curva logística pode ou não exibir comportamento caótico, dependendo do valor do parâmetro de controle $a$. A evolução do sistema pode ser melhor compreendida analisando o gráfico que representa os valores do mapa em função do parâmetro de controle. Este gráfico, conhecido como diagrama de bifurcações, é apresentado na Figura 4 para o caso da curva logística. Para cada valor do parâmetro $a$, temos a representação dos valores ocorrendo durante a evolução. Por exemplo, quando $a=2,8$ [Figura 3(a)], o mapa terá apenas um valor durante toda sua evolução. Essa característica se mantém até $\mathrm{r}=3$. Quando $a=3,2$ [Figura 3(b)], o mapa logístico é periódico com período 2 , o que é indicado pelos dois valores de $\mathrm{x}$ associados a $a$ $=3,2$ no diagrama de bifurcações.

Isto também acontece em fenômenos reais, como por exemplo na ecologia e na previsão de populações biológicas (38). A equação seria simples se a população simplesmente aumentasse indefinidamente, mas o efeito dos predadores e um suprimento limitado de alimentos tornam essa equação incorreta. A equação mais simples que leva em consideração 


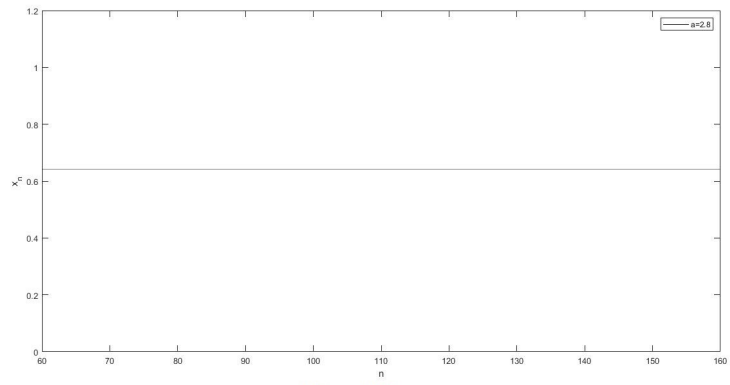

(a) $a=2,8$

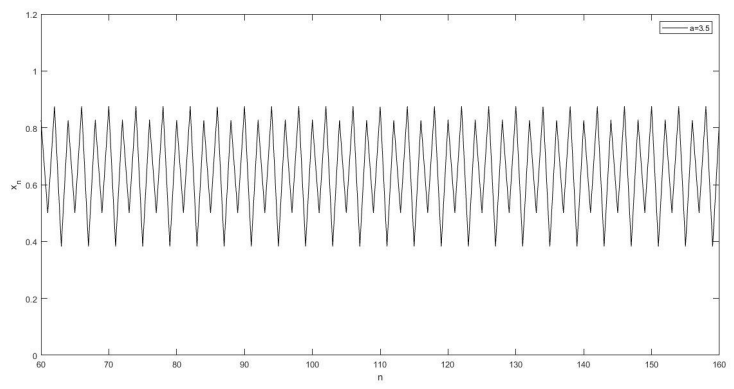

(c) $a=3,8$

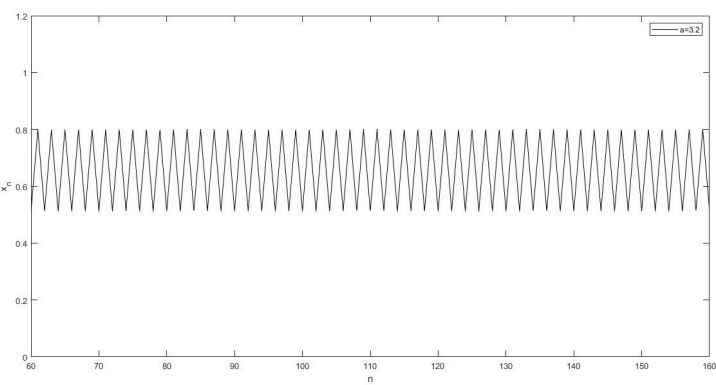

(b) $a=3,2$

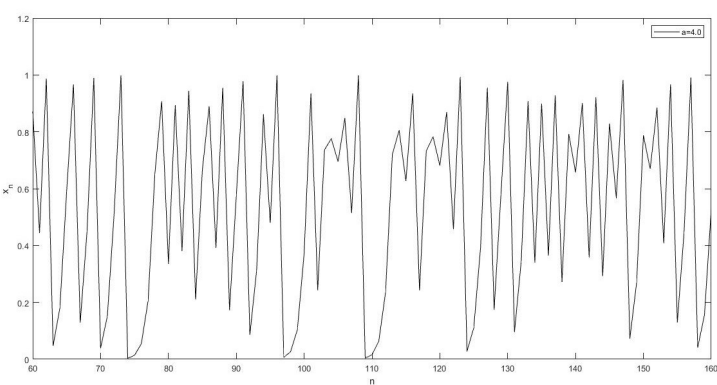

(d) $a=4,0$

Figura 3 - Evolução da curva logística para (a) $a=2,8$ (regime constante), (b) $a=3,2$ (período igual a 2), (c) $a=3,5$ (período igual a 4) e (d) $a=4,0$ ( comportamento caótico). Em todos os casos a condição inicial foi definida por $\mathrm{x} 0=0 ; 1$, os 60 primeiros valores foram descartados para garantir a estabilização e os 100 pontos seguintes foram plotados. Fonte: Figura gerada pelo autor.

o efeito dos predadores e um suprimento limitado de alimentos é a seguinte:

população do próximo ano $=r *$ população deste ano $*(1-$ população deste ano $)$. (2.6)

Pela equação 2.6, a população é um número entre 0 e 1, de forma que 1 representa a população máxima possível e 0 a extinção. O parâmetro $r$ é a taxa de crescimento (39). A forma esperada de como o parâmetro $r$ afeta a equação, é de que uma taxa de crescimento alta significa que a população se estabelecerá em uma população alta, enquanto uma taxa de crescimento baixa significa que a população se estabelecerá em um número baixo. Como podemos ver na figura 4 Essa tendência é verdadeira para algumas taxas de crescimento, mas não para todas. Notamos que para valores da taxa de crescimento baixos, a população se estabelece em um único número, como por exemplo, se o valor da taxa de crescimento é 2,7 , a população vai se estabelecer até 0,6292 . Com o aumento da taxa de crescimento, a população final também aumentaria. Contudo, algo estranho aconteceu. Na medida em que a taxa de crescimento passou de 3, a linha se partiu em duas. Em vez de se estabelecer em uma única população, ele saltaria entre duas populações diferentes. Seria um valor para um ano, mudaria para outro valor no ano seguinte e, então, repetiria o ciclo para sempre. Ao se aumentar um pouco mais a taxa de crescimento ocorre um salto entre quatro valores diferentes. Conforme o parâmetro aumenta ainda mais, a linha se bifurca novamente. As bifurcações ocorrem cada vez mais rápidas até que, de repente, o caos apareceu. Após 
uma certa taxa de crescimento, torna-se impossível prever o comportamento da equação 2.6. No entanto, ao examinar mais de perto, é possível ver faixas brancas. Olhar mais de perto essas faixas revela pequenas janelas de ordem, onde a equação passa novamente pelas bifurcações antes de retornar ao caos. Essa auto-similaridade, o fato de o gráfico ter uma cópia exata de si mesmo escondido bem no fundo. Duas das implicações práticas

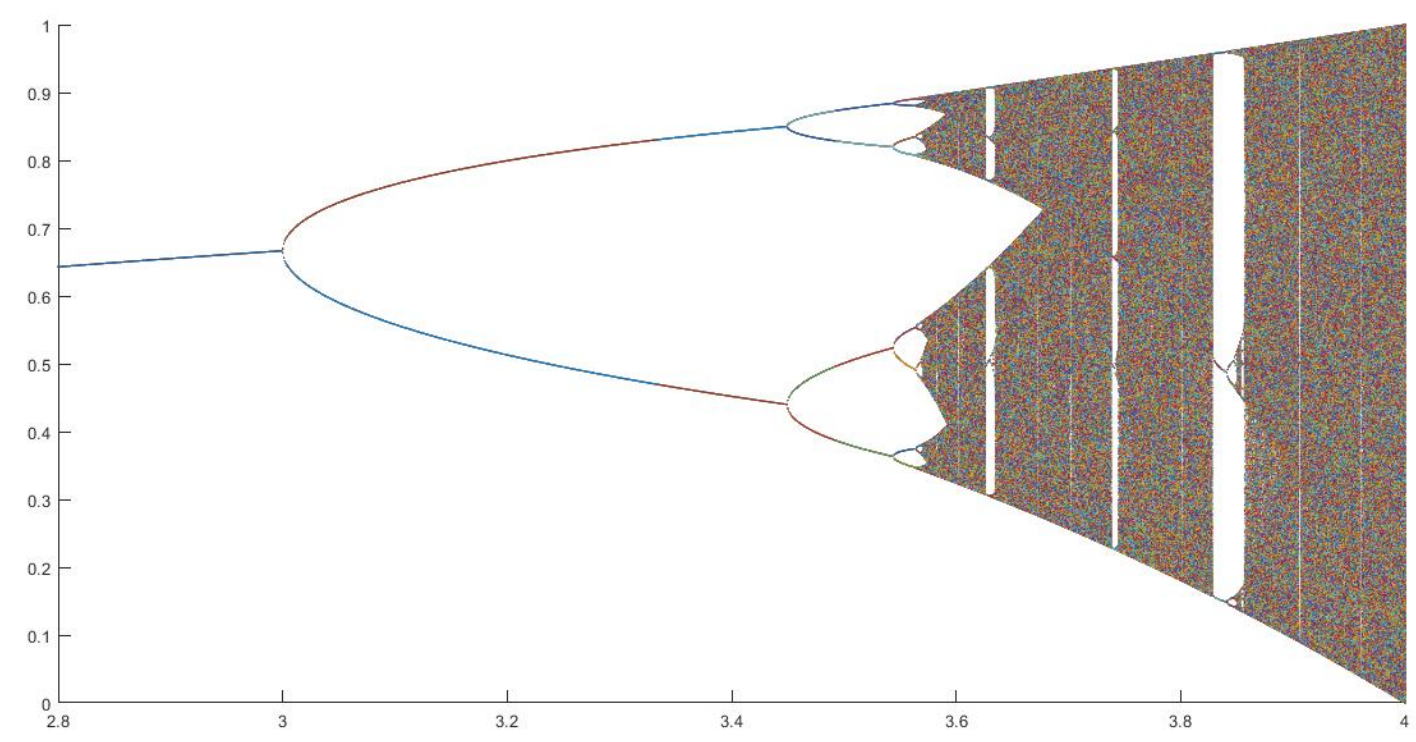

Figura 4 - Diagrama de bifurcação do mapa logístico. Para cada valor de r, foram obtidos 2000 pontos sequenciais do mapa logístico, desprezando-se os primeiro 500 pontos para estabilização. O diagrama de bifurcação para a equação 2.6. Fonte: Figura gerada pelo autor.

importantes do caos são que as previsões a longo prazo sob condições caóticas são inúteis e o comportamento complexo pode ter causas simples. O caos é difícil de identificar em dados do mundo real porque as ferramentas disponíveis geralmente foram desenvolvidas para condições ideais que são difíceis de ocorrer na prática. Assim, o caos lida com o que os especialistas gostam de se referir como teoria dos sistemas dinâmicos (o estudo de fenômenos que variam com o tempo) ou dinâmica não linear (o estudo do movimento não linear ou evolução). O caos (caos determinístico) lida com a evolução de longo prazo como algo muda ao longo do tempo. Uma série temporal caótica parece irregular. Duas das implicações práticas importantes do caos são que as previsões de longo prazo sob condições caóticas são inúteis e o comportamento complexo pode ter causas simples. O caos é difícil de identificar em dados do mundo real porque as ferramentas disponíveis geralmente foram desenvolvidas para condições idealistas que são difíceis de cumprir na prática. O caos é uma evolução de longo prazo sustentada e de aparência desordenada que satisfaz certos critérios matemáticos especiais e que ocorre em um sistema não linear determinístico, definido por sensibilidade às condições iniciais, ou seja, expoente de Lyapunov maior que 1. Assim como um fractal não tem uma característica ou escala única de comprimento, 
um processo caótico gera flutuações complexas que não têm uma escala de tempo única ou característica. Em vez disso, o caos produz um sinal de "aparência barulhenta"que varia de maneira errática e imprevisível.

\subsubsection{Dinâmica não Linear em Sistemas Fisiológicos}

Apesar de não existir um consenso universal estabelecido a respeito da definição de complexidade $(40,22)$, consideramos nesse trabalho em particular a caracterização da imprevisibilidade de um sistema como uma medida de sua complexidade $(40,22)$. As função fisiológicas em um sistema saudável constituem uma integração de redes complexas de sistemas de controle, circuitos de feedback e vários outros mecanismos reguladores que operam em uma ampla gama de escalas temporais e espaciais, permitindo a que um organismo se adapte ao estresses da vida cotidiana (10) e execute uma variedade de atividades que são necessárias para sua sobrevivência. Os sistemas de controle do corpo humano existem em níveis de organização molecular, subcelular, celular, de órgão e sistêmico que operam em várias escalas de tempo. A interação contínua entre os componentes elétricos, químicos e mecânicos desses sistemas garante que as informações sejam trocadas constantemente, mesmo quando o organismo está em repouso. Esses processos dinâmicos são evidentes na variabilidade complexa dos sistemas de controle fisiológico, como pressão arterial (PA), frequência cardíaca (FC), atividade elétrica cerebral, marcha, equilíbrio e concentrações hormonais, quando são medidos em um momento para momento ou batimento a batimento (41). Dinâmicas fisiológicas complexas permitem que um organismo responda rapidamente a perturbações internas e externas. Uma descoberta contra-intuitiva foi que o comportamento caótico caracteriza a saída de uma série de sistemas fisiológicos diferentes que já foi considerado como sendo relativamente periódico (42). Por exemplo, a figura 5 mostra que o batimento cardíaco normal do ritmo sinusal em um sujeito jovem saudável em repouso não é estritamente regular, mas mostra um tipo complexo de variabilidade ("aleatoriedade restrita") que lembra o caos. Uma abordagem que podemos usar para definir a complexidade de um processo, como o controle fisiológico da frequência cardíaca, é determinar até que ponto esse processo gera flutuações aperiódicas que se assemelham ao caos não linear. Posto isso, a questão que surge é: como faremos para determinar a complexidade de estruturas e processos não lineares?

Quantificar e modelar tal repertório desconcertante de comportamentos exibida por organismos vivos é,em geral,um enorme desafio da ciência. A combinação de não linearidade e não estacionariedade, mais a regra do que há exceção na produção de sistemas fisiológicos, representa um grande desafio para avaliações bioestatísticas convencionais e subterfúgios de modelagem reducionistas padrão. Para responder a questão acima devemos observar que muitas estruturas anatômicas têm uma morfologia semelhante a um fractal 

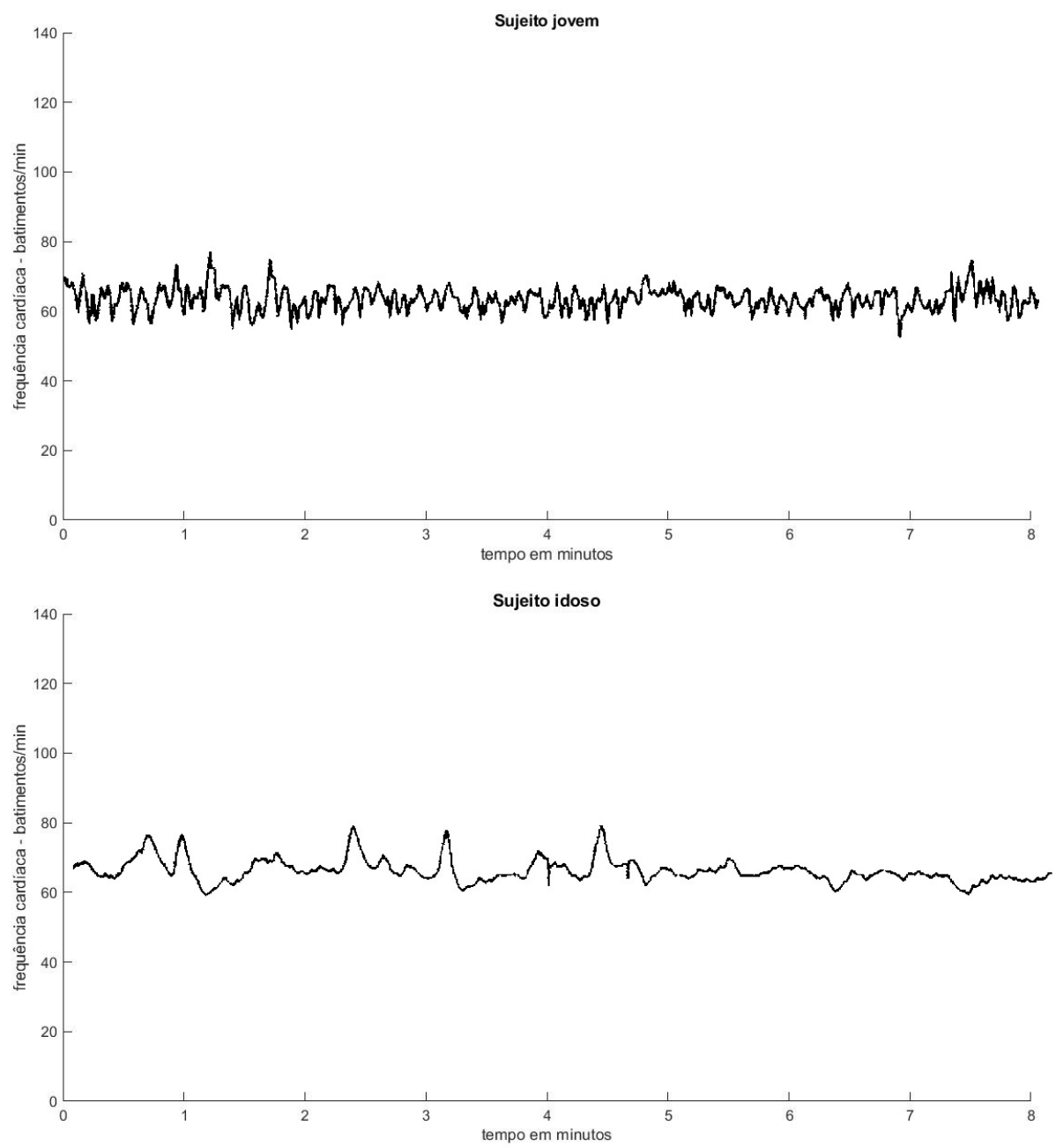

Figura 5 - Série temporal de frequência cardíaca para um sujeito do sexo feminino de 22 anos (painel superior) e um sujeito do sexo masculino de 73 anos (painel inferior). A média de batimentos cardíacos por minuto para o jovem foi de 64,7 ; desvio padrão, 3,9; e entropia aproximada, 1,09. A média de batimentos cardíacos por minuto para o idoso era de 64,5; desvio padrão, 3,8; e entropia aproximada, 0,48. A entropia aproximada é uma medida de "complexidade não linear". Apesar das medias e desvios padrão da frequência cardíaca quase idênticas para as duas séries temporais, a "complexidade"do sinal do sujeito mais velho é significativamente menor. Figura adaptada Lewis, Lipsitz,Ary e Goldberger (1)

complexo e que os processos fisiológicos apresentam variabilidade complexa, sendo assim é importante que tenhamos métricas que sejam suficientemente capazes de capturarem de forma adequada tais características não lineares. De fato medidas convencionais como comprimento, área e volume (com dimensões inteiras de um, dois e três, respectivamente) não são suficientes para caracterizar estruturas fractais. Objetos fractais têm dimensões não inteiras porque mostram estruturas em várias escalas de comprimento. A estrutura fractal pode ser quantificada computando-se a chamada dimensão fractal (31). Essa medição fornece um índice de quanto espaço um objeto em particular ocupa. Intuitivamente, uma 
estrutura de ramificações relativamente esparsa pareceria ter uma dimensão fractal menor do que a de um objeto mais complexo, mais "espesso". Outro fato é que, assim como as estruturas fractais não podem ser caracterizadas com medidas geométricas convencionais, o comportamento complexo e caótico não pode ser medido adequadamente com estatísticas baseadas simplesmente na média e na variância. Conforme mostrado na figura 5, é possível que dois processos tenham saídas com médias e variações quase idênticas, mas dinâmicas muito diferentes. Uma abordagem possível é o estudo dos sinais de saída gerados por sistemas biológicos complexos. Segundo Costa, et al., as flutuações dinâmicas desses sinais na saúde e também na doença fornecem informações a respeito do comportamento de funcionamento livre dos sistemas integrativos o que possibilita identificar comportamentos no nível do sistema que são essenciais para a compreensão da dinâmica saudável e dos distúrbios patológicos (43). Assim podemos realizar investigações seguindo três hipóteses complementares:

1. A complexidade de um sistema biológico reflete sua capacidade de se adaptar e funcionar no ambiente em constante mudança.

2. Os sistemas biológicos precisam operar em várias escalas de espaço e tempo, portanto sua complexidade também é multi-escala e hierárquica.

3. Uma ampla classe de estados de doença, assim como o envelhecimento, parecem degradar essa complexidade biológica e reduzir a capacidade adaptativa do sistema. Assim, a perda de complexidade pode ser uma característica genérica e definidora da dinâmica patológica e a base de novas abordagens diagnósticas, prognósticas e terapêuticas.

Uma série de técnicas foi desenvolvida para permitir que fisiologistas e médicos meçam a complexidade dos sinais biológicos, independentemente de sua média e variância $(44,45)$.

Uma técnica tradicional é medir os componentes de frequência de um sinal usando a análise padrão de Fourier, onde se decompõe o sinal em suas frequências constituintes $(46,47)$. Se a saída for perfeitamente periódica (ou seja, uma onda senoidal), ela terá apenas um componente de frequência e para processos caóticos, o espectro de frequência é bastante amplo, compreendendo uma ampla faixa de frequências baixas a altas. Em geral, os sinais mais complexos têm um padrão de frequência mais amplo. Por outro lado, a perda de complexidade geralmente é acompanhada por um estreitamento do espectro de frequência. (Compare um gerador de tons puros e uma orquestra sinfônica.) Normalmente, para processos fisiológicos, a perda de complexidade também é caracterizada pela redução relativa nos componentes de alta frequência e aumento correspondente na contribuição relativa dos componentes de frequência mais baixa $(30,47)$. Um exemplo é a perda seletiva da responsividade auditiva de alta frequência com o envelhecimento (presbiacusia) (48). No 
entanto, a análise espectral, uma técnica baseada na matemática linear, tem valor limitado na avaliação da complexidade de sistemas não lineares. Outras medidas mais diretas de complexidade foram propostas com base em conceitos da teoria do caos $(49,44,45,8,50,4)$. Uma metodologia de medir a complexidade de um processo que usa o conceito da dimensão de um sistema não linear, ou seja, para sistemas complexos, a dimensão está relacionada ao número de variáveis dinâmicas necessárias para reproduzir a saída desse sistema. Quanto maior a dimensão, maior o número de variáveis e mais complexo o sinal. Um processo estritamente periódico tem uma dimensão 1, o que significa que apenas uma variável é necessária. Outra maneira de medir a complexidade é calcular a chamada entropia do sistema $(8,49,9)$. Essa abordagem conceitual da senescência difere da visão intuitiva de que o envelhecimento aumenta o grau de desordem ou entropia termodinâmica $(50,51)$. A entropia não linear, um conceito apenas indiretamente relacionado à entropia termodinâmica clássica, é uma medida da quantidade de informações necessário para prever o estado futuro do sistema (52). Quanto mais complexa for a dinâmica, maior será a entropia e menos previsível será o sistema. Algumas propostas de aproximações de dimensão não linear e entropia podem ser aplicadas em amostras de séries com duração relativamente curta, compreendendo, por exemplo, apenas 1000 pontos $(8,53)$ como no caso da figura 5. Essas medições permitem a comparação de conjuntos de dados de diferentes indivíduos, bem como o exame dos efeitos de várias intervenções na complexidade de um sistema dinâmico (50).

\subsubsection{Dinâmica Cardíaca}

A variabilidade da frequência cardíaca (VFC), a variação batimento a batimento na frequência cardíaca ou a duração do intervalo $\mathrm{RR}$ - o período cardíaco, como visto no exemplo da Figura 6, tornaram-se ferramentas importante de avaliação de risco (2). Uma VFC reduzida está associada a um mal prognóstico para muitas condições clínicas, enquanto, por outro lado, mudanças periódicas robustas no intervalo RR são frequentemente associadas a uma condição saudável $(54,55,56,57)$. A maior parte dessas mudanças temporais na frequência cardíaca ocorrem em sincronia com a respiração, a frequência cardíaca aumenta, consequentemente, o intervalo RR diminuí, durante a inspiração e diminui, prolongando o intervalo $R R$, durante a expiração e, portanto, chamado de arritmia sinusal respiratória (ASR)(2). Embora a VFC e a ASR não sejam exatamente iguais, esses termos são frequentemente usados de forma trocada e acredita-se que ambos refletem as alterações na regulação cardíaca autônoma. As contribuições exatas das divisões parassimpática e simpática do sistema nervoso autônomo para essa variabilidade são controversas e permanecem objeto de investigação ativa e debate (58). 

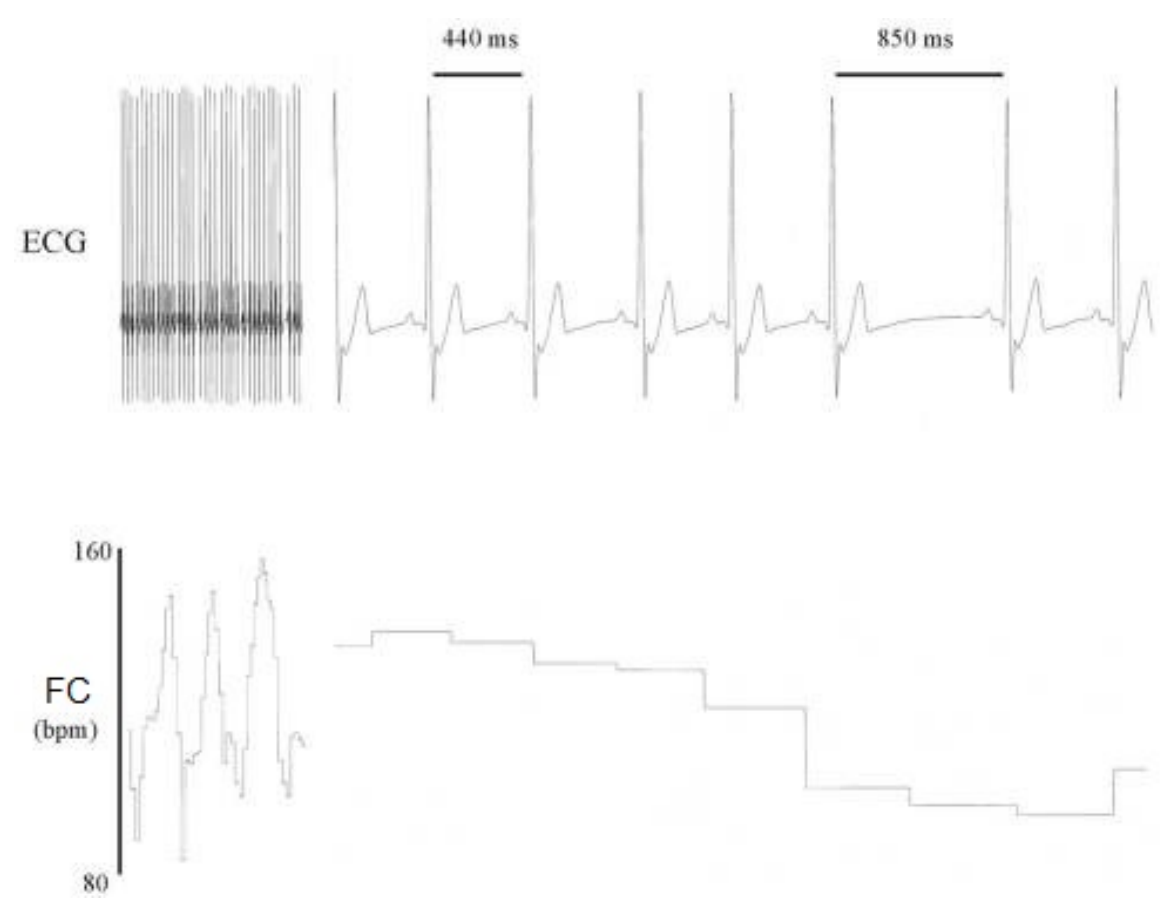

Figura 6 - Variabilidade da frequência cardíaca: registros representativos de eletrocardiograma (ECG) de um cão consciente que ilustram as variações batimento a batimento no intervalo RR e na frequência cardíaca. Figura adaptada Billman (2)

\subsubsection{Objetivos}

Nas últimas décadas, vários estudos propuseram algoritmos de estimativa de entropia, como a entropia de Shannon (52), entropia de Kolmogorov (59), entropia espectral (60), entropia SVD (61), entropia wavelet (62), entropia de permutação (63), entropia aproximada (53) e entropia amostral (SampEn) (9), com o intuito de quantificar a complexidade de várias séries temporais. Todavia, os resultados da maioria dos algoritmos para estimar a entropia nem sempre estão associados à complexidade. Um bom exemplo disso é que o SampEn do ruído branco é maior do que o ruído $1 / f$, o que contraria a pesquisa de Fogedby (12). Costa (4) propôs entropia multi-escala (MSE) para calcular SampEn em uma faixa de escalas e assim representar a complexidade de uma série temporal. Usando o método MSE, o resultado é consistente com o resultado de Fogedby. O método MSE foi aplicado para quantificar a complexidade de muitos sinais fisiológicos $(14,64)$. Os trabalhos demonstram a eficácia do algoritmo da MSE para a análise de séries temporais complexas.

Embora estudos anteriores tenham mostrado o uso bem-sucedido de MSE, sua confiabilidade permanece questionável para análise de séries temporais de curta duração. O método MSE incorpora dois procedimentos: (1) a representação da dinâmica de um sistema em diferentes escalas de tempo são derivadas conduzindo um procedimento coarse-grained; e (2) as regularidades das séries temporais coarse-grained são quantificadas aplicando SampEn. O procedimento de coarse-grained encurta a duração da série temporal, e assim a 
SampEn pode produzir uma estimativa imprecisa de entropia ou induzir entropia indefinida quando a série temporal é muito curta. Portanto, o método MSE convencional não pode fornecer uma análise confiável para séries temporais de curto prazo.

Nossa hipótese é que o critério de similaridade adotado pela SampEn para a contagem de padrões que se dá pelo uso da função de Degrau da distância máxima entre dois padrões, ou seja, os padrões são considerados semelhantes ou não (uma abordagem binária) de acordo com um limite de tolerância definido pode levar a valores de entropia indefinidos, uma vez que as probabilidades são calculadas de acordo com o número de correspondências.

Nossa tese é de que a introdução da entropia fuzzy (FuzzyEn) foi um avanço significativo nesse sentido. Em vez de usar uma abordagem binária para a pertinência de padrões, Chen et al. (16) introduziram o conceito de funções de pertinência fuzzy, onde uma função suave, contínua e convexa é usada para estimar a similaridade entre os padrões. Assim, como as probabilidades são mais bem estimadas, a FuzzyEn é mais precisa e mais robusto para séries de tempo curto do que SampEn.

O objetivo desse estudo é propor o algoritmo da entropia multi-escala modificada (MMFE), inspirado nas vantagens da entropia multi-escala modificada (MMSE) (6) e introduzindo o conceito da FuzzyEn com delay, para ser aplicada em análises de séries temporais fisiológicas curtas, avaliar a eficácia do algoritmo MMFE na análise ruídos estocásticos segmentados e séries de variabilidade da frequência cardíaca (VFC) real, bem como, compará-lo às variações do algoritmo MSE, MSE composta (CMSE)(5), MSE composta refinada (RCMSE)(20), MSE modificado (MMSE) e suas versões fuzzy, adaptadas a séries temporais curtas em séries temporais de variabilidade da frequência cardíaca (VFC) humana e de rato. 


\section{Análise Não Linear de Sérịes Temporais Curtas Por Meio de Entropia}

A entropia, no que se refere aos sistemas dinâmicos, é a taxa de produção de informações. A classificação de sistemas dinâmicos via entropia deriva dos trabalhos de Kolmogorov (59) e Sinai (65), é um único número $K$, que é propriedade única do sistema dinâmico considerado (66). A entropia $K S$ é definida da seguinte forma: Considere um sistema dinâmico com $F$ graus de liberdade. Suponha que o espaço de fase $F$-dimensional é particionado em caixas de tamanho $\epsilon^{F}$. Suponha que haja um atrator no espaço de fase e que a trajetória $x(t)$ esteja na bacia de atração ${ }^{2}$. O estado do sistema agora é medido em intervalos de tempo $\tau$. Seja $p\left(i_{1}, i_{2}, \ldots, i_{d}\right)$ a probabilidade conjunta de que $\vec{x}(t=\tau)$ está na caixa $i_{1}, \vec{x}(t=2 \tau)$ está na caixa $i_{2}, \ldots$, e $\vec{x}(t=d \tau)$ está na caixa $i_{d}$. A entropia $K S$ é então (67)

$$
K=-\lim _{\tau \rightarrow 0} \lim _{\epsilon \rightarrow 0} \lim _{d \rightarrow \infty} \frac{1}{d_{\tau}} \sum_{i_{1}, \ldots, i_{d}} p\left(i_{1}, \ldots, i_{d}\right) \times \ln p\left(i_{1}, \ldots, i_{d}\right)
$$

Assim temos que $K$ é 0 em um sistema ordenado, $K$ é infinito em um sistema aleatório e $K$ é uma constante $\neq 0$ em um sistema caótico determinístico, ou seja, que o comportamento desorganizado e de aparência complexa surge a partir um fator determinístico elementar, equação ou causa subjacente simples (67). Dessa forma então podemos afirmar que a entropia $K S$ indica a taxa de perda de informação ao longo do atrator ou o grau de previsibilidade de pontos ao longo do atrator com evolução do tempo no sistema (68). Além disso, a partir do teorema de Brudno, pode-se provar que entropia $K S$ é a imprevisibilidade média da informação de todas as trajetórias possíveis no espaço de fase. Por outro lado, é sabido que o caos na dinâmica clássica pode ser definido pelo aumento exponencial da distância entre duas trajetórias que partem de condições iniciais

2 Uma região no espaço fase associada a um atrator. É o conjunto de todos os pontos de partida (valores inicias) que convergem para o atrator. 
vizinhas (69). Quantitativamente, está relacionado com o expoente de Lyapunov positivo do sistema (70). A positividade do expoente de Lyapunov implica instabilidade exponencial de movimento. Por sua vez, a instabilidade exponencial do movimento é caótica, pois quase todas as trajetórias são imprevisíveis no sentido da teoria da informação. Essas duas quantidades, entropia $K S$ e os expoentes de Lyapunov, estão relacionadas entre si pelo teorema de Pesin o qual estabelece que $(71,72,73)$

$$
K=\int_{\Gamma}\left[\sum_{\sigma_{i}(\phi)>0} \sigma(\phi)\right] d^{2(N+1)} \phi
$$

onde $\sigma_{i}(\phi)$ são os expoentes de Lyapunov do sistema dinâmico e $2(N+1)$ é a dimensão do espaço de fase. O teorema de Pesin relaciona a entropia $K S$, ou seja, a imprevisibilidade média da informação de todas as trajetórias possíveis no espaço de fase, com a instabilidade exponencial do movimento. Então, o conteúdo principal do teorema de Pesin é que $K>0$ é uma condição suficiente para o movimento caótico (69).

Esses trabalhos estão baseados em teoremas ergódicos aplicáveis a cenários probabilísticos teóricos, não sendo concebidos como um meio para analisar sistemas dinâmicos finitos já que para alcançar a convergência, tais algoritmos necessitam de uma gama de dados muito grande o que os torna impraticáveis, ou seja, não são adequados para a análise de conjuntos de dados curtos e ruidosos encontrados em estudos cardiovasculares e outros estudos biológicos. Contudo vários métodos para estimar a entropia de um sistema representado por uma série temporal finita foram propostos, tornando a entropia um índice comum para quantificar a complexidade das séries temporais em vários campos. Nesse capítulo iremos descrever alguns desses métodos.

\subsection{Entropia Aproximada - ApEn}

Pincus introduziu a Entropia Aproximada (ApEn) (49) com objetivo de fornecer um desenvolvimento matemático preliminar de uma família de fórmulas e estatísticas, para quantificar o conceito de complexidade e estabelecer uma medida de complexidade, com uma quantidade finita de pontos necessários e de forma robusta. Os parâmetros ApEn $(m, r)$ podem distinguir uma grande variedade de sistemas, e que para $m$ pequeno, especialmente $m=2$, a estimativa de $\operatorname{ApEn}(m, r)$ pela $\operatorname{ApEn}(m, r, N)$ pode ser obtido com número pontos aplicáveis na prática. Um algoritmo de dimensão amplamente utilizado na análise de dados é a dimensão de correlação (68). Fixe $m$, um número inteiro positivo e $r$, um número real positivo.

Dada uma série temporal de dados $u(1), u(2), \ldots, u(N)$, a partir de medições igualmente espaçadas no tempo, formam uma sequência de vetores $x(1), x(2), \ldots, x(N-$ $m+1)$ em $\mathbb{R}^{m}$, definido por $x(i)=[u(i), u(i+1), \ldots, u(i+m-1)]$. Definimos para cada 
$i, 1 \leq i \leq N-m+1$

$$
C_{i}^{m}=(\text { número de vetores } \boldsymbol{j} \text { tal qued }[x(i), x(j)] \leq r) /(N-m+1),
$$

onde $d[x(i), x(j)]$ a maior diferença entre duas correspondentes componentes escalares é dada por

$$
d[x(i), x(j)]=\max \{|u(i+k)-u(j+k)|: 0 \leq k \leq m-1\} .
$$

Assim, temos que

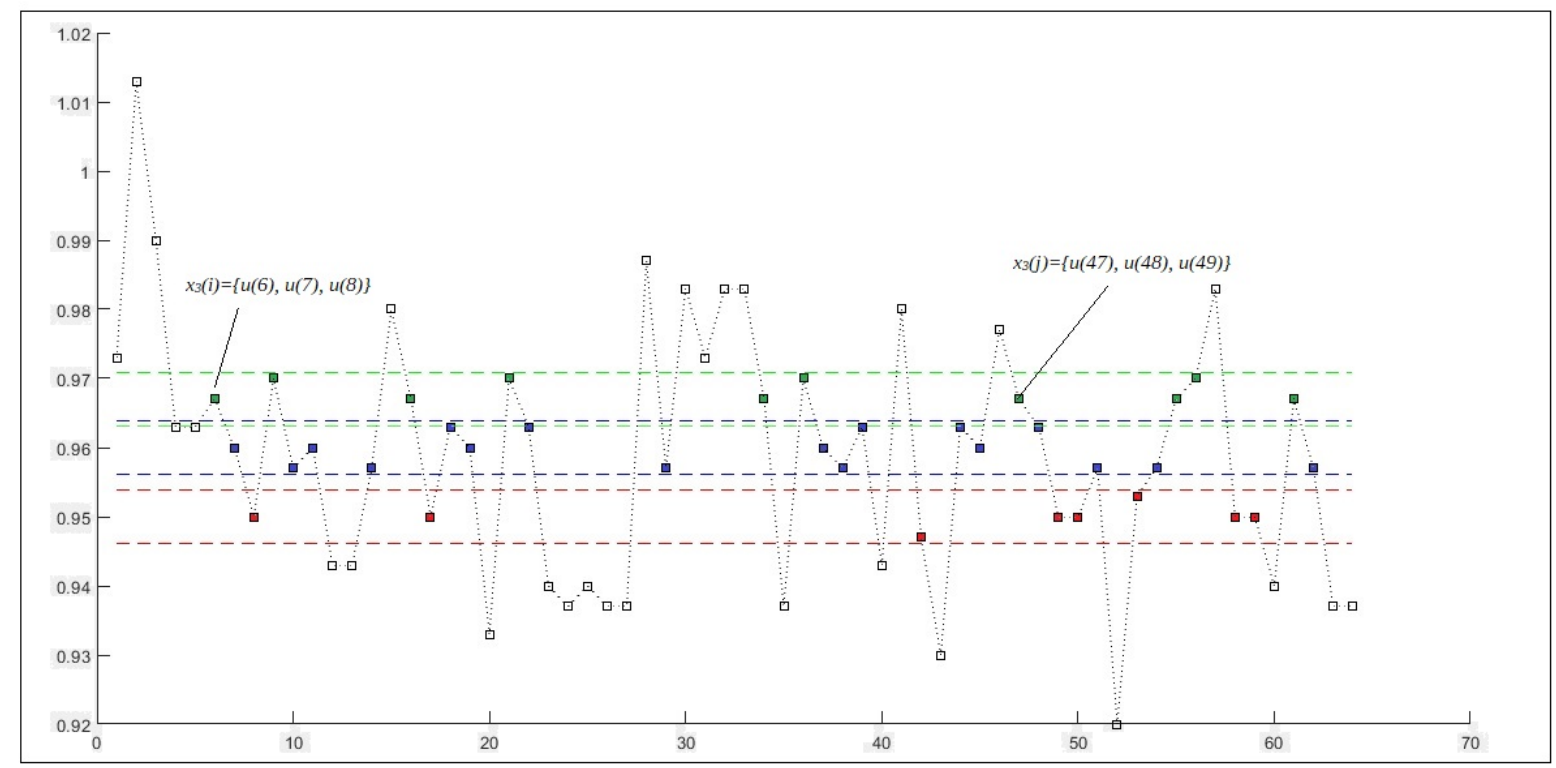

Figura 7 - Exemplo de contagem de padrões (match) conforme a equação 3.3. Nesse exemplo, considerando $m=3$, e tendo $x_{3}(i)=\{u(6), u(7), u(8)\}$ como o primeiro padrão. As linhas tracejadas horizontais indicam a tolerância $(r)$ para cada um dos três pontos do padrão que segundo a equação 3.4 é $x_{m}(i) \pm r$. Os pontos em verde estão no intervalo de tolerância do ponto $\mathrm{u}(6)$, em azul do $\mathrm{u}(2)$ e em vermelho, do $\mathrm{u}(3)$. Podemos notar que apenas a sequência $\{u(47), u(48), u(49)\}$ é um padrão no qual os três pontos reaparecem em sequência dentro das tolerâncias definidas. Para o caso de $m=2$, e tomando $x_{2}(i)=\{u(6), u(7)\}$ teremos 5 padrões considerados iguais $(\{u(9), u(10)\},\{u(21), u(22)\},\{u(36), u(37)\},\{u(47), u(48)\}$ e $\{u(61), u(62)\})$

$$
\Phi^{m}(r)=1 /(N-m+1) \sum_{i=1}^{N-m+1} \ln C_{i}^{m}(r) .
$$

A ApEn é definida por:

$$
\operatorname{ApEn}(m, r)=\lim _{N \rightarrow \infty} \Phi^{m}(r)-\Phi^{m+1}(r)
$$

Para uma série de tamanho $N$, a ApEn é estimada pela estatística

$$
\operatorname{ApEn}(m, r, N)=\Phi^{m}(r)-\Phi^{m+1}(r)
$$

Na prática a ApEn quantifica a porcentagem de padrões semelhantes para dimensão $m$ que permanecerá semelhante para a dimensão $m+1$. A equação 3.7 calcula a probabilidade 
(logarítmica) de ocorrência dos padrões para a dimensão $m$ também ocorrer para a dimensão $m+1$. O valor dessa probabilidade indica regularidade da série, ou seja, se o valor dessa indica uma série regular, e consequentemente o valor da ApEn será baixo. Por outro lado se o valor dessa probabilidade for pequeno indica uma série irregular, e portanto o valor da ApEn será alto. Podemos notar que se $C_{i}^{m+1}(r)$ é próximo de $C_{i}^{m}(r)$ temos então uma série com comportamento repetitivo. Agora, se $C_{i}^{m+1}(r)$ é pequeno em relação a $C_{i}^{m}(r)$ temos uma série cujo comportamento tende a ser mais imprevisível porque para padrões semelhantes de dimensão $m$ temos valores diferentes para $m+1$ (74). Segundo o autor a ApEn pode ser calculada para qualquer série temporal, caótica ou não e é capaz de distinguir diferentes periodicidades dos sistemas, porém a ApEn não pode certificar o caos. A definição dos parâmetros $m$ e $r$ para estatísticas ApEn, segundo o autor, leva em consideração que $m=2$ é o mais indicada por ser melhor que $m=1$ e pelo fato de que $m>2$ produz probabilidades condicionais pobres na maioria das vezes e que, com base em cálculos e também pela análise teórica, a concluiu-se que para $m=2$ e $N=$ 1000, escolha de $r$ variando de 0,1 a 0,2 do desvio padrão da série de os dados $u(i)$ temos validade estatística razoável para $\operatorname{ApEn}(m, r, N)$. Para valores de $r$ menores, geralmente não tem-se boas estimativas de probabilidade condicional na equação 3.6, enquanto para valores de $r$ maiores, muitas informações detalhadas do sistema serão perdidas. Para evitar uma contribuição significativa de ruído no cálculo da ApEn, deve-se escolher $r$ maior do que a maioria dos ruídos (74).

A ApEn apresenta dois viés. O primeiro vem do fato de que $N$ deve ser fixo devido ao viés estatístico de $\operatorname{ApEn}$, o valor esperado de $\operatorname{ApEn}(m, r, N)$ aumenta assintoticamente com $N$, como podemos observar na figura 8, tornando somente confiável comparações entre conjuntos de dados para o mesmo valor de $N(74)$. O segundo viés do fato de que na definição de $C_{i}^{m}(r)$, o próprio vetor padrão $x_{m}(i)$ é contado como similaridade (selfmatch) de vetores próximos a $x_{m}(i)$. Isso é feito para garantir que os cálculos envolvendo logaritmos permaneçam finitos, mas tem como consequência o fato de que as probabilidades condicionais estimadas pela equação 3.3 sejam subestimadas. Este procedimento pode resultar em um viés de $20 \%$ a $30 \%$ na estatística ApEn (74).

\subsection{Entropia Amostral - SampEn}

Como vimos a Entropia Aproximada (ApEn) forma um conjunto de medidas de complexidade do sistema intimamente relacionadas à entropia, que é facilmente aplicado à análise de séries temporais. A ApEn, no entanto, nos leva a resultados inconsistentes, fundamentalmente por considerar em seu algoritmo a auto similaridade, ou seja, conta cada sequência como similaridade de si mesma, uma prática retirada do trabalho de Eckmann e Ruelle (75) para evitar a ocorrência de $\ln (0)$ nos cálculos. A Entropia Amostra 
(SampEn) é um algoritmo proposto por Richman e Moorman (9) baseado na definição de Grassberger e Procaccia (68) que contorna esse viés, fato esse que a faz ter uma melhor precisão das estatísticas, tornando-a mais útil no estudo de séries temporais, em particular séries fisiológicas. Considere a série temporal de $N$ pontos $u(1), u(2), \ldots, u(N)$, considere também $m$ a dimensão da sequência a ser comparada e uma tolerância $r$ determinada por uma porcentagem do desvio padrão da série temporal original. Formamos $N-m+1$ vetores $x_{m}(i)$ para $\{i \mid 1 \leq i \leq N-m+1\}$, onde $x_{m}(i)=\{u(i+k): 0 \leq k \leq m-1\}$ são vetores de dimensão $m$ pontos de $u(i)$ até $u(i+m-1)$. A distância entre dois vetores é definida pela equação 3.4.

Seja $B_{i}$ a quantidade de vetores $x_{m}(j), 0 \leq j \leq N$, dentro de $r$ e $A_{i}$ a quantidade de vetores $x_{m+1}(j)$, dentro de $r$ de $x_{m+1}(i)$.

Definimos

$$
\begin{aligned}
C_{i}^{m} & =\frac{B_{i}}{N-m-1} \\
C^{m}(r) & =\frac{\sum_{i=1}^{N-m} C_{i}^{m}(r)}{N-m}
\end{aligned}
$$

e

$$
\begin{aligned}
C_{i}^{m+1} & =\frac{A_{i}}{N-m-1} \\
C^{m+1}(r) & =\frac{\sum_{i=1}^{N-m} C_{i}^{m+1}(r)}{N-m}
\end{aligned}
$$

No cálculo de $B_{i}$, o vetor $x_{m}(i)$ é chamado de template e o instante em que o vetor $x_{m}(j)$ está dentro da tolerância $r$ é chamado de template match.

A Entropia amostral para os parâmetros $m, r$ e $N$ é

$$
\operatorname{SampEn}(m, r, N)=-\ln \frac{C^{m+1}(r)}{C^{m}(r)}
$$

Se $N_{T}(m+1)$ representa a quantidade de vetores template de dimensão $m+1$ então

$$
N_{T}(m+1)=N-m
$$

Temos ainda, para o algoritmo da Sampen, que

$$
N_{T}(m)=N_{T}(m+1)=N-m
$$

logo, a quantidade total $\left(N_{T}\right)$ de pares de vetores templates gerados por esse processo é dado pela equação:

$$
N_{T}=\frac{(N-m-1) \times(N-m)}{2}
$$

A SampEn é portanto um conjunto de estatísticas semelhante às estatísticas ApEn que medem complexidade e a regularidade de séries temporais obtidas de dados clínicos e 


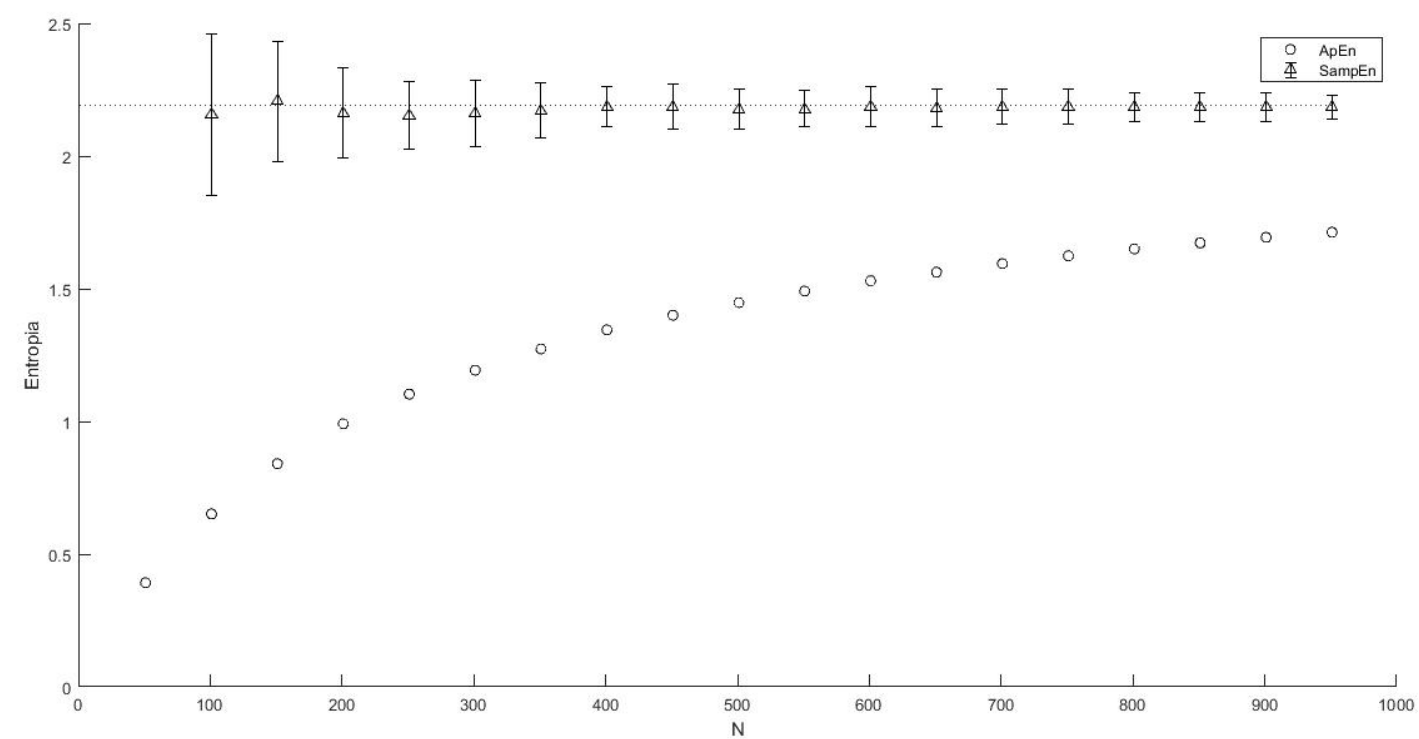

Figura 8 - SampEn e ApEn como funções de $N(m=2, r=0,2)$ calculadas para ruídos branco simulados. Os intervalos de confiança para estatísticas SampEn são exibidos como barras de erro. A linha reta é o valor teoricamente do parâmetro $\operatorname{SampEn}(2,0.2)$.

de dados experimentais. Comparada à ApEn, a SampEn concorda melhor com a teoria para números aleatórios com caráter probabilístico conhecido, mantêm consistência relativa onde as estatísticas ApEn não têm (9). Em estudos com séries de VFC fetal, um dos autores da SampEn comenta que vária regras existentes definem que para séries com 100 a 5000 pontos, são utilizados valores de $m=1$ ou $m=2$ e $10 \%<r<25 \%$ do desvio padrão da série (76). Outros estudos tem proposto maneiras de se estimar estes valores ótimos de $m$ e $r(77,78)$.

\subsection{Métodos Variantes da Entropia Amos- tral}

Os algoritmos da SampEn e da ApEn quantificam a complexidade, ou grau de desordem, de uma série temporal com a premissa de que a entropia aumenta com o grau de desordem e é máxima para sistemas completamente aleatórios. No entanto, um aumento na entropia nem sempre pode estar associado a um aumento na complexidade dinâmica (4). Por exemplo, os sistemas doentes, quando associados ao surgimento de comportamentos mais regulares, apresentam valores de entropia reduzidos em comparação com a dinâmica de sistemas saudáveis (10). No entanto, certas patologias, incluindo arritmias cardíacas como fibrilação atrial, estão associadas a flutuações altamente erráticas com propriedades estatísticas semelhantes a ruído não correlacionado $(79,80,81)$. Os algoritmos da SampEn nos 
darão valores de entropia alto para esses sinais patológicos quando comparados à dinâmica saudável, mostrando propriedades correlacionadas do tipo $1 / f$, ainda que dinâmicas saudáveis representem estados adaptativos mais complexos fisiologicamente. Essa inconsistência pode estar relacionada ao fato de que as medidas de entropia amplamente utilizadas são baseadas em análises de escala única e não levam em consideração as flutuações temporais complexas inerentes aos sistemas de controle fisiológico saudáveis. Uma abordagem que leva em consideração as múltiplas escalas de tempo em sistemas físicos foi feita por Zhang $(11,12)$. Essa medida, baseada em uma soma ponderada de entropias dependentes da escala, de fato, produz valores mais altos para ruídos correlacionados em comparação com os não correlacionados, porém, uma vez que é baseado na definição de entropia de Shannon, o método de Zhang requer uma grande quantidade de dados quase sem ruído, a fim de mapear um sinal para uma sequência simbólica discreta com precisão estatística suficiente, apresentando limitações óbvias quando aplicado a sinais fisiológicos típicos que variam continuamente e têm comprimento finito. Uma técnica de entropia multi-escala aplicável à análise das séries temporais biológicas foi proposta por Costa et al (4), definida como entropia multi-escala (MSE), cujoso resultados são consistente com o resultado de Fogedby (12). O método MSE foi aplicado para quantificar a complexidade de muitos sinais fisiológicos $(14,64)$ e sinais de vibração (5). Os trabalhos demonstram a eficácia do MSE algoritmo para a análise de séries temporais complexas. Embora varios estudos anteriores tenham mostrado o uso bem sucedido de MSE, sua confiabilidade permanece questionável para análise de séries temporais de curta duração (6). A seguir vamos definir a entropia multi-escala (MSE) e suas variantes.

\subsubsection{Entropia Multi-escala - MSE}

A abordagem da entropia multi-escala (MSE) foi proposta por Costa et al. para representar a complexidade de um sinal (4). A MSE consiste do cálculo da entropia amostral em uma faixa de escalas, isto é, no algoritmo MSE, as séries temporais coarse-grained - que representam a dinâmica do sistema em diferentes escalas - são analisadas com o algoritmo de entropia amostral. Desde a sua introdução, o MSE tornou-se um método predominante para quantificar a complexidade dos sinais (13). Considere a série temporal $u(1), u(2), \ldots$, $u(N)$. Para calcular a MSE, primeiro se constrói as séries coarse-grained em diferentes escalas $(4,3)$. Cada elemento de uma série em escala $\tau$ é definido por:

$$
u^{\tau}(j)=\frac{1}{\tau} \sum_{i=(j-1) \tau+1}^{j \tau} u(i), 1 \leqslant j \leqslant N / \tau
$$

Para as séries $u^{\tau}(j)$ geradas é calculada a entropia amostral em várias escalas $\left(1 \leq \tau \leq \tau_{\max }\right)(4,3)$ as regularidades no tempo nas séries para um fator de escala $\tau$ são quantificadas aplicando SampEn com um delay unitário de tempo $(\delta=1)$, isto é 


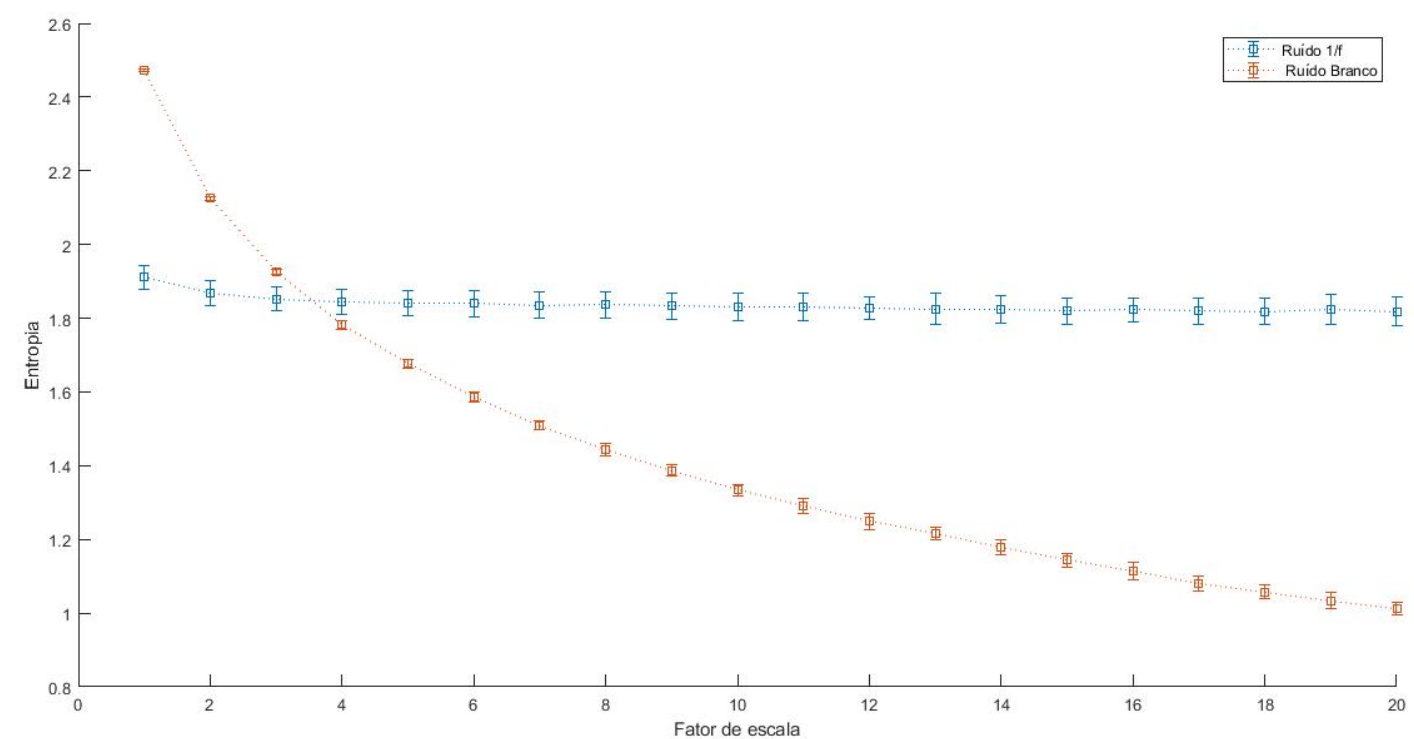

Figura 9 - MSE calculada para ruídos simulados de distribuição gaussiana branco (média zero e variância 1), e para série temporal de ruído $1 / f$, de comprimento 30000 pontos cada. Os símbolos representam valores médios de entropia para 30 séries temporais e barras de erro do desvio padrão. As linhas representam a avaliação numérica do cálculo analítico da SampEn. Adaptado de (3).

$$
\operatorname{MSE}(x, m, r)=\operatorname{SampEn}\left(u^{\tau}, m, \delta=1, r\right) .
$$

e então é construído o gráfico da entropia em função do fator de escala $\tau$ como por

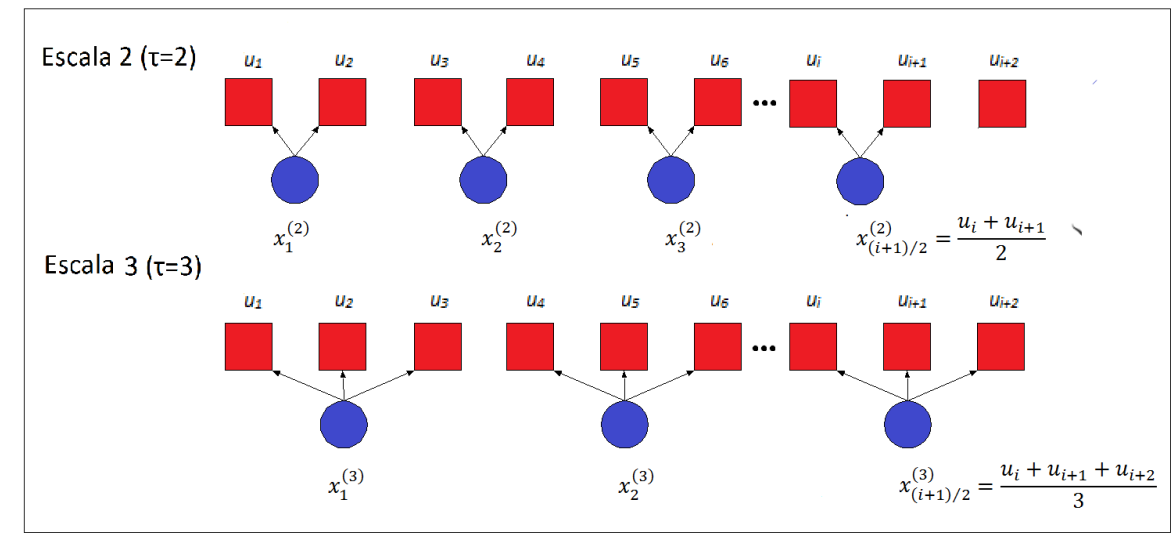

Figura 10 - Ilustração do processo de construção de séries temporais coarse-grained para fatores de escala $\tau=2$ e $\tau=3$ segundo o método da MSE, onde cada ponto na escala $\tau$ da série coarse-grained é obtido pela média móvel sem sobreposição de $\tau$ pontos da série original. Adaptado de (4)

exemplo na figura 9.

Note que o comprimento coarse-grained para um fator de escala $\tau$ é reduzido para $N / \tau$, logo, o número de vetores template usado para calcular a SampEn em um fator de 
escala $\tau$ é dado por $N(\tau)=(N / \tau)-m=N_{\tau}$. Segundo a equação 3.15 o total $N_{T, \tau}$ de pares de vetores template verificados para cada fator de escale $\tau$ é $N_{T, \tau}=\left[\left(N_{\tau}-1\right) \times N_{\tau}\right] / 2$.

O algoritmo MSE, segundo os autores, tem resultados consistentes quando aplicado na avaliar da complexidade de ruídos simulados correlacionados e não correlacionados e também a saída integrada de um grande sistema de controle fisiológico (intervalos entre batimentos cardíacos) em condições saudáveis e patológicas. Nesse estudo também reportaram que a dinâmica patológica associada ao aumento da regularidade e consequentemente diminuição da variabilidade ou ao aumento da variabilidade devido à perda de propriedades de correlação são ambos caracterizados por uma redução na complexidade, concluindo que o método MSE tem enorme potenciais para ser aplicada no estudo de uma ampla variedade de outras séries temporais fisiológicas e físicas.

\subsubsection{Entropia Multi-escala Composta - CMSE}

Proposta por $\mathrm{Wu}$ et al. a entropia multi-escala composta (CMSE) tem como objetivo reduzir a variância dos valores estimados de entropia em grandes escalas (5). Wu et al. aplicou a MSE original e CMSE na análise dos ruídos branco e $1 \backslash f$ (5) em séries de diferentes comprimentos. Os autores relataram que ocorre uma superestimação da entropia devido ao curto comprimento da série temporal com CMSE no ruído $1 \backslash f$ (5). Também foi constatado que o CMSE mostra melhor desempenho em séries temporais curtas em relação ao algoritmo MSE original, pois a MSE original e a CMSE fornecem valores de entropia similares,porém a CMSE pode estimar os valores de entropia com mais precisão do que a MSE original em relação aos valores de desvio padrão da amostra que são menores com CMSE. Eles também mencionam que para ruído branco e ruído $1 \backslash f$, CMSE fornece uma estimativa mais confiável de entropia do que o algoritmo MSE original, conforme mostrado pelos resultados da simulação. A CMSE também foi aplicado em dados reais $(5,82)$. Na CMSE, para cada fator de escala $k$ são obtidas $k$ séries temporais coarse-grained onde a k-ésimo é definida como (5)

$$
y_{k, j}^{\tau}=\frac{1}{\tau} \sum_{i=(j-1) \tau+k}^{j \tau+k-1} x_{i} .1 \leq j \leq \frac{N}{\tau}, 1 \leq k \leq \tau
$$

A figura 11 ilustra as séries temporais coarse-grained para a escala $\tau=2$ e $\tau=3$ segundo a equação 3.18 .

O valor a ser obtido pela CMSE é definido como a média dos valores de entropia $\tau$, ou seja

$$
C M S E(x, \tau, m, r)=\frac{1}{\tau} \sum_{k=1}^{\tau} \operatorname{SampEn}\left(y_{k}^{(\tau)}, m, r\right)=\frac{1}{\tau} \sum_{k=1}^{\tau}\left(-\ln \frac{n_{k, \tau}^{m+1}}{n_{k, \tau}^{m}}\right),
$$




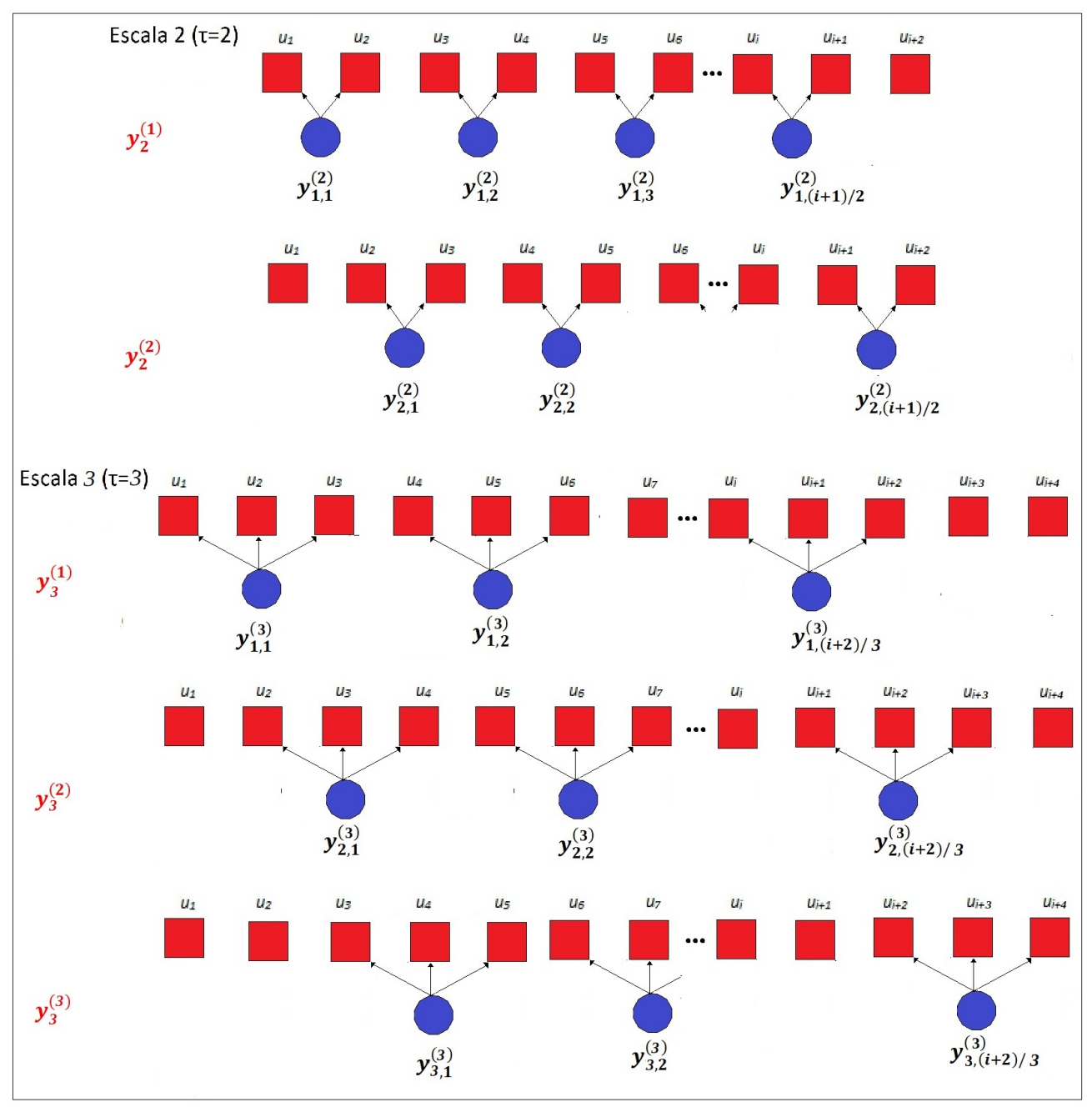

Figura 11 - Ilustração esquemática do procedimento coarse-grained segundo a CMSE para a escala $\tau=2$ e $\tau=3$ (5).Para cada fator de escala $\tau$, são consideradas $\tau$ séries, duas séries na escala $\tau=2$, três séries na escala $\tau=3$ e assim sucessivamente. Figura adaptada de (5).

onde $n_{k, \tau}^{m}$ é o número total de pares de vetores similares de dimensão $m$, obtido a partir da $k$-ésima série temporal coarse-grained para um fator de escala $\tau$.

O método CMSE apresentou melhor desempenho em séries temporais curtas em comparação com a MSE. Quando feita a análise de ruído branco e ruído $1 / f$, os resultados da simulação mostram que o CMSE fornece uma estimativa mais confiável da entropia do que o MSE (5). Também é visto que nos resultados da simulação que o CMSE pode aumentar a distinguibilidade linear em comparação com o MSE. Os resultados experimentais também demonstram que o CMSE proposto fornece uma maior precisão no diagnóstico de falhas em rolamentos (5). 


\subsubsection{Entropia Multi-escala Composta Redefinida - RCMSE}

A Entropia Multi-escala Composta Redefinida (RCMSE) foi proposta como ajuste para melhorar o desempenho da CMSE já que esta não resolve o problema da entropia indefinida em séries temporais curtas (20). Apesar da CMSE estimar a entropia com maior precisão com relação à MSE em séries temporais curtas, seu algoritmo aumenta a probabilidade de induzir entropia indefinida $(20,13)$. Podemos notar que no algoritmo da CMSE, mais precisamente na equação 3.19 os logaritmos de $\frac{n_{k, \tau}^{m+1}}{n_{k, \tau}^{m}}$ são determinados para todas as séries temporais corseing graned num primeiro passo e só então a média dos resultados é calculado para gerar o valor de entropia (13). No caso de $n_{k, \tau}^{m+1}=0$ ou $n_{k, \tau}^{m}=0$ a CMSE nos leva a um valor indefinido. Como consequência, quando analisamos séries temporais curtas, a CMSE leva a muito mais valores indefinidos do que o algoritmo MSE original (13). Para contornar esse fato, a RCMSE foi proposto como um aprimoramento do algoritmo CMSE (20). Segundo os autores o algoritmo RCMSE supera o algoritmo CMSE em validade e precisão da estimativa de entropia, independência do comprimento dos dados e eficiência computacional. Para analisar séries temporais curtas, o algoritmo RCMSE pode ser usado para aumentar a precisão da estimativa de entropia e reduzir a probabilidade de induzir entropia indefinida em comparação com o algoritmo CMSE (20).

O algoritmo da RCMSE é definido da seguinte forma: o procedimento para se obter o corseing graned na RCMSE é o descrito pela equação 3.18. Para cada fator de escala $\tau$ consideramos $n_{k, \tau}^{m+1}$ e $n_{k, \tau}^{m}$ o número de pares de vetores similares calculados para todas as $\tau$ séries temporais corseing graned. A RCMSE é então definida como

$$
\operatorname{RCMSE}(x, \tau, m, r)=-\ln \left(\frac{n_{k, \tau}^{-m+1}}{n_{k, \tau}^{-m}}\right)
$$

onde $n_{k, \tau}^{-m+1}=\frac{1}{\tau} \sum_{k=1}^{\tau} n_{k, \tau}^{m+1}$ e $n_{k, \tau}^{-m}=\frac{1}{\tau} \sum_{k=1}^{\tau} n_{k, \tau}^{m}$ são respectivamente as médias de $n_{k, \tau}^{m+1}$ e $n_{k, \tau}^{m}$ obtidos da equação 3.18 .

Apesar de os resultados obtidos, os autores fazem menção ao fato do custo computacional do RCMSE ser superior ao do MSE, e segundo eles, para análises de séries temporais longas, as melhorias na precisão e validade não são significativas ao usar o RCMSE (20). Portanto, para análises de séries temporais longas, é sugerido um método híbrido para ser usado de forma a se equilibrar precisão e custo computacional. Nesse método híbrido, as análises em pequena e grande escala são realizadas usando o MSE e o RCMSE, respectivamente. O fato da SampEn ser significativamente independente do comprimento dos dados quando o número de pontos de dados é maior que 750 (14), o método híbrido propõe uso do algoritmo RCMSE para uso quando a série temporal 
coarse-grained $(N / \tau)$ for menor que 750 .

\subsubsection{Entropia Multi-escala Modificada - MMSE}

A MSE modificado (MMSE) é uma proposta específica para superar a estimativa imprecisa de entropia e também valores de entropia indefinidos obtidos com séries temporais de curtas devido à forma como séries coarse-grained são geradas pela MSE original (6). O método da MSE propõe que a representação da dinâmica de um sistema em diferentes escalas de tempo, coarse-grained, são construídas pelo cálculo da média aritmética sem sobreposição, conforme a Figura 10, e que as regularidades no tempo nas séries para um fator de escala $\tau$ são quantificadas aplicando SampEn com um delay unitário de tempo.

Como vimos na subseção 3.3.1 o comprimento da série coarse-grained para um fator de escala $\tau$ é reduzido para $N / \tau$, logo, o número de vetores template usado para calcular a SampEn em um fator de escala $\tau$ é dado por

$$
N(\tau)=(N / \tau)-m=N_{\tau}
$$

Segundo a equação 3.15 o total $N_{T, \tau}$ de pares de vetores template verificados para cada fator de escale $\tau$ é

$$
N_{T, \tau}=\frac{\left(N_{\tau}-1\right) \times N_{\tau}}{2}
$$

O método MMSE propõe que o coarse-grained seja construído pelo cálculo da média móvel $Z_{j}^{\tau}$ (ver a Figura 12), conforme a equação

$$
Z_{j}^{\tau}=\frac{1}{\tau} \sum_{i=1}^{j+\tau-1} x_{i}, \quad 1 \leq j \leq N-\tau+1
$$

e que as regularidades no tempo nas séries para um fator de escala $\tau$ são quantificadas aplicando SampEn com um delay e tempo $\tau$, isto é

$$
M M S E(x, m, \tau, r)=\operatorname{SampEn}\left(Z^{\tau}, m, \tau, r\right) .
$$

Nesse procedimento o comprimento do coarse-grained obtido por meio da média móvel para um escalar de $\tau$ é dado por

$$
n_{(\tau)}=N-\tau+1
$$

De acordo com as equações 3.13 e 3.14 o número de vetores templates usados no algoritmo da Sampen para o delay $\tau$ é

$$
n_{(\tau, m)}=N-\tau+1-m \tau=N-(m+1) \tau=n_{\tau}
$$




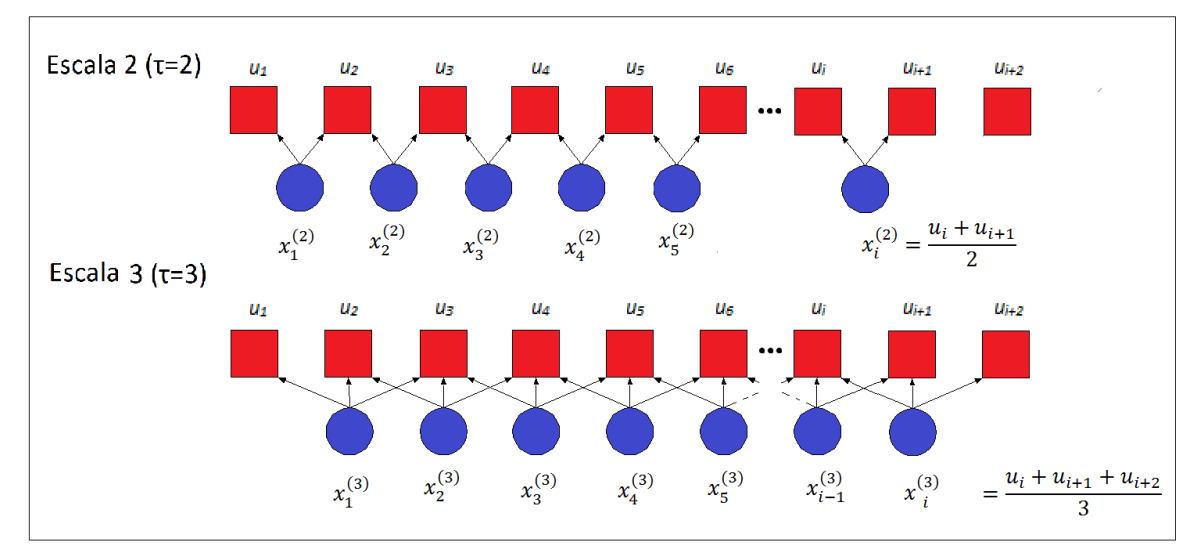

Figura 12 - O coarse-grained segundo a MMSE (6), ilustrando a média móvel com sobreposição para os fatores de escala $\tau=2$ e $\tau=3$. Fonte: figura gerada pelo autor.

assim o número de pares de vetores template que são determinados na SampEn é

$$
n_{T, \tau}=\frac{n_{\tau} \times\left(n_{\tau}-1\right)}{2}-\left((\tau-1) \times\left(n_{\tau}-\frac{\tau}{2}\right)\right)
$$

Conforme vemos pelas equações 3.21 e 3.26 a quantidade de vetores template usados no algoritmo da MMSE é maior do que o usado no algoritmo da MSE.

O autor comenta que ao ser comparada a MSE, a MMSE pode estimar a entropia com mais precisão e também evitar indução a uma entropia indefinida na análise de séries temporais curtas (6). Ao testada para a detecção de falha de rolamento, a MMSE pode extrair os recursos que exibem alta distinguibilidade. O autor comenta também que para séries temporais de longo prazo, a melhoria na precisão para estimativa de entropia não é significativa, e o custo computacional do MMSE é maior do que do MSE, portanto, o método MMSE não é adequado para aplicação direta na análise séries temporais longas. Assim é sugerido fazer uma compensação entre precisão e custo computacional ao trabalhar com séries temporaislondas, é recomendado usar a MSE para realizar uma análise em pequena escala da série temporal e usar a MMSE para realizar uma análise em grande escala.

\subsection{Entropia Fuzzy - FuzzyEn}

A entropia fuzzy (FuzzyEn) é uma família de estatísticas proposta como uma medida de complexidade derivada do conceito de conjuntos fuzzy de Zadeh (16). Nas formas de se medir a regularidade na SampEn e ApEn, a similaridade entre vetores é dada por uma função Degrau, que pode ser representa por

$$
\Theta(x)= \begin{cases}1 & x \geq 0 \\ 0 & x<0\end{cases}
$$


classificando a similaridade somente entre dois estados, onde se decide sobre a pertinência do padrão de entrada para uma determinada classe pois satisfaz certas propriedades especificadas. Contudo, para fenômenos naturais os limites entre classes podem ser ambíguos(16) sendo extremamente difícil determinar se um padrão de entrada pertence totalmente a uma classe. Em 1965, Zadeh (17) propõe a Teoria dos conjuntos Fuzzy afim de caracterizar a relação de pertinência em um ambiente de imprecisão. Ele propõe um "Grau de Adesão"dado por uma função Fuzzy, onde cada ponto se associa a um número real no intervalo $[0,1]$. criando um mecanismo para medir o grau ao qual um padrão pertence a uma determinada classe. A entropia Fuzzy é um método baseado nos conjuntos Fuzzy (16) cujo grau de similaridade entre vetores template é dado por uma função exponencial do tipo $\exp \left(-\left(d_{i j}^{m}\right)^{n} / r\right)$. Tal função deve $(i)$ ser contínua de modo que a semelhança não mude bruscamente; (ii) ser convexa para que a auto-similaridade seja o valor máximo. Considere a série temporal de $N$ pontos $u(1), u(2), \ldots, u(N)$. Dado $m$ e sequência de vetores $X_{i}^{m}, i=1, \ldots, N-m+1$, definimos então

$$
X_{i}^{m}=\{u(i), u(i+1), \ldots, u(i+m-1)\}-u 0(i),
$$

onde

$$
u 0(i)=\frac{1}{m} \sum_{j=0}^{m-1} u(i+j) .
$$

A distância $d_{i j}^{m}$ entre os $X_{i}^{m}$ e $X_{j}^{m}$ é obtido conforme o algoritmo da SampEn, ou seja

$$
d_{i j}^{m}=d\left[X_{i}^{m}, X_{j}^{m}\right]=\max |(u(i+k)-u 0(i))-(u(j+k)-u 0(j))|
$$

Sejam $m$ comprimento dos vetores template, $r$ e $n$ respectivamente a largura e o gradiente do limite da função exponencial, temos que no grau de similaridade de $X_{i}^{m} \mathrm{e}$ $X_{j}^{m}$ é

$$
D_{i j}^{m}=\exp \left(-\left(d_{i j}^{m}\right)^{n} / r\right)
$$

Definimos

$$
\phi^{m}(n, r)=\frac{1}{N-m} \sum_{i=1}^{N-m}\left(\frac{1}{N-m-1} \sum_{j=1, j \neq i}^{N-m} D_{i j}^{m}\right) .
$$

Analogamente, para $\left\{X_{i}^{m+1}\right\}$ segue que

$$
\phi^{m+1}(n, r)=\frac{1}{N-m} \sum_{i=1}^{N-m}\left(\frac{1}{N-m-1} \sum_{j=1, j \neq i}^{N-m} D_{i j}^{m+1}\right),
$$

assim podemos estimar, para um conjunto finito de dados, entropia Fuzzy pela estatística

$$
F u z z y \operatorname{En}(m, n, r)=\ln \phi^{m}(n, r)-\ln \phi^{m+1}(n, r)
$$




\subsection{Métodos Variantes da Entropia Fuzzy}

Segundo Chen et al a SampEn e ApEm apresentam certas falhas causadas pela função Degrau, o que segundo os autores ficou demonstrado pelo melhor desempenho de FuzzyEn em comparação com ApEn e SampEn por meio de análises e experimentos (83). Os resultados mostram que FuzzyEn é mais precisa medição da complexidade, pois não apenas possui consistência relativamente mais forte e menos dependência do comprimento dos dados, o que significa menos viés, como também atinge continuidade, isto é, uma seleções de parâmetros mais livres e mais robustez em relação ao ruído(83). Nessa seção vamos descrever alguns métodos que se utilizam de uma função Fuzzy para contagem de similaridades.

\subsubsection{Multiscale Fuzzy Entropy - MFE}

O método da entropia multi-escala Fuzzy (MFE) foi introduzida para medir a complexidade e irregularidade das séries temporais em diferentes fatores de escala (84). Segundo os autores, quando comparada com a SampEn, FuzzyEn, dimensão fractal ou outros métodos de medida de complexidade da dinâmica não linear, a MFE fornece informações mais precisas e detalhadas das séries temporais (84). Originalmente a MFE foi introduzida para medir a complexidade dos sinais de vibração de rolamentos.

O algoritmo da MFE $(84,85)$ segue o algoritmo da MSE substituindo a SampEn pela FuzzyEn na equação 3.17, isto é,

$$
\operatorname{MFE}(x, m, n, r)=F u z z y E n\left(u^{\tau}, m, n, r\right),
$$

onde $u^{\tau}$ é obtido pela equação 3.16 .

Ao analisar os dados experimentais, os resultados mostram que o método da MFE pode diferenciar as categorias de falhas de rolamentos de forma eficaz. Contudo, o mecanismo de falha do rolamento é complexo, sendo difícil saber qual característica é mais importante e qual não está entre os recursos extraídos. Para este problema, outros métodos complementares devem ser empregados para melhorar a eficiência do diagnóstico de falhas (85).

\subsubsection{Entropia Fuzzy Multi-escala Composta - CMFE}

O algoritmo CMFE foi proposto por Zheng et al. (19) para aprimorar o método MFE, bem como o FuzzyEn. O algoritmo da CMFE propõe combinar informações de várias séries temporais coarse-grained na mesma escala. Segundo os autores, os valores de MFE 
são afetados pelo comprimento dos dados, especialmente quando os dados não são longos o suficiente (19). No entanto, comparado com o MFE, a medida que aumentamos o fator de escala, o CMFE obtém valores muito mais estáveis e consistentes para uma série temporal de curta duração. O CMFE foi empregado inicialmente na medição da complexidade dos sinais de vibração de rolamentos, sendo aplicado para extrair as características não lineares ocultas nos sinais de vibração.

O algoritmo da CMFE pode ser descrito como:

$$
C M F E(x, \tau, m, r)=\frac{1}{\tau} \sum_{k=1}^{\tau} F u z z y \operatorname{En}\left(y_{k}^{(\tau)}, m, r\right)
$$

onde $y_{k}^{(\tau)}$ são as séries coarse-grained obtidas da equação 3.18.

Os resultados da comparação com a MFE mostram que o CMFE tem como vantagem obter um valor estável e coerente mesmo quando o comprimento da série temporal for curto, superando o problema da coarse-grained no MFE. A consequecia direta é o aumento do fator de escala, assim o CMFE tem uma tendência de mudança mais plana do que o MFE.

\subsubsection{Entropia Fuzzy Multi-escala Composta Refi- nida - RCMFE}

Como já foi dito, um dos problemas mais importantes ga MSE é que, quando aplicado a sinais biológicos curtos, os resultados podem ser indefinidos e imprecisos (20,86). Também foi dito que uma tentativa de resolver tal problema foi a introdução do método da RCMSE (20) que se utiliza da média dos valores SampEn de várias séries coarse-grained para cada fator de escala. Embora os resultados da simulação tenham mostrado que o RCMSE tem melhor estabilidade para todas as escalas temporais quando comparado à MSE, o problema de valores indefinidos para sinal curto ainda existe (20). Baseado nestes conceitos e nos conceitos de entropia fuzzy para combinar suas vantagens, Azami et al. propuseram a Entropia Fuzzy Multi-escala Composta Redefinida, $\mathrm{RCMFE}_{\mu}$ e $\mathrm{RCMFE}_{\sigma}(21)$, que se utilizam, respectivamente, da média $\mu$ e do desvio padrão $\sigma$ para a aquisição das séries coarse-grained. A hipótese dessa proposta é de que essas medidas serão mais precisas, robustas e estáveis em relação às medidas de entropia anteriores. Nesse trabalho não discutimos o filtro para a aquisição das séries coarse-grained, nós nos atemos à proposta clássica, sendo assim iremos tratar apenas do caso da $\mathrm{RCMFE}_{\mu}$, a qual trataremos apenas por RCMFE. O método RCMSE se utiliza da equação $3.18(5,87)$ para obter as séries temporais coarse-grained $Z_{k}^{(\tau)}=\left\{y_{k, j}^{\tau}\right\}$. Para cada fator de escala $\tau$ e uma dada dimensão $m$ é determinado $\bar{\phi}_{\tau}^{m+1}$ e $\bar{\phi}_{\tau}^{m}$ respectivamente as médias de $\phi_{\tau, k}^{m+1}$ e $\phi_{\tau, k}^{m}$, sendo estas 
calculadas para todos $Z_{k}^{(\tau)}(21)$. A RCMFE então é definida por

$$
R C M F E(x, \tau, m, n, r)=-\left(\ln \frac{\bar{\phi}_{\tau}^{m+1}}{\bar{\phi}_{\tau}^{m}}\right) .
$$

Com base nas tendências recentes nesse campo, os autores também apresentam o uso de desvio padrão no processo de coarse-grained (substitui o cálculo da média pelo cálculo do desvio padrão na equação 3.16) e propõe $\mathrm{RCMFE}_{\sigma}$, além da RCMFE propriamente dita, equação 3.38, como métricas de complexidade de flutuações no desvio padrão e média, respectivamente, de uma série temporal. Segundo os autores esse método supera várias limitações de abordagens anteriores e fornecem informações complementares. Além disso, concluem que os métodos multi-escala baseados em FuzzEn foram mais estáveis do que os algoritmos baseados em SampEn e que a técnica de composição refinada (ver seção 3.3.3) melhorou visivelmente a estabilidade de MSE e MFE. No geral, os resultados obtidos pelos algoritmos $\mathrm{RCMFE}_{\sigma}$ e RCMFE tiveram os menores valores de desvio padrão entre as abordagens baseadas em entropia multi-escala existentes e propostas. Os resultados da classificação mostraram que as características baseadas no $\mathrm{RCMFE}_{\sigma}$ levam a maiores precisões de classificação em comparação com as baseadas no RCMFE (21).

\subsubsection{Entropia Multi-escala Fuzzy Modificada - MMFE}

A FuzzyEn considera a similaridade entre vetores template por suas formas ao invés de suas coordenadas absolutas, fato que faz com que a FuzzyEn seja capaz de descobrir vetores semelhantes em sinais com flutuação lenta que estejam submersos pela flutuação da curva. Com a intensão de analisar amostras curtas de séries temporais fisiológicas, propomos nesse trabalho a entropia Multi-escala Fuzzy modificada (MMFE), um algoritmo que apresenta resultados mais eficientes que a MMSE quando ambos são confrontados com o método da MSE, como veremos nos resultados apresentados a seguir.

O método MMFE definido por Borin et al. (7) e que se propõe a ser um método robusto para análise de séries temporais fisiológicas de curta duração, consiste no refinamento do método MMSE. Pelas propriedades já descritas propomos construir as séries coarse-grained usando a média móvel e substituir a SampEn com delay na análise de similaridade entre dois vetores templates pela FuzzyEn com delay. Dessa forma o método consiste de dois passos:

1. para cada fator de escala $\tau$, construímos as séries temporais coarse-grained conforme a equação 3.23 .

2. a similaridade entre dois vetores templates é calculada pela FuzzyEn com delay, logo 


$$
M M F E(x, m, \tau, r)=F u z z y \operatorname{En}\left(Z^{\tau}, m, \tau, r\right) .
$$

onde $Z^{\tau}$ é obtido pela equação 3.23 .

Como veremos em detalhes mais adiante nós mostramos que nossa proposta é muito mais robusta para séries fisiológicas do que uma abordagem muito comum usada com a mesma intenção. Também mostramos a existência de uma relação exponencial entre nosso parâmetro de entropia e o comprimento da série. 


\section{Conjunto de dados e Experimentos}

Vamos descrever o conjuntos de dados que usamos nos experimentos, bem como descrever os detalhes de cada experimento realizado.

\subsection{Teste de Robustez da MMFE}

Uma das variantes mais importantes para a MSE na análise de séries temporais curtas é a entropia multi-escala modificada (MMSE), embora ainda possa produzir estimativas enviesadas devido aos critérios de similaridade rígidos da entropia amostral. Aproveitando as vantagens do MMSE e do conceito de entropia fuzzy, propomos a entropia multiescala fuzzy modificada (MMFE). Avaliamos a robustez do MMSE e MMFE usando ruídos estocásticos segmentados e séries de variabilidade da frequência cardíaca real, em comparação com os resultados de MSE clássicos obtidos com os sinais completos. Os resultados mostram que o MMFE é muito mais robusta do que o MMSE para séries temporais fisiológicas curtas, assemelhando-se à MSE para séries menores de 400 amostras. Também mostramos a existência de uma relação exponencial entre o parâmetro fuzzy MMFE e o tamanho do sinal. Sugerimos o uso dessa relação para escolher o parâmetro MMFE ideal como parte do método.

\subsubsection{Conjuntos de Dados}

Avaliamos o desempenho do MMFE para a análise da série de variabilidade da frequência cardíaca (VFC) e ruídos estocásticos. Selecionamos dois conjuntos de dados para as séries de VFC, um obtido de ratos e humanos, ambos os grupos saudáveis.

O primeiro conjunto de dados do VFC consiste em 18 ratos Wistar saudáveis, obtidos de estudos anteriores realizados no laboratório de fisiologia cardiovascular da Faculdade de Medicina de Ribeirão Preto. A descrição detalhada dos dados pode ser encontrada em (88). 
Resumidamente, os ratos tiveram seu ECG registrado durante uma hora em condições basais. Um software de computador foi usado (LabChart, ADInstruments, Austrália) para criar séries RR a partir dos registros de ECG. Todas as séries RR foram inspecionadas visualmente quanto a artefatos e corrigidas manualmente quando necessário. Como o comprimento da série temporal variou de 15.892 a 32.333 pontos, todas as séries RR foram reduzidas para 15.892 pontos.

O segundo conjunto de dados VFC foi obtido da base de dados de ritmo sinusal normal Physionet MIT-BIH (89). Os registros de ECG de 12 pacientes foram selecionados aleatoriamente no banco de dados. As séries RR foram calculadas usando a ferramenta ann2rr do pacote WFDB Physionet, que usa as anotações de batida das gravações para calcular os intervalos RR. Apenas os intervalos RR normais foram considerados, ou seja, os intervalos entre dois batimentos normais sucessivos. Todas as séries RR foram truncadas para 15.892 pontos, de forma que as séries de ratos e humanos tenham exatamente o mesmo tamanho. O período de todas as séries $\mathrm{RR}$ vai das $8 \mathrm{~h}$ às $22 \mathrm{~h}$.

\subsubsection{Ruídos Estocásticos}

Usamos processos simulados de ruído branco e rosa $(1 / f)$ para o grupo de ruídos estocásticos. Os sinais de ruído branco foram criados como uma sequência de números aleatórios não correlacionados no intervalo $[0,1]$. Por outro lado, geramos sinais de ruído rosa usando o seguinte procedimento: criamos um sinal de ruído branco e calculamos sua transformada de Fourier. Então, o espectro de potência foi multiplicado pelo decaimento $1 / f$ (onde $f$ é a frequência) e transformado de volta para o domínio do tempo. Observe que quando as propriedades simétricas de Fourier são respeitadas, a transformada inversa de Fourier resultará em um sinal puramente real. Realizamos dez simulações de cada ruído com comprimento de 15.000 para cada uma das amostras.

\subsubsection{Substituição do Filtro Média Móvel pelo Filtro Butterworf}

Uma preocupação interessante com relação a nossa proposta de entropia fuzzy multi-escala modificada (MMFE) é a de que um filtro Butterworth deve substituir o procedimento clássico de coarse-graining (média móvel) usado para criar versões em escala da dinâmica original (90). Outra dúvida é a escolha ótima da dimensão de incorporação $(m)$ da entropia de amostra multi-escala modificada (MMSE) é $m=1$, e não $m=2$ como adotamos em nosso estudo (90).

Entendemos que a substituição da média móvel pelo filtro Butterworth é inspirada 
na resposta de frequência aprimorada deste último. No entanto, acreditamos que a entropia multi-escala não requer uma separação rigorosa dos componentes de frequência nas diferentes escalas de tempo, uma vez que se destina a estimar propriedades não lineares da dinâmica (91). Além disso, a filtragem Butterworth é baseada na suposição de linearidade e estacionariedade, sendo demonstrado que esta substituição tem um forte efeito nos ruídos estocásticos, mas bastante baixo nas séries VFC reais $(92,93)$. No entanto, para verificar o efeito da substituição da média móvel pelo filtro Butterworth, cuja magnitude quadrada da resposta de frequência do filtro é escolhida como

$$
\left|H\left(e^{2 \pi i j}\right)\right|^{2}=\frac{1}{1+\left(f / f_{c}\right)^{2 n}}
$$

onde $n$ é a ordem do filtro e $f_{c}$ é a frequência de corte (92). A MMFE foi estimada usando os dois procedimentos de coarse-graining (ver Figura 18).

Outro ponto importante está relacionado com a escolha da dimensão de incorporação $(m)$ para o cálculo do MMSE e MMFE. Concordamos que valores mais baixos para $m$ resultarão em estimativas MMSE mais estáveis porque a probabilidade de correspondências de padrões aumentará.

\subsubsection{Teste de Robustez}

Para avaliar a capacidade do MMFE de levar em conta a entropia multi-escala para diferentes tamanhos de sinais, dividimos cada série analisada em segmentos de tamanhos iguais de 400, 800, 1200, ..., 15600 amostras, adotando uma sobreposição de $90 \%$ para o processo de segmentação. Calculamos o algoritmo MSE original sempre a partir da série completa, ou seja, com $N=15892$ amostras para a série VFC e $N=15000$ amostras para ruídos, enquanto aplicamos MMFE a cada segmento da mesma série, e eventualmente , estimou a curva média de MMFE. Para cada tamanho de segmento, comparamos o MMFE médio obtido de todos os segmentos com o MSE original, empregando um erro quadrático médio em todas as escalas de tempo. Aplicamos a mesma abordagem ao MMSE para comparação. Para todos os algoritmos, adotamos $m=2, r=0,15 *$ desvio padrão da série temporal e $\tau=1, \ldots, 20$. O expoente de MMFE fuzzy MF variou no intervalo $n=[0,100]$, mas os resultados são mostrados apenas para o intervalo ótimo de expoentes para cada conjunto de dados. Para fornecer uma comparação justa entre MMSE e MMFE, nós as estimamos usando $m=1$ e $m=2$. Para $m=1$, a MMFE foi calculado usando a entropia fuzzy global, ou seja, sem a remoção das linhas de base dos padrões. 


\subsubsection{Resultados e Discussão do Teste de Robustez da MMFE}

A figura 13 mostra exemplos de MMSE e MMFE para os conjuntos de dados VFC, calculados para segmentos de tamanho $N=400$ e $N=1200$. Observe que o MSE original é o mesmo para ambos os tamanhos de segmento, pois sempre calculamos o MSE a partir da série RR de comprimento total. Pode-se observar que o MMSE superestima os valores reais de entropia para séries temporais curtas. Além disso, para $N=400$, o MMSE não é definida para escalas grandes. Em contraste, a MMFE virtualmente sobrepõe o MSE original em ambos os tamanhos de segmento quando escolhemos o expoente $n$ apropriado. Para o conjunto de dados VFC de ratos, os melhores expoentes são $n=0,95$ (para $N=400$ ) e $n=1,10$ (para $N=1200$ ). Para o conjunto de dados de humanos, os melhores expoentes são $n=0,90$ (para $N=400)$ e $n=0,88$ (para $N=1200)$.

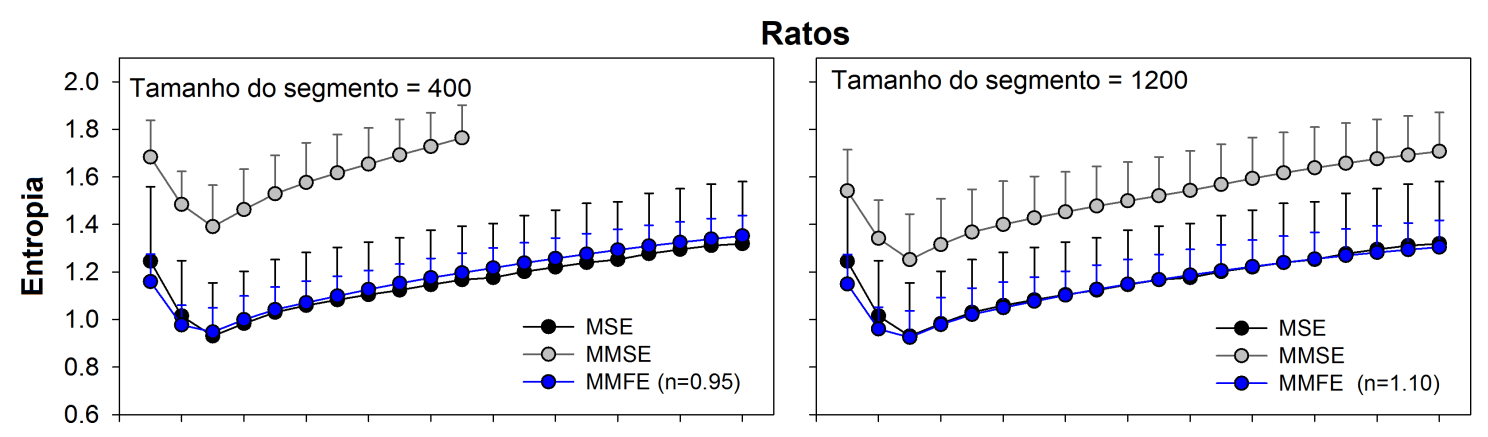

Humanos
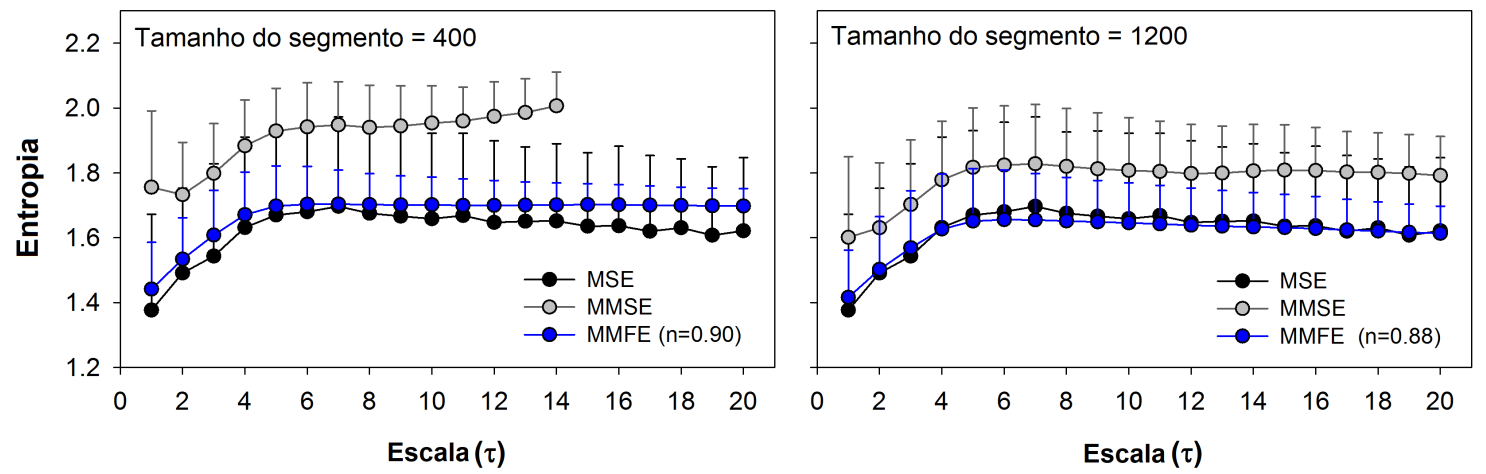

Figura 13 - Entropia multi-escala (MSE), MSE modificada (MMSE) e a entropia fuzzy multiescala modificada proposta (MMFE) calculada para os conjuntos de dados VFC. Os valores representam a entropia média, ou seja, MSE, MMSE e MMFE, \pm SD plotado como uma função de escalas de tempo $(\tau)$. Os resultados para ratos (painéis superiores) e humanos (painéis inferiores) são mostrados. Os gráficos mostram que as curvas MMFE estão mais próximas para a MSE quando comparadas ao MMSE, para séries segmentadas em janelas de 400 (plotagens à esquerda) e 1200 pontos (plotagens à direita). O MMSE não pode estimar valores de entropia para escalas maiores que $\tau=11$ (ratos) ou $\tau=14$ (humanos) para séries RR com 400 pontos. Observe que o MSE original é o mesmo nos gráficos da esquerda e da direita, pois é sempre calculado a partir da série RR completa. 
A superestimação da entropia por MMSE, observada para os conjuntos de dados VFC, é provavelmente devido a como SampEn mede a similaridade entre vetores. Quando as distâncias entre os vetores são maiores que $r$, o Degrau levará a correspondências não detectadas. Portanto, quando as distâncias entre os vetores tendem a ser maiores que $r$, mesmo que ligeiramente, o baixo número de correspondências pode superestimar o valor real da entropia. Por outro lado, o uso de um MF exponencial para estimativa de similaridade garante que MMFE sempre associará uma similaridade válida e proporcional entre um par de vetores, tornando-o menos sensível a séries temporais curtas, onde o número de correspondências pode ser reduzido $(16,83,21)$. Além disso, FuzzyEn considera a similaridade entre vetores de template por suas formas e não apenas por suas coordenadas absolutas, o que faz com que FuzzyEn seja capaz de descobrir vetores semelhantes em sinais não estacionários.

A figura 14 mostra exemplos de MMSE e MMFE para os ruídos estocásticos, calculados para segmentos de tamanho $N=400$ e $N=1200$. O MSE original é o mesmo para ambos os tamanhos de segmento. Como pode ser observado, o MMSE virtualmente se sobrepõe à curva MSE de ruído branco para ambos os tamanhos de segmento. Para ruído rosa, MMFE está mais próximo de MSE do que MMSE para $N=400$, mas o oposto acontece para $N=1200$. O expoente MF fuzzy que fornece o erro mínimo de MMFE é $n=0,5$, para todas as condições. Observe também que, para $N=400$, o MMSE de ruído rosa não é definido para escalas maiores que $\tau=15$.

Curiosamente, embora o MMFE se aproxime melhor da curva MSE para os conjuntos de dados VFC, o MMSE é uma aproximação melhor para os ruídos estocásticos. Além disso, o MMSE superestima o ruído rosa para tamanhos de sinal curtos, mas não o ruído branco. Portanto, torna-se claro que as propriedades dinâmicas das séries são fatores chave para as limitações de uso do limite rígido fornecido pela função de similaridade de Degrau, e para a capacidade do MF fuzzy de ajustar bons critérios de similaridade para a estimativa da entropia. Ele também destaca a complexidade intrínseca dos sinais fisiológicos em comparação com as simulações. Embora o ruído rosa seja reconhecido como uma sequência de valores correlacionada de longo alcance, fractal não imita perfeitamente a estrutura dos dados fisiológicos reais.

A figura 15 mostra o erro quadrático médio de MMSE e MMFE para os conjuntos de dados VFC em função do tamanho do segmento e para diferentes valores do expoente MF fuzzy $n$. Conforme observado na figura 14, MMSE superestima a entropia dos conjuntos de dados VFC, razão pela qual o erro quadrático médio para MMSE é bastante alto para tamanhos de segmento curtos. O erro do MMSE diminui monotonicamente com o comprimento do sinal. Curiosamente, os resultados sugerem um $n$ ideal de MMFE para cada comprimento de série até o tamanho da série $N=11200$ (ratos) ou $N=13600$ (humanos), que é o intervalo onde MMFE retorna melhores estimativas de MSE original 
Ruído Branco
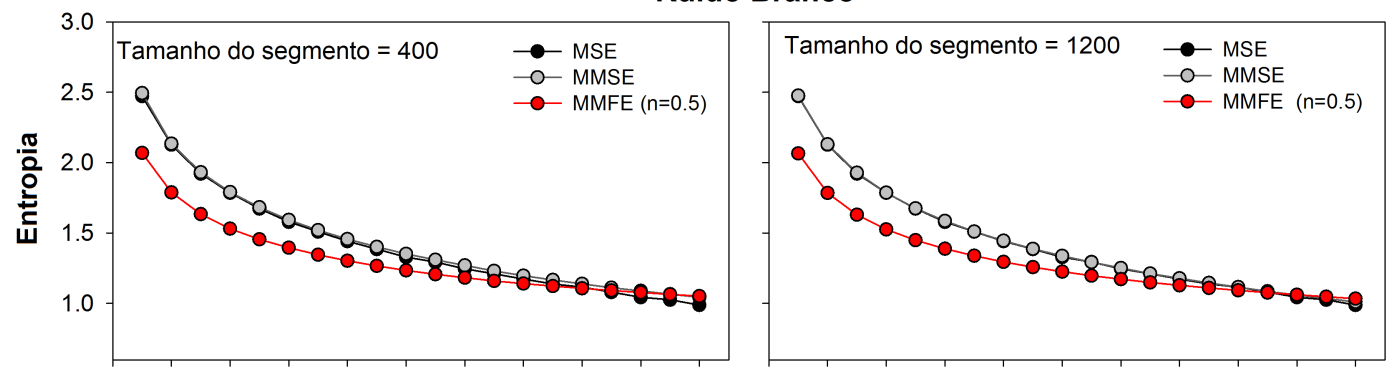

Ruído Rosa (1/f)
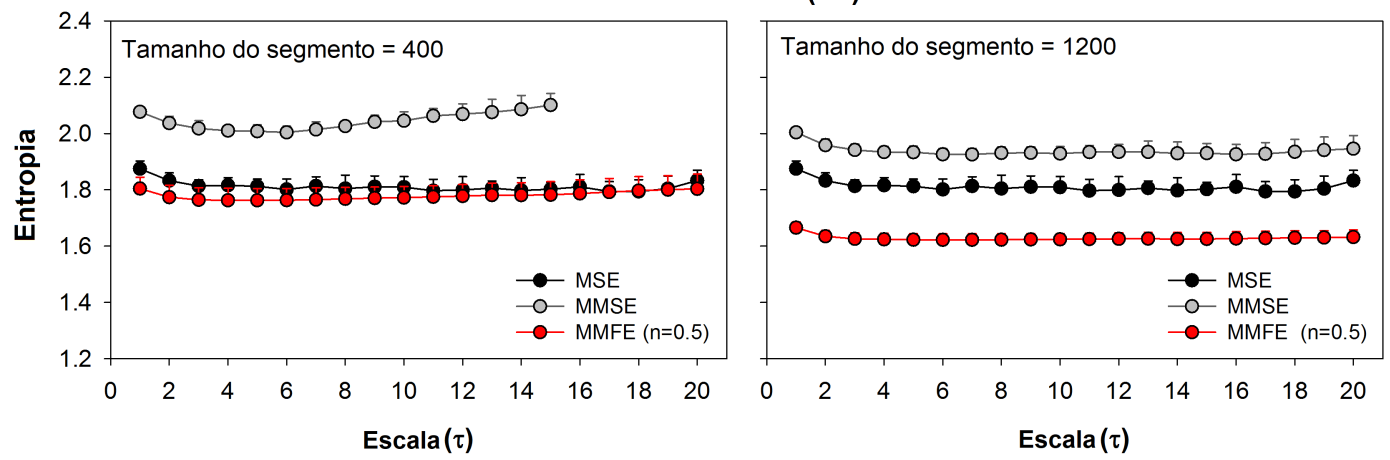

Figura 14 - Entropia multi-escala (MSE), MSE modificada (MMSE) e a proposta da entropia fuzzy multi-escala modificada (MMFE) calculada para os ruídos estocásticos. Os valores representam a entropia média, ou seja, MSE, MMSE e MMFE, \pm desvio padrão plotado como uma função de escalas de tempo $(\tau)$. Os resultados para ruído branco (painéis superiores) e ruído rosa (painéis inferiores) são mostrados. Os gráficos mostram que as curvas MMSE virtualmente se sobrepõem ao MSE para ruído branco, para segmentos de $N=400$ (gráficos à esquerda) e $N=1200$ pontos (gráficos à direita). Para ruído rosa, MMFE está mais próximo de MSE do que MMSE para $N=400$, mas o oposto acontece para $N=1200$. Além disso, o MMSE não pode estimar os valores de entropia do ruído rosa para escalas maiores que $\tau=15$. Observe que o MSE original é o mesmo nos gráficos da esquerda e da direita, pois é sempre calculado a partir da série RR completa.

comparado ao MMSE veja os painéis inferiores direitos na figura 15). Portanto, garantindo a escolha adequada de $n$, o MMFE pode retornar estimativas muito robustas de MSE para séries VFC tão curtas quanto 400 amostras.

A figura 16 mostra o erro quadrático médio de MMSE e MMFE para ruídos branco e rosa (1/f), também em função do tamanho do segmento e diferentes valores do expoente MF fuzzy $n$. Em contraste com os resultados observados para as séries de VFC, o melhor expoente MF não é dependente do tamanho do segmento para os ruídos estocásticos. Para $n=0,5$, MMFE resulta nos erros mais baixos, para ruídos brancos e rosa. No entanto, mesmo para o melhor expoente MF, MMFE não pode se aproximar de MSE tão bom quanto MMSE, exceto para o caso específico de $N=400$ em ruído rosa. Também pode ser notado na figura 14. Portanto, embora o MMFE tenha um desempenho melhor do que o MMSE para a série VFC, ele não parece se estender para as séries estocásticas, revelando que as propriedades dinâmicas intrínsecas da série influenciam a capacidade do MMSE e 

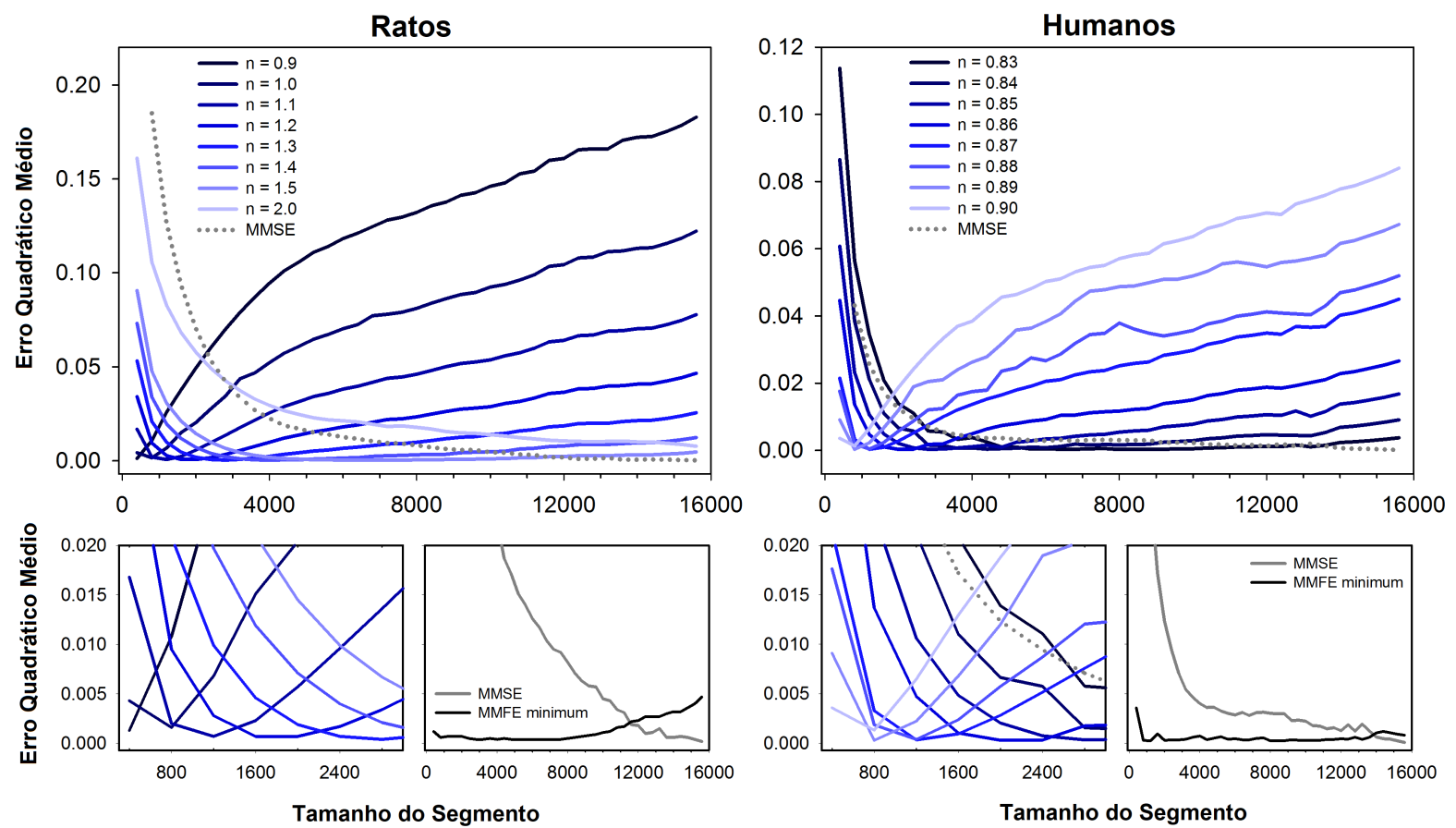

Figura 15 - Erro quadrático médio de conjuntos de dados VFC calculados para MMSE (linhas cinzas) e MMFE (linhas azuis e pretas), tomando o MSE original, calculado usando a série temporal completa, como padrão ouro. Os painéis da esquerda mostram os resultados para ratos e os painéis da direita mostram os resultados para humanos. O gráfico na parte superior mostra o erro para diferentes expoentes $n$ de MMFE, indicando que, para séries curtas, MMFE apresentou estimativas muito mais precisas em relação a toda a dinâmica. Os gráficos no canto inferior esquerdo são uma ampliação do anterior. O gráfico no canto inferior direito mostra o erro mínimo obtido com MMFE ( $n$ diferente para cada tamanho de segmento) em comparação com o erro obtido com MMSE. O erro do MMFE está sempre abaixo do erro do MMSE para um comprimento de série de até $N=11200$ (ratos) ou $N=13600$ (humanos) amostras quando escolhemos o $n$ adequado.

do MMFE de estimar corretamente o MSE.

Considerando que o melhor expoente do MMFE MF, ou seja, o valor de $n$ que retorna o erro mínimo, depende do comprimento da série no caso dos conjuntos de dados VFC, propomos expressões matemáticas para selecionar o expoente ótimo $n$ de acordo com o duração da série. A figura 17 mostra o comportamento empírico do expoente MF ótimo versus o comprimento da série, bem como os ajustes exponenciais para os pontos observados. Os expoentes apresentados na figura 17 (painéis esquerdo e central) são os utilizados para calcular os erros mínimos MMFE da figura 16 (painéis inferiores direitos). Descobrimos que as funções exponenciais fornecem a maior precisão de ajuste para os expoentes ideais. Assim, a função $f(N)=1,52-0,67 \times \exp \left(-\frac{N}{2500}\right)$ pode ser usada para selecionar o melhor expoente MF fuzzy MMFE para o conjunto de dados de ratos e a função $f(N)=0,82+0,09 \times \exp \left(-\frac{3 N}{10^{4}}\right)$ pode ser usado para selecionar o melhor expoente MMFE para o conjunto de dados de humanos, onde $N$ é o comprimento do VFC Series. 

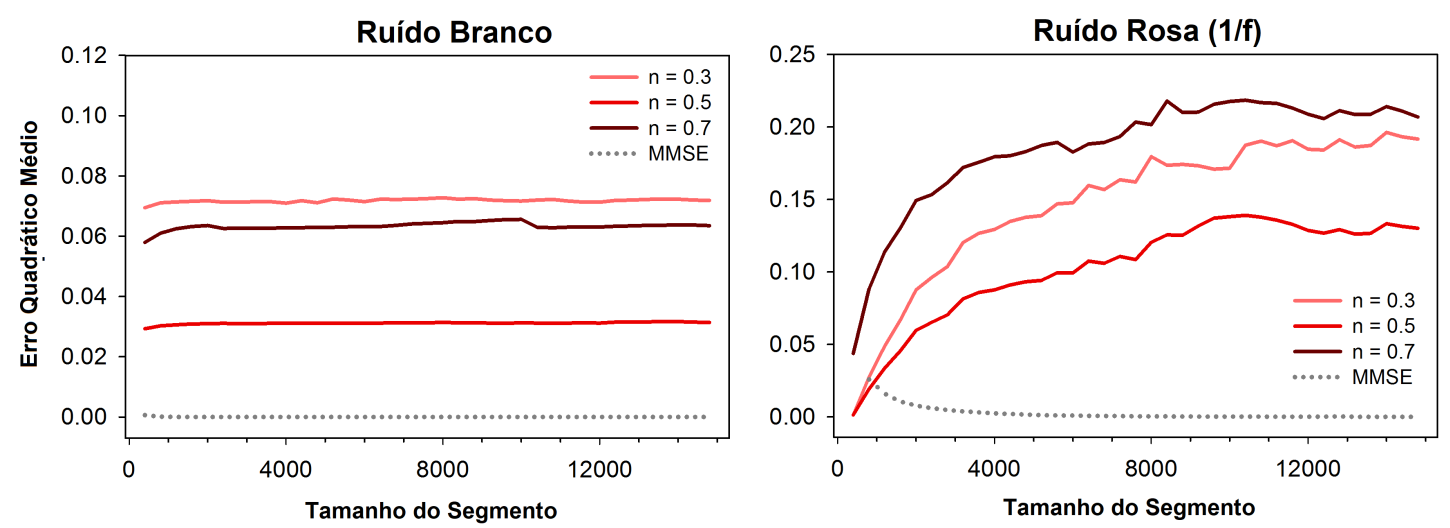

Figura 16 - Erro quadrático médio dos ruídos estocásticos calculados para MMSE (linhas cinzas) e MMFE (linhas vermelhas), tomando o MSE original, calculado usando a série temporal completa, como padrão ouro. O painel esquerdo mostra os resultados para o ruído branco e o painel direito mostra os resultados para o ruído rosa. $\mathrm{O}$ expoente fuzzy MF que retorna o menor erro para MMFE é $n=0,5$ para ruídos brancos e rosa. No entanto, mesmo para o melhor expoente, MMSE retorna os erros mais baixos, exceto para $N=400$ no ruído rosa. Diferentemente dos resultados para conjuntos de dados VFC, o melhor expoente MF do MMFE não depende do tamanho do segmento para ruídos estocásticos.
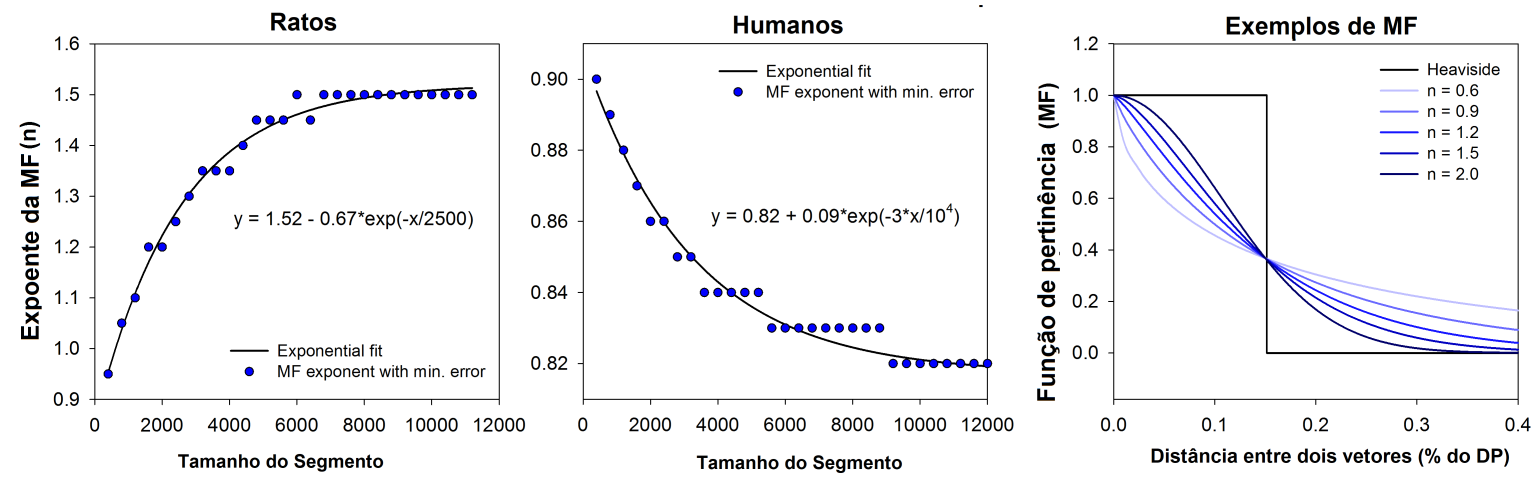

Figura 17 - Melhores expoentes de funções fuzzy MMFE e exemplos ilustrativos de funções de pertinência (MF). O gráfico à esquerda e ao centro mostra os melhores expoentes para cada tamanho de segmento, ou seja, os valores de $n$ que resultam no erro inferior, para os conjuntos de dados VFC de ratos e humanos, respectivamente. (ver figura 16). As linhas pretas mostram o ajuste exponencial sugerido para ser usado na escolha do melhor $n$. À direita, o contraste entre a função de passo de Degrau usada em MSE convencional e MMSE (linha preta), e a função fuzzy exponencial contínua, definida como $\exp \left[-\left(\frac{d}{r}\right)^{n}\right]$, usada em MMFE (linhas azuis). Usamos $r=0,15$ para o exemplo da ilustração.

Pode-se notar na figura 17 (à direita) que quando o expoente fuzzy MF cresce de $n=0,6$ para $n=2,0$, o MF torna-se menos restritivo para distâncias vetoriais menores que o parâmetro de tolerância $r$ e mais restritivo para distâncias vetoriais maiores que $r$, com transições suaves. Assim, quanto maior o $n$, mais privilegiadas são as distâncias curtas (menores que $r$ ), onde a função de Degrau caracteriza o caso limite. Se a série VFC é caracterizada principalmente por curtas distâncias entre os padrões, aumentar o 
expoente MF resultará na diminuição da entropia. Em contraste, se a série é caracterizada principalmente por longas distâncias entre os padrões (maiores que $r$ ), aumentar o expoente MF resultará no aumento da entropia. Uma vez que o expoente MF ótimo cresce com o comprimento da série para séries de VFC derivadas de ratos, podemos dizer que, para recuperar o MSE original, é necessário afrouxar os critérios para pequenas distâncias e/ou restringi-lo para grandes distâncias quando o tamanho do sinal aumenta. Em outras palavras, para manter a estimativa de MSE por MMFE inalterada nos diferentes tamanhos de sinal, distâncias curtas entre vetores devem ser privilegiadas (similaridade aumentada) enquanto distâncias longas devem ser restritas (similaridade diminuída). O oposto ocorre no caso de séries de VFC derivadas de humanos, uma vez que o expoente MF ótimo diminui à medida que o comprimento da série aumenta. Portanto, de acordo com as propriedades específicas da dinâmica, o expoente MF fuzzy pode ser ajustado para dar pesos diferentes a distâncias de padrão pequenas e grandes, de modo que o MSE original possa ser recuperado.

O desempenho do MMFE em ruídos estocásticos mostra que o MMSE é mais precisa do que a MMFE para ruído branco, independentemente do comprimento do sinal. Por outro lado, o MMFE apresenta erros menores do que o MMSE para séries muito curtas de ruído rosa (1/f). Embora MMFE mostre ser muito menos precisa para janelas de séries mais longas, esse recurso não invalida o objetivo principal do método, ou seja, o aprimoramento da análise multi-escala para séries temporais curtas. É importante notar que MMSE para restritividade de similaridade alta ou baixa resulta em erros elevados para MMFE, enquanto restritividade moderada, ou seja, $n=0,5$, apresenta a melhor estimativa (erro mínimo).

A figura 18 mostra o erro quadrático médio de MMFE e MMSE. Ambas as abordagens foram calculadas usando o procedimento clássico de coarse-graining (cg) e um filtro Butterworth de $6^{a}$ ordem (bw). Duas referências diferentes de MSE foram usadas para calcular os erros: o MSE clássico (MSE cg) e o MSE com o filtro Butterworth no lugar do procedimento de coarse-graining (MSE bw). A dimensão de incorporação usada para referência MSE foi correspondente para MMFE e MMSE.

Como pode ser notado na figura, não importa a escolha por $m(m=1$ ou $m=2)$ nem o procedimento para criar as versões em escala da dinâmica original ('cg' ou 'bw' ), O MMSE sempre mostra valores de erro marcadamente mais altos para tamanhos de segmento curtos. Além disso, embora o erro do MMSE calculado para $m=1$ seja sempre menor do que o erro calculado para $m=2$, ele nem sempre é válido para o MMFE. Acreditamos que isso seja devido à função de similaridade suave da entropia fuzzy, que é menos afetada pelo comprimento do padrão do que a função de Degrau adotada pela entropia da amostra. Além disso, o erro do MMSE tende a ser maior para estimativas baseadas em Butterworth (curvas vermelhas), não importando se as referências são o 

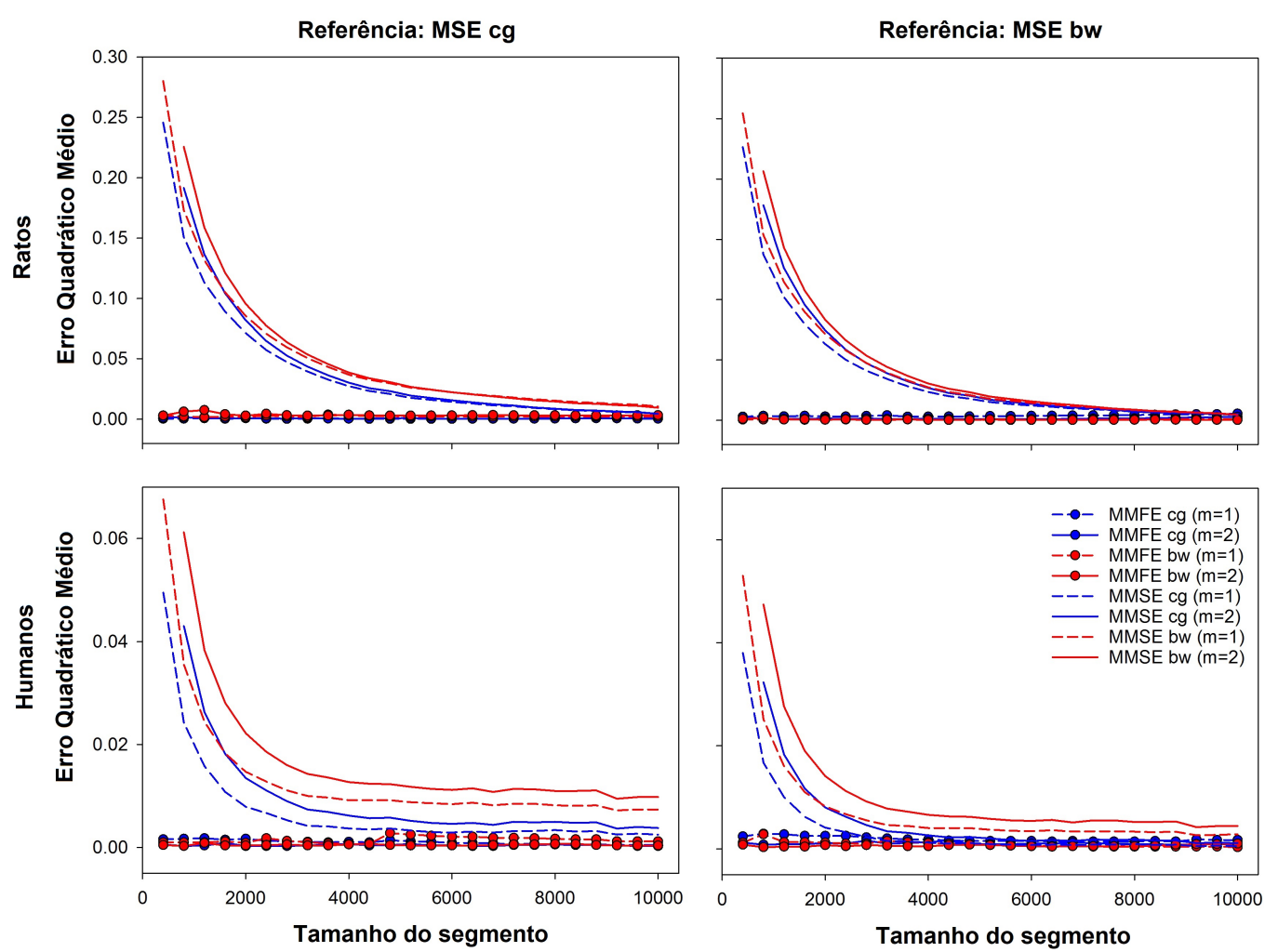

Figura 18 - Erros médios quadrados de MMFE (curvas com símbolos) e MMSE (curvas sem símbolos) em função do tamanho do segmento. Apenas erros ótimos para MMFE são mostrados, obtidos com os expoentes fuzzy ótimos para cada tamanho de segmento. As linhas tracejadas mostram os resultados para $m=1$, enquanto as linhas sólidas mostram os resultados para $m=2$. Os erros foram calculados usando duas referências diferentes: o MSE original (MSE cg, gráficos à esquerda) e o MSE com o procedimento de coarse-graining substituído por um filtro Butterworth de $6^{\mathrm{a}}$ ordem (MSE bw, gráficos à direita). Os resultados para conjuntos de dados de ratos (primeira linha) e humanos (segunda linha) são mostrados. Detalhes sobre os conjuntos de dados podem ser encontrados no artigo original (7).

MSE clássico (MSE cg) ou o MSE com Butterworth (MSE bw). Para MMFE, o erro depende da referência adotada, tendendo a ser menor para a estimativa que utiliza o mesmo procedimento de escalonamento do MSE de referência.

Este estudo apresenta algumas limitações que devem ser mencionadas. Em primeiro lugar, o efeito das não estacionariedades no MMFE ainda precisam ser abordado. Embora MSE seja conhecida por ser afetada pelas não estacionaridades presentes em escalas maiores do que aquelas avaliadas pela MSE (94), a comparação entre padrões usando entropia fuzzy não leva em conta o nível médio de cada padrão. Assim, acreditamos que o MMFE pode ser menos sensível a não estacionaridades do que o MSE, mas essa hipótese deve ser testada em estudos futuros.

Finalmente, embora o MMSE seja atualmente o estado da arte em análise de 
irregularidade multi-escala, na próxima seção faremos estudos para comparar a robustez do MMFE a outras variantes do MSE, como a entropia multi-escala composta e a entropia multi-escala composta refinada. Além disso, diferentes conjuntos de dados de VFC também estão sendo investigados, incluindo pacientes com doença cardíaca, para verificar se as propriedades do MMFE são semelhantes entre indivíduos saudáveis e doentes.

\subsection{Testes de Robustez de Variantes da MSE Baseadas em Entropia Fuzzy}

Como já foi dito a análise de entropia multi-escala (MSE) é uma abordagem fundamental para acessar a complexidade de uma série de tempo, estimando sua taxa de informações em uma gama de escalas temporais. No entanto, como vimos, a MSE pode não ser precisa ou válido para séries temporais curtas. É por isso que estudos anteriores aplicaram diferentes tipos de derivações do algoritmo a séries temporais de curto prazo. Porém, nenhum estudo analisou e comparou sistematicamente suas confiabilidades. Neste estudo comparamos as variações do algoritmo MSE adaptadas a séries temporais curtas em séries temporais de variabilidade da frequência cardíaca (VFC) humana e de rato. São estudadas as variações mais utilizadas de MSE: MSE composta (CMSE), MSE composta refinada (RCMSE), MSE modificada (MMSE) e suas versões fuzzy. Também analisamos os erros nas estimativas de MSE para uma gama de expoentes fuzzy incorporados. Os resultados mostram que as versões fuzzy MSE - em função do comprimento da série temporal apresentam erros mínimos em comparação com os algoritmos não fuzzy. O algoritmo de entropia multi-escala tradicional com contagem fuzzy (MFE) tem precisão semelhante a algoritmos alternativos com melhor desempenho de computação. Para a melhor precisão, os resultados sugerem expoentes fuzzys diferentes de acordo com o comprimento da série temporal.

\subsubsection{Conjunto de Dados}

As séries de variabilidade da frequência cardíaca (VFC) de ratos e humanos foram obtidas de estudos anteriores $(7,93)$. O primeiro grupo de dados de ECG foi registrado em 18 ratos Wistar saudáveis. As gravações foram realizadas no Laboratório de Fisiologia Cardiovascular das Faculdades de Medicina de Ribeirão Preto da Universidade de São Paulo. Resumidamente, os ratos tiveram seu ECG registrado por aproximadamente $1 \mathrm{~h}$ (40 a 80 minutos) nas condições basais. Um software de computador (LabChart, ADInstruments, Austrália) foi usado para criar séries RR a partir de registros de ECG. Todas as séries RR foram inspecionadas visualmente quanto a artefatos e corrigidas quando 
necessário. Como a duração da série temporal variou de 15.892 a 32.333 pontos, todas as séries RR foram truncadas para 15.892 pontos. O segundo grupo da série VFC consiste em 12 indivíduos humanos saudáveis, obtidos da base de dados Physionet MIT-BIH Normal Sinus Rhythm (89). Os 12 registros de ECG foram selecionados aleatoriamente do banco de dados. As séries RR foram calculadas usando a ferramenta ann2rr do pacote WFDB Physionet, que usa as anotações de batida das gravações para calcular os intervalos RR. Foram considerados apenas os intervalos RR normais, ou seja, intervalos entre dois batimentos normais sucessivos. Eventualmente, todas as séries RR foram truncadas para 15.892 amostras para que as séries de ratos e humanos tivessem o mesmo comprimento. O período de gravação de todas as séries vai das $8 \mathrm{~h}$ às $22 \mathrm{~h}$.

\subsubsection{Experiments}

Segmentamos a série completa VFC (15892 pontos) em segmentos iguais de 400, 800, 1200, ..., 15.600 pontos, com uma sobreposição de $90 \%$ ao segmento anterior. Para cada segmento, todas as variantes de MSE descritas acima foram calculadas, e o valor médio sobre os segmentos com o mesmo tamanho foi considerado para representar toda a série. O fator de escala máximo avaliado foi vinte, ou seja, $\tau=1,2, \ldots, 20$. A dimensão de incorporação e o fator de tolerância dos estimadores de entropia foram definidos como $m=2$ e $r=0,15 \times$ desvio padrão da série, respectivamente. Para avaliar a acurácia de cada variante para a MSE na estimativa para a MSE original, foi calculado o erro quadrático médio em todas as escalas de tempo, sempre tomando como referência o MSE original, obtido da série completa. O erro foi calculado para cada série e cada tamanho de segmento, e os erros médios foram relatados em função do tamanho do segmento.

Além disso, para avaliar o custo-efetividade das variantes MSE baseadas em fuzzys, medimos o tempo médio de computação de cada algoritmo. A análise foi realizada em um computador desktop equipado com processador Intel Core i7 930 @ 2,8 GHz e 16 Gb de RAM. Para garantir a isonomia dos resultados, todos os testes foram realizados com o software MATLAB (The MathWorks, Inc.) e o comando maxNumCompThreads $=1$ para que todos os métodos utilizassem uma única CPU. O tempo médio consumido para processar três séries de VFC humana selecionadas aleatoriamente é relatado como uma função de tamanho de segmento (de 400 a 12.000 pontos). O expoente fuzzy $n$ adotado neste experimento seguiu a equação encontrada anteriormente para a escolha do melhor expoente de acordo com o tamanho do segmento $(x)(7)$ :

$$
n=0.82-0.10 \exp \left(-3 \times x / 10^{4}\right)
$$



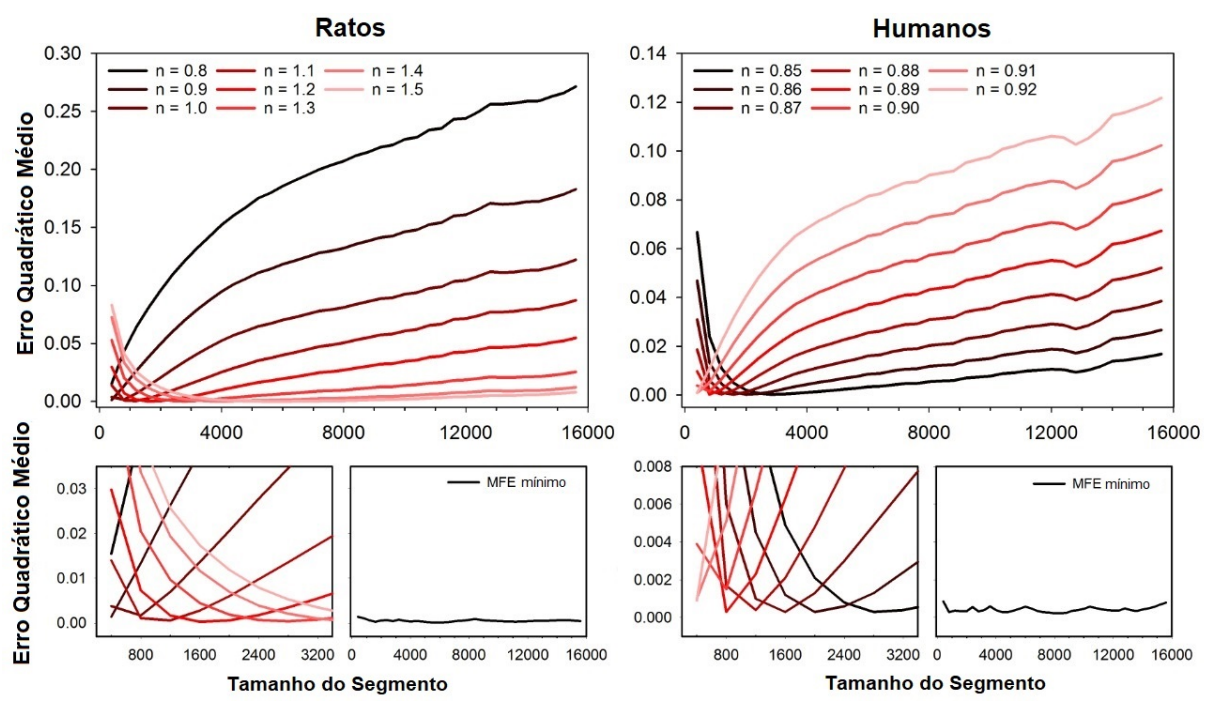

Figura 19 - Erro Quadrático Médio de MFE em função do tamanho do segmento. Os erros foram obtidos para expoentes fuzzys variando no intervalo $n=0,8$ a $n=1,5$ (ratos) e $n=0,85$ a $n=0,92$ (humanos). Os gráficos superiores mostram todas as curvas de erro, enquanto os gráficos inferiores mostram a ampliação dos erros de tamanhos de segmentos curtos. Pode-se notar que o expoente fuzzy que dá a melhor precisão (menor erro) varia de acordo com o tamanho do segmento. O erro mais baixo para todos os tamanhos de segmento é ilustrado nos gráficos à direita dos gráficos de ampliação (MFE mínimo).

\subsubsection{Resultados e Discussão dos Testes de Robustez de Variantes da MSE Baseadas em Entropia Fuzzy}

A precisão de CMSE, RCMSE, MMSE, CMFE, RCMFE, MMFE e MFE foi avaliada como o erro em comparação com o MSE calculada usando a série completa. A Figura 19 mostra a precisão da MFE obtida com as séries VFC de ratos e humanos. O gráfico superior esquerdo mostra os erros quadrados médios como uma função do tamanho do segmento do conjunto de dados do rato. Ilustramos diferentes curvas de erro para diferentes expoentes fuzzys variando de $n=0,8$ a $n=1,5$. A ampliação das curvas dos erros para tamanhos de segmento curtos é mostrada no canto inferior esquerdo, e o erro mínimo para cada tamanho de segmento é mostrado no lado direito do gráfico de ampliação. Os erros médios quadrados são mostrados como uma função de tamanho de segmento para o conjunto de dados dos humanos no canto superior direito. Ilustramos diferentes curvas de erro para diferentes expoentes fuzzys variando de $n=0,85$ a $n=0,92$. Pode-se encontrar a ampliação das curvas de erros para segmentos curtos no canto inferior direito, bem como os erros mínimos obtidos para cada tamanho de segmento.

Como pode ser visto na figura 19, o erro para cada expoente fuzzy $n$ depende 

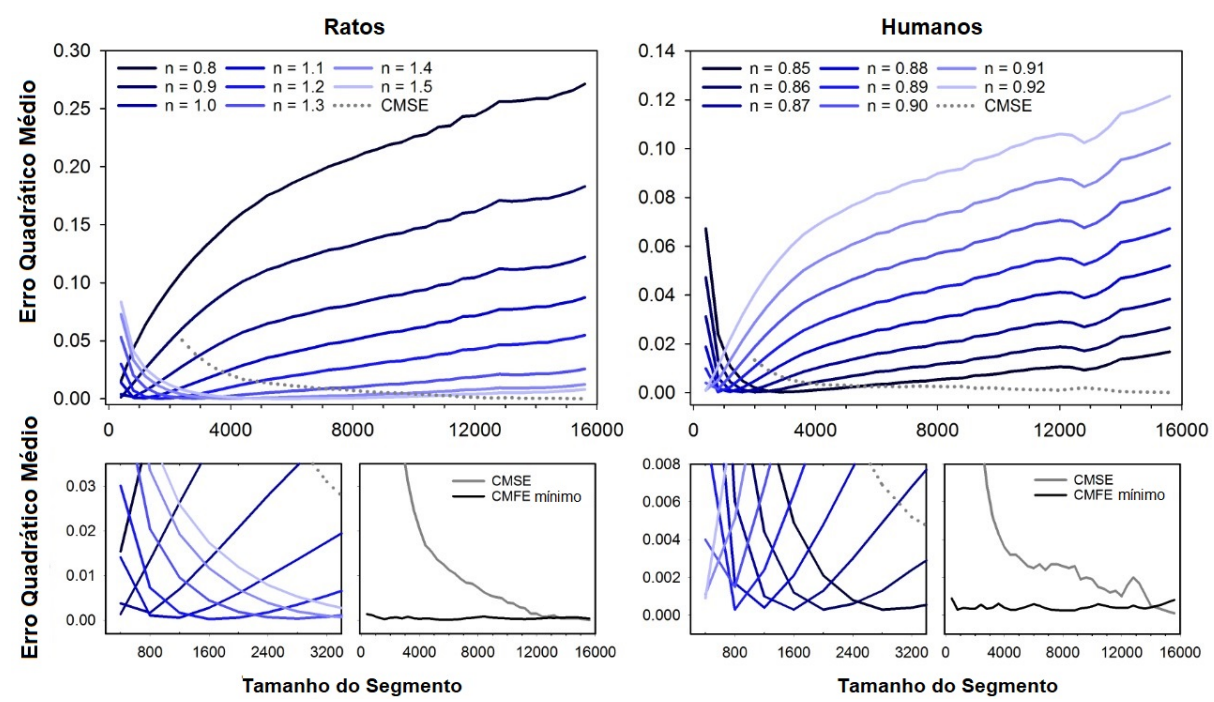

Figura 20 - Erros médios quadrados de CMFE e CMSE em função do tamanho do segmento. Os erros de CMFE foram obtidos para expoentes fuzzy variando no intervalo $n=0,8$ a $n=1,5$ (ratos, à esquerda) e $n=0,85$ a $n=0,92$ (humanos, à direita). Os gráficos superiores mostram as curvas de erro completas de CMFE (linhas sólidas) e CMSE (linhas tracejadas), enquanto os gráficos inferiores mostram uma ampliação dos erros para tamanhos de segmento curtos. Pode-se notar que o expoente fuzzy que dá a melhor precisão (menor erro) para o CMFE varia de acordo com o tamanho do segmento. O erro mais baixo para CMFE (linhas pretas) e CMSE (linhas cinza) para todos os tamanhos de segmento são ilustrados nos gráficos à direita dos gráficos de ampliação.

do tamanho do segmento (comprimento da série), e os $n$ ótimos são os que fornecem os menores erros. Para a série VFC de ratos, os melhores expoentes aumentam com o tamanho do segmento, enquanto diminui para a série VFC humana.

A Figura 20 mostra os erros quadráticos médios para CMSE (linhas tracejadas) e CMFE (linhas sólidas). As curvas de erro para CMFE são ilustradas para expoentes fuzzys variando de $n=0,8$ a $n=1,5$ (ratos) e $n=0,85$ a $n=0,92$ (humanos), semelhante à Figura 19. Nos gráficos inferiores, pode-se ver as ampliações das curvas de erro para tamanhos de segmento curtos e os erros mínimos para CMFE (linha preta) em comparação com CMSE (linha cinza). Semelhante aos resultados com MFE, os erros dependem do tamanho do segmento. Os melhores expoentes aumentam com o tamanho do segmento para ratos, enquanto diminui para a série VFC humana.

A figura 21 apresenta as curvas de erro para RCMSE (linhas tracejadas) e RCMFE (linhas sólidas). As curvas de erro são ilustradas para os expoentes fuzzys que variam de $n=0,8$ a $n=1,5$ (ratos) e $n=0,85$ a $n=0,92$ (humanos). A ampliação das curvas de erro e os erros mínimos para todos os tamanhos de segmento são mostrados nos gráficos inferiores. Como MFE e CMFE, os erros de RCMFE são dependentes do tamanho do segmento, e os melhores expoentes aumentam com o tamanho do segmento para ratos, 

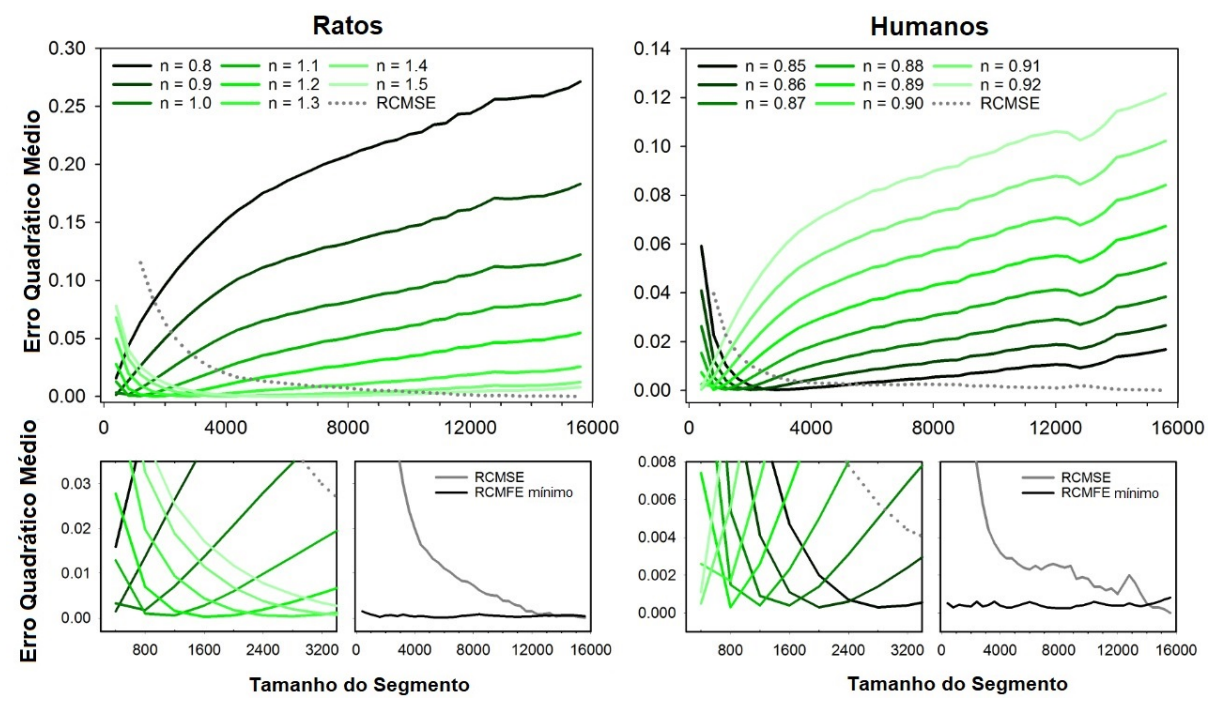

Figura 21 - Erros quadrados médios de RCMFE e RCMSE em função do tamanho do segmento. Os erros de RCMFE foram obtidos para expoentes fuzzys variando na faixa de $n=0,8$ a $n=1,5$ (ratos, à esquerda) e $n=0,85$ a $n=0,92$ (humanos, à direita). Os gráficos superiores mostram as curvas de erro completas de RCMFE (linhas sólidas) e RCMSE (linhas tracejadas), enquanto os gráficos inferiores mostram a ampliação dos erros de tamanho de segmento curto. Pode-se notar que o expoente fuzzy que dá a melhor precisão (menor erro) para o RCMFE varia de acordo com o tamanho do segmento. O menor erro para RCMFE (linhas pretas) e RCMSE (linhas cinzas) para todos os tamanhos de segmento são ilustrados nos gráficos à direita dos gráficos de ampliação.

enquanto diminui para a série VFC humana.

As curvas de erro obtidas com MMFE e MMSE são mostradas na figura 22. Embora um gráfico de erro semelhante possa ser encontrado em um estudo anterior (7), aqui expandimos a gama de expoentes avaliados para calcular o erro mínimo de MMFE. As curvas de erro são ilustradas para os expoentes fuzzys que variam de $n=0,8$ a $n=1,5$ (ratos) e $n=0,85$ a $n=0,92$ (humanos). A ampliação das curvas de erro, juntamente com os gráficos dos erros mínimos de MMFE e MMSE para todos os tamanhos de segmento, são mostrados nos gráficos inferiores. Como todas as outras variantes de MSE baseadas em fuzzy, os erros de MMFE dependem do tamanho do segmento, e os melhores expoentes aumentam com o tamanho do segmento para ratos, enquanto diminui para séries humanas de VFC. A Figura 23 mostra a comparação dos erros de todas as variantes multi-escala estudadas, ou seja, CMSE, RCMSE, MMSE, CMFE, RCMFE, MMFE e MFE. Para métodos baseados em entropia fuzzy, apenas o erro mínimo é mostrado, calculado com o expoente fuzzy ótimo de cada tamanho de segmento. Conforme mostrado na figura, todas as variantes baseadas em entropia fuzzy têm erros mais baixos do que qualquer variante baseada em entropia amostral, para segmentos de tamanho de até 13.000 pontos.

A figura 24 mostra os expoentes fuzzy ótimos das variantes MSE baseadas em fuzzy 

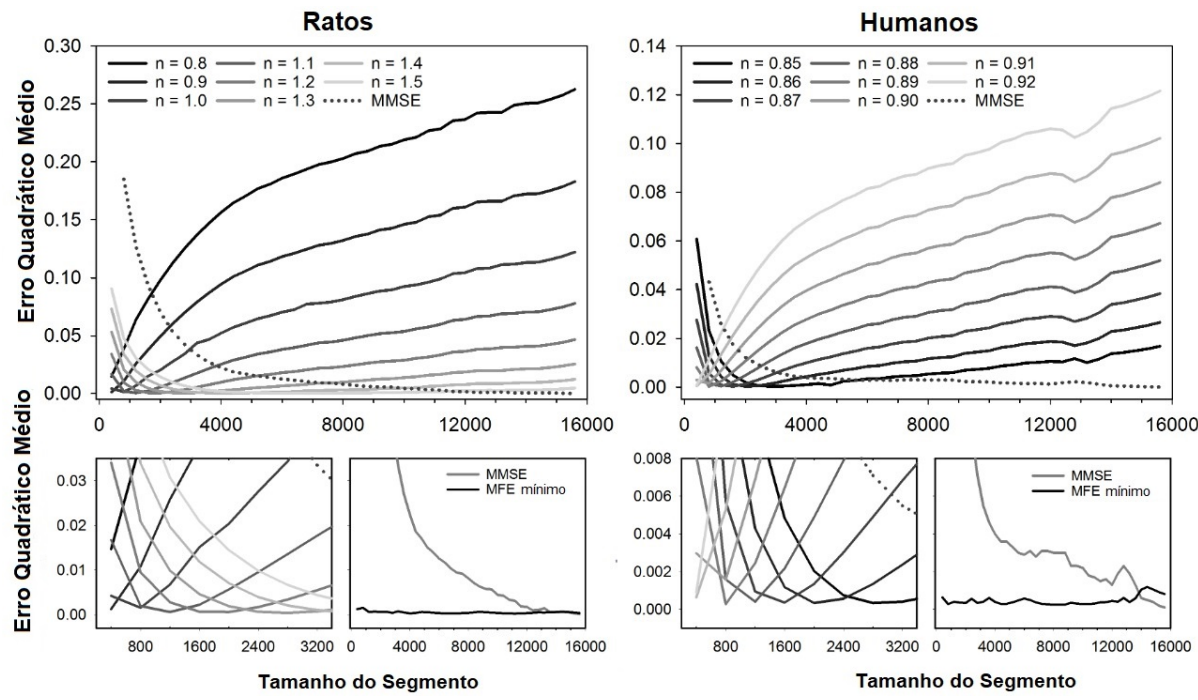

Figura 22 - Erros quadrados médios de MMFE e MMSE em função do tamanho do segmento. Os erros de MMFE foram obtidos para expoentes fuzzys variando na faixa de $n=0,8$ a $n=1,5$ (ratos, à esquerda) e $n=0,85$ a $n=0,92$ (humanos, à direita). Os gráficos superiores mostram as curvas de erro completas de MMFE (linhas sólidas) e MMSE (linhas tracejadas), enquanto os gráficos inferiores mostram uma ampliação dos erros para tamanhos de segmento curtos. Pode-se notar que o expoente fuzzy que dá a melhor precisão (menor erro) para o MMFE varia de acordo com o tamanho do segmento. O menor erro para MMFE (linhas pretas) e MMSE (linhas cinzas) para todos os tamanhos de segmento são ilustrados nos gráficos à direita dos gráficos de ampliação.
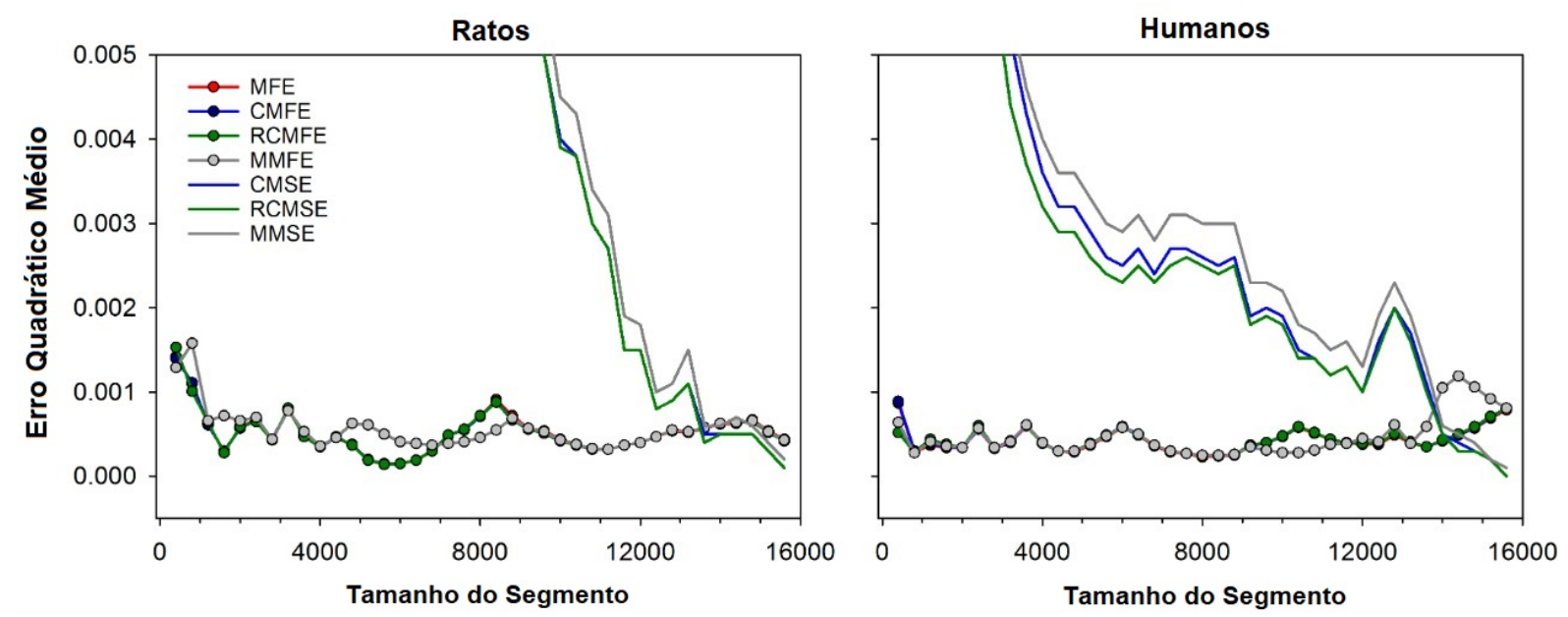

Figura 23 - Erro quadrático médio para todas as abordagens consideradas, ou seja, CMSE, RCMSE, MMSE, CMFE, RCMFE, MMFE e MFE. Para abordagens baseadas em entropia fuzzy, apenas o erro mínimo é mostrado, obtido com o expoente fuzzy ótimo para cada tamanho de segmento. Os resultados são mostrados para bancos de dados de ratos (esquerda) e humanos (direita). Observe que os erros são calculados em relação ao MSE de séries temporais de comprimento total, ou seja, 15892 batimentos. 

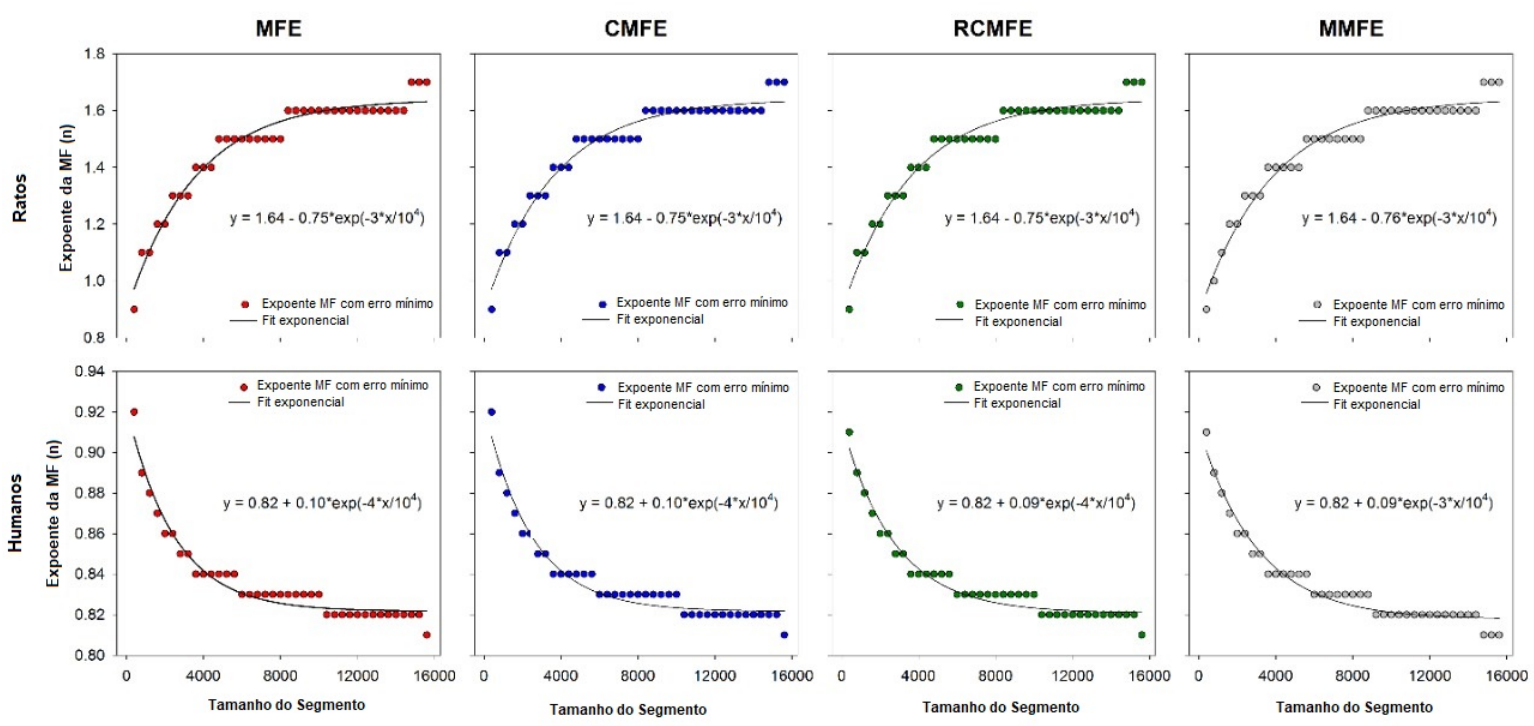

Figura 24 - Os melhores expoentes fuzzy encontrados para cada tamanho de segmento em conjuntos de dados VFC de ratos e humanos. As linhas sólidas representam as funções de melhor ajuste, ou seja, uma função exponencial decrescente $y=1,64-0,75 \times \exp \left(-3 \times x / 10^{4}\right)$ para ratos e um exponencial crescente $y=0,82-0,10 \times \exp \left(-4 \times x / 10^{4}\right)$ para humanos. Essas funções podem ser usadas para escolher o melhor expoente fuzzy desses conjuntos de dados de acordo com o comprimento da série.

para cada tamanho de segmento. Esses expoentes foram utilizados para calcular as curvas de erro mínimo para variantes multi-escala baseadas na entropia fuzzy (ver figura 24). As curvas foram ajustadas a funções exponenciais, que podem ser empregadas para encontrar o melhor expoente fuzzy desses conjuntos de dados de acordo com o comprimento da série temporal. Observe que para a série de VFC de ratos, o expoente fuzzy ótimo aumenta com o comprimento da série, diminuindo a série de VFC de humanos.

Para efeito de comparação, a figura 25 mostra o erro quadrático médio de MFE usando a função fuzzy alternativa $\exp \left(-0,6931 \times(d / r)^{n}\right)$. Os erros são ilustrados para o expoente fuzzy variando de $n=1,3$ a $n=3,0$ (ratos) e de $n=2,0$ a $n=5,5$ (humanos). Os resultados mostraram que a MFE com esta função fuzzy alternativa também apresenta dependência do tamanho do segmento, semelhante à função fuzzy original (figura 19). No entanto, os valores dos expoentes ideais para cada tamanho de segmento são marcadamente diferentes da função fuzzy original, e os melhores $n$ aumentam com o tamanho do segmento para as séries de VFC de ratos e humanos.

A Figura 26 mostra o tempo médio (ao longo de três séries VFC humanas) gasto calculando as diferentes variantes multi-escala baseadas na entropia fuzzy em tamanhos de segmento crescentes (até 12000 amostras). Como esperado, o tempo computacional necessário para executar qualquer método aumenta com o tamanho do segmento. No 

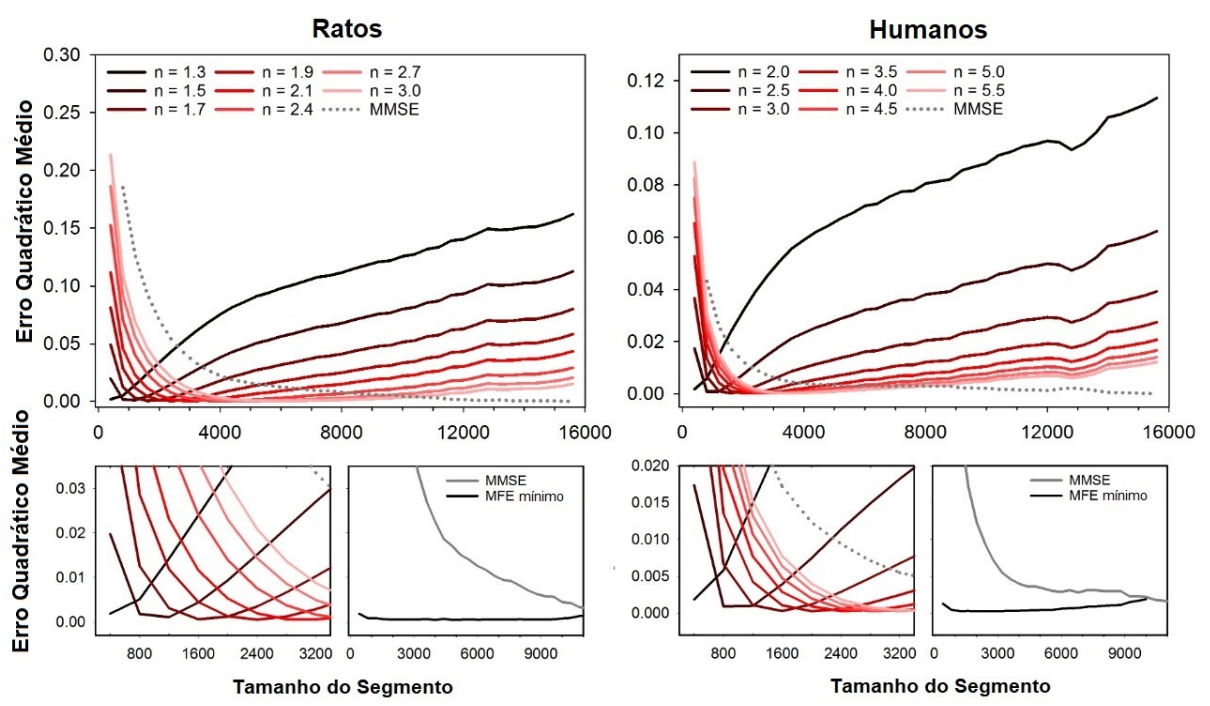

Figura 25 - Erros quadrados médios de MFE em função do tamanho do segmento, obtidos com a função fuzzy alternativa, ou seja, $\exp \left(-0,6931 \times(d / r)^{n}\right)$. Os erros são ilustrados para o expoente fuzzy variando no intervalo $n=1,3$ a $n=3,0$ (ratos) e $n=2,0$ a $n=5,5$ (humanos). Os gráficos superiores mostram todas as curvas de erro, enquanto os gráficos inferiores mostram a ampliação dos erros de tamanhos de segmentos curtos. Pode-se notar que o expoente fuzzy que dá a melhor precisão (menor erro) varia de acordo com o tamanho do segmento, embora os expoentes ótimos sejam diferentes daqueles obtidos com a função fuzzy original. O erro mais baixo para todos os tamanhos de segmento é ilustrado nos gráficos ampliados à direita (MFE mínimo). Para referência, o MMSE também é ilustrado nos gráficos (linhas cinza).

entanto, MMFE tem o maior custo computacional, enquanto MFE apresentou o menor. CMFE e RCMFE apresentaram praticamente o mesmo tempo computacional (as curvas se sobrepõem na figura26).

No presente estudo, adotamos uma comparação sistemática entre três variantes de MSE (CMSE, RCMSE, MMSE) e suas adaptações baseadas em fuzzy (CMFE, RCMFE, MMFE, MFE) para verificar a precisão deles para estimar o MSE real para breve sinais de prazo. Como esperado, todos os métodos baseados em fuzzy tiveram um desempenho superior em comparação aos algoritmos baseados na entropia da amostra. Surpreendentemente, a precisão de todos os métodos baseados em fuzzy é bastante semelhante, apontando que o uso de entropia fuzzy no lugar da entropia de amostra parece suficiente para fornecer estimativas ótimas de MSE para sinais de curto prazo. Em outras palavras, as melhorias adotadas na coarse-graining para CMFE, RCMFE e MMFE parecem ter pouco ou nenhum efeito nas variantes baseadas em fuzzy, uma vez que MFE forneceu erros na estimativa para a MSE original tão inferior quanto os encontrados no CMFE, RCMFE e MMFE. A substituição da similaridade rígida de SampEn (função de Degrau) pela função fuzzy suave em FuzzyEn parece ser a melhoria mais relevante para uma boa estimativa de entropia em séries temporais curtas. No entanto, deve-se estar ciente de que a escolha dos expoentes 


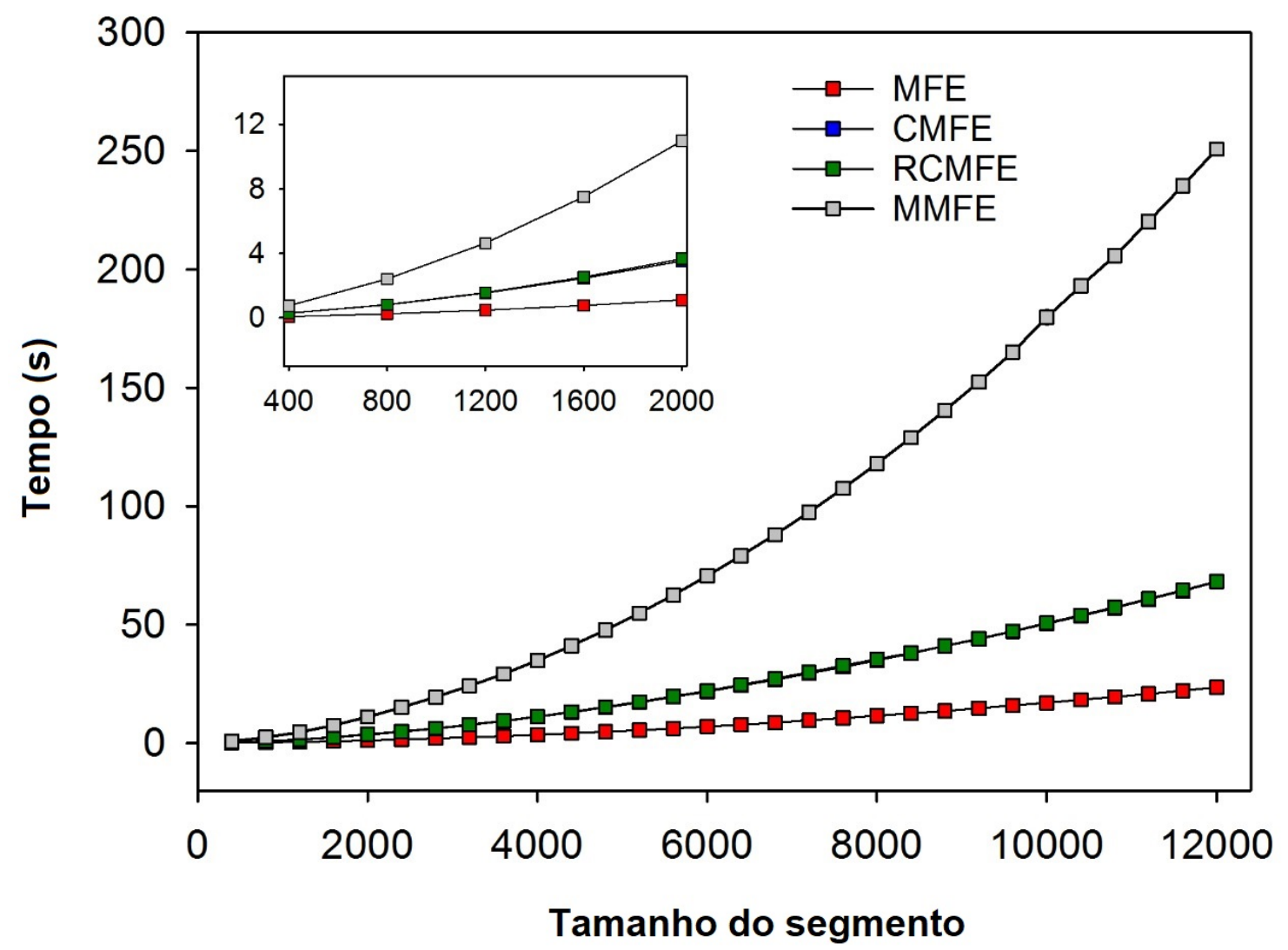

Figura 26 - Tempo de computação das variantes baseadas em entropia fuzzy de MSE, ou seja, MFE, CMFE, RCMFE e MMFE. O gráfico mostra o tempo médio consumido (em segundos) para calcular as variantes de MSE para três séries de VFC de humanos até segmentos de 12.000 pontos. É importante notar que o CMFE e o RCMFE levam praticamente o mesmo tempo para serem calculados e, portanto, essas curvas são sobrepostas.

fuzzy ideais é crucial para obter alta precisão.

No teste anterior (Seção 4.1) com o mesmo conjunto de dados, mostramos que o MMFE fornece melhores estimativas para a MSE original do que o MMSE quando as escolhas adequadas do expoente fuzzy $n$ são feitas (7). Aqui, mostramos que CMFE, RCMFE e MFE também dependem de $n$ e que os expoentes ótimos encontrados para MMFE são virtualmente os mesmos para CMFE, RCMFE e MFE, como pode ser visto na figura 24. Embora os conjuntos de dados de ratos e humanos representem condições de saúde, os melhores expoentes para ratos aumentam com o comprimento da série, enquanto diminui para humanos. É provável que seja uma consequência das diferentes espécies, mas ainda tem de ser investigado juntamente com conjuntos de dados com séries de VFC patológicas. No entanto, as equações de ajuste fornecidas na figura 24 podem ser utilizadas para a escolha dos expoentes fuzzy ótimos no conjunto de dados aqui avaliado. 
Para verificar a influência da função fuzzy na precisão das variantes MSE baseadas em fuzzy, calculamos o erro quadrático médio de MFE usando uma função fuzzy alternativa, ou seja, $\exp \left(-0,6931 \times(d / r)^{n}\right)(95)$. Curiosamente, esta função alternativa também apresentou uma dependência do erro mínimo na escolha do expoente $n$. No entanto, o intervalo de valores $n$ ideais é marcadamente diferente daqueles encontrados para a função fuzzy original e, curiosamente, o expoente sempre aumenta com o comprimento da série para ambos os conjuntos de dados (ratos e humanos). A extensa avaliação de diferentes funções fuzzy está fora do escopo do presente estudo, e deve-se estar ciente de que mudar a função fuzzy requer a busca pelos expoentes fuzzy ótimos. Para uma revisão extensiva sobre as possíveis funções fuzzy e suas diferenças, por favor consulte (96).

Para estimadores de entropia baseados em uma função de similaridade entre padrões (como SampEn e FuzzyEn), o fator de tolerância, $r$, é comumente definido como uma porcentagem do desvio padrão do sinal, tornando os resultados comparáveis de sinais com magnitudes diferentes. Alternativamente, o sinal pode ser normalizado para média zero e desvio padrão 1, um procedimento que tem o mesmo efeito de multiplicar o fator de tolerância pelo desvio padrão do sinal. Porém, na FuzzyEn, esses dois procedimentos nem sempre são equivalentes e dependem da função fuzzy adotada. No caso de $\exp \left(d^{n} / r\right)$ (a função fuzzy adotada neste estudo), pode-se notar que a distância entre os padrões $(d)$ e $r$ não são elevados à mesma potência ( exceto quando $n=1$ ). Assim, normalizar a série (afetando $d$ ) ou normalizar $r$ pode resultar em valores de entropia diferentes. A função fuzzy alternativa avaliada com MFE $\left(\exp \left(-0.6931 \times(d / r)^{n}\right)\right)$ não mostra essa limitação, uma vez que $d$ e $r$ são elevados para $n$.

A análise de custo de computação (tempo) necessária para calcular todas as variantes baseadas em fuzzy de MSE mostrou que MMFE é o mais demorado. Por outro lado, o MFE é o algoritmo mais rápido entre eles. Uma vez que a precisão de todos os algoritmos é muito semelhante, a simplicidade e eficiência computacional do MFE tornam este algoritmo o mais atraente para ser usado na análise de sinais de curto prazo, o que fornece boa precisão para séries VFC menores que 400 pontos. 


\section{Conclusão}

No teste de robustez concluímos que a medida MMFE proposta foi capaz de estimar a entropia multi-escala para uma série de tempo muito curta de forma robusta. No caso da série VFC, o desempenho do MMFE pode se aproximar de seu máximo quando se escolhe o expoente fuzzy apropriado de acordo com o comprimento da série. No caso de ruídos estocásticos, o melhor expoente fuzzy não depende do comprimento da série, mas a precisão do MMFE não é tão boa quanto o MMSE. Por outro lado, nossos resultados demonstraram que o MMFE é mais robusto do que o MMSE para séries temporais de VFC com comprimento de até $N=11200$ pontos (para ratos) ou $N=13600$ pontos (para humanos). Os resultados relatados neste estudo sugerem o uso confiável de MMFE em investigações com sinais de tempo curto quando os sistemas fisiológicos estão em foco. A MMFE fornece estimativas notavelmente melhores em comparação com MMSE quando os expoentes fuzzy adequados são usados. Isso também é válido se o filtro Butterworth substituir o procedimento de coarse-graining ou se uma dimensão de incorporação inferior for usada.

Com relação ao estudo a respeito da robustez de variantes da MSE baseadas em entropia fuzzy, várias propostas de MSE baseadas em SampEn e FuzzyEn foram calculadas em séries temporais de VFC curtas e sua precisão para estimar o MSE real foi investigada. Todos os algoritmos baseados em entropia fuzzy forneceram melhor precisão (dada a escolha adequada do expoente fuzzy) em comparação com as variantes baseadas em SampEn. Além disso, todos os algoritmos baseados em FuzzyEn avaliados apresentaram precisão semelhante. Portanto, como o MFE é o algoritmo mais simples e econômico entre eles, recomendamos o uso do MFE para a análise de séries temporais de curto prazo. Os resultados também indicam que diferentes funções fuzzy podem fornecer boas precisões. No entanto, a dependência do expoente fuzzy $(n)$ para o comprimento da série pode variar de uma função para outra em relação a diferentes conjuntos de dados. Mais estudos são necessários para determinar os expoentes fuzzy ideais em conjuntos de dados com sinais patológicos. Nossos resultados foram publicados nos 
artigos Artigo: "Modified multiscale fuzzy entropy: A robust method for short-term physiologic signals", https://doi.org/10.1063/5.0010330 e Artigo: "Response to "Comment on "Modified multiscale fuzzy entropy: A robust method for short-term physiologic signals" https://doi.org/10.1063/5.0040708 e no manuscrito "Multiscale Entropy Analysis of Short Signals: the Robustness of Fuzzy Entropy-Based Variants". Temos ainda como perspectivas futuras a análise de séries patológicas. 


\section{Referências}

1 LIPSITZ, L. A.; GOLDBERGER, A. L. Loss of 'Complexity' and Aging: Potential Applications of Fractals and Chaos Theory to Senescence. JAMA: The Journal of the American Medical Association, v. 267, n. 13, p. 1806-1809, 1992. ISSN 15383598.

2 BILlMAN, G. E. Heart rate variability - A historical perspective. Frontiers in Physiology, v. 2 NOV, p. 1-27, 2011. ISSN 1664042X.

3 COSTA, M.; GOLDBERGER, A. L.; PENG, C.-K. Multiscale entropy analysis of biological signals. Physical review E, APS, v. 71, n. 2, p. 21906, 2005.

4 COSTA, M.; GOLDBERGER, A. L.; PENG, C.-K. Multiscale entropy analysis of complex physiologic time series. Physical review letters, APS, v. 89, n. 6, p. 68102, 2002.

5 WU, S.-D. et al. Time series analysis using composite multiscale entropy. Entropy, Multidisciplinary Digital Publishing Institute, v. 15, n. 3, p. 1069-1084, 2013.

6 WU, S. D. et al. Modified multiscale entropy for short-term time series analysis. Physica A: Statistical Mechanics and its Applications, Elsevier B.V., v. 392, n. 23, p. 5865-5873, 2013. ISSN 03784371. Disponível em: <http://dx.doi.org/10.1016/j.physa.2013.07.075>.

7 BORIN, A. M. S.; SILVA, L. E. V.; MURTA, L. O. Modified multiscale fuzzy entropy: A robust method for short-term physiologic signals. Chaos (Woodbury, N.Y.), AIP Publishing LLC, v. 30, n. 8, p. 083135, 2020. ISSN 10897682.

8 PINCUS, S. M. Approximate entropy as a measure of system complexity. Proceedings of the National Academy of Sciences, National Acad Sciences, v. 88, n. 6, p. 2297-2301, 1991.

9 RICHMAN, J. S.; MOORMAN, J. R. Physiological time-series analysis using approximate entropy and sample entropy maturity in premature infants Physiological time-series analysis using approximate entropy and sample entropy. Americal Journal of Physiology Heart and Circulatory Physiology, v. 278, p. H2039-H2049, 2000.

10 GOLDBERGER, A. L.; PENG, C.-K.; LIPSITZ, L. A. What is physiologic complexity and how does it change with aging and disease? Neurobiology of aging, Elsevier, v. 23, n. 1, p. 23-26, 2002.

11 ZHANG, Y.-C. Complexity and 1/f noise. a phase space approach. Journal de Physique I, EDP Sciences, v. 1, n. 7, p. 971-977, 1991.

12 FOGEDBY, H. C. On the phase space approach to complexity. Journal of statistical physics, Springer, v. 69, n. 1-2, p. 411-425, 1992. 
13 HUMEAU-HEURTIER, A. The multiscale entropy algorithm and its variants: A review. Entropy, v. 17, n. 5, p. 3110-3123, 2015. ISSN 10994300.

14 COSTA, M. et al. Multiscale entropy analysis of human gait dynamics. Physica A: Statistical Mechanics and its applications, Elsevier, v. 330, n. 1-2, p. 53-60, 2003.

15 CHANG, Y. C. et al. Application of a modified entropy computational method in assessing the complexity of pulse wave velocity signals in healthy and diabetic subjects. Entropy, v. 16, n. 7, p. 4032-4043, 2014. ISSN 10994300.

16 CHEN, W. et al. Characterization of surface EMG signal based on fuzzy entropy. IEEE Transactions on Neural Systems and Rehabilitation Engineering, v. 15, n. 2, p. 266-272, 2007. ISSN 15344320.

17 ZADEH, L. A. Fuzzy sets. Information and control, Elsevier, v. 8, n. 3, p. 338-353, 1965.

18 LI, Y. et al. A fault diagnosis scheme for rolling bearing based on local mean decomposition and improved multiscale fuzzy entropy. Journal of Sound and Vibration, Elsevier, v. 360, p. 277-299, 2016. ISSN 10958568. Disponível em: <http://dx.doi.org/10.1016/j.jsv.2015.09.016>.

19 ZHENG, J.; PAN, H.; CHENG, J. Rolling bearing fault detection and diagnosis based on composite multiscale fuzzy entropy and ensemble support vector machines. Mechanical Systems and Signal Processing, Elsevier, v. 85, n. January 2015, p. 746-759, 2017. ISSN 10961216. Disponível em: <http://dx.doi.org/10.1016/j.ymssp.2016.09.010>.

20 WU, S. D. et al. Analysis of complex time series using refined composite multiscale entropy. Physics Letters, Section A: General, Atomic and Solid State Physics, Elsevier B.V., v. 378, n. 20, p. 1369-1374, 2014. ISSN 03759601.

21 AZAMI, H.; FERNÁNDEZ, A.; ESCUDERO, J. Refined multiscale fuzzy entropy based on standard deviation for biomedical signal analysis. Medical \& biological engineering $\&$ computing, Springer, v. 55, n. 11, p. 2037-2052, 2017.

22 BOFFETTA, G. et al. Predictability: a way to characterize complexity. Physics reports, Elsevier, v. 356, n. 6, p. 367-474, 2002.

23 LAPLACE, P. S. marquis de. Essai philosophique sur les probabilités. [S.l.]: Bachelier, 1825.

24 FEIGENBAUM, M. J. Universal behavior in nonlinear systems. Universality in Chaos, Second Edition, p. 49-84, 2017.

25 WILliAMS, G. Chaos theory tamed. [S.l.]: CRC Press, 1997.

26 MANDELBROT, B. The fractal geometry of nature. [S.l.]: WH freeman New York, 1982. v. 1.

27 PENTLAND, A. P. Fractal-Based Description of Natural Scenes. IEEE Transactions on Pattern Analysis and Machine Intelligence, PAMI-6, n. 6, p. 661-674, 1984. ISSN 01628828. 


\section{Referências}

28 Keller, J. M.; CHEN, S.; CROWNOVER, R. M. Texture description and segmentation through fractal geometry. Computer Vision, Graphics, and image processing, Elsevier, v. 45, n. 2, p. 150-166, 1989.

29 GOLDBERGER, A. L.; RIGNEY, D. R.; WEST, B. J. Chaos and fractals in human physiology. Scientific American, JSTOR, v. 262, n. 2, p. 42-49, 1990.

30 GOLDBERGER, A. L.; WEST, B. J. Applications of Nonlinear Dynamics to Clinical Cardiology. Annals of the New York Academy of Sciences, v. 504, n. 1, p. 195-213, 1987. ISSN 17496632.

31 WEST, B. J. et al. Physiology in Fractal Dimensions. v. 75, n. 4, p. 21-78, 1990.

32 GOLDBERGER, A. L.; WEST, B. J. Fractals in physiology and medicine. The Yale journal of biology and medicine, v. 60, n. 5, p. 421-435, 1987. ISSN 00440086.

33 MIZRAHI, S. S. Dinâmica Estocástica e Irreversibilidade, por Tânia Tomé e Mário José de Oliveira, EDUSP, 241 p. (2001). Revista Brasileira de Ensino de Física, v. 23, n. 3, p. 0, 2001. ISSN 1806-1117.

34 CATTANi, M. et al. Deterministic chaos theory: Basic concepts. Revista Brasileira de Ensino de Fisica, v. 39, n. 1, p. 1-13, 2017. ISSN 01024744.

35 MAY, R. M. Simple mathematical models with very complicated dynamics. Nature, Springer, v. 261, n. 5560, p. 459-467, 1976.

36 MAY, R. M.; OSTER, G. F. Bifurcations and dynamic complexity in simple ecological models. The American Naturalist, University of Chicago Press, v. 110, n. 974, p. 573-599, 1976.

37 VARLEY, G. C.; GRADWELL, G. R.; HASSELL, M. P. Insect population ecology: an analytical approach. [S.l.]: Univ of California Press, 1974.

38 BRAUER, F.; CASTILlO-CHAVEZ, C.; CASTILLO-CHAVEZ, C. Mathematical models in population biology and epidemiology. [S.1.]: Springer, 2012. v. 2.

39 GLEICK, J. Chaos: Making a new science. [S.1.]: Open Road Media, 2011.

40 LIU, X. et al. Author summary Introduction 1 Increment Entropy.

41 LIPSITZ, L. A. Physiological complexity, aging, and the path to frailty. Science of aging knowledge environment: SAGE KE, v. 2004, n. 16, p. pe16-pe16, 2004.

42 GOLDBERGER, A. L. Is the normal heartbeat chaotic or homeostatic? Physiology, v. 6 , n. 2, p. 87-91, 1991.

43 COSTA, M.; GOLDBERGER, A. R. Y. L. in Physiologic Time Series. v. 1, n. 1, p. 61-70, 2009.

44 PAULUS, M. P. et al. Application of entropy measures derived from the ergodic theory of dynamical systems to rat locomoter behavior. Proceedings of the National Academy of Sciences of the United States of America, v. 87, n. 2, p. 723-727, 1990. ISSN 00278424. 
45 GLENNY, R. W. et al. Applications of fractal analysis to physiology. Journal of Applied Physiology, v. 70, n. 6, p. 2351-2367, 1991.

46 DEBOER, R. W.; KAREMAKER, J. M.; STRACKEE, J. Comparing Spectra of a Series of Point Events Particularly for Heart Rate Variability Data. IEEE Transactions on Biomedical Engineering, BME-31, n. 4, p. 384-387, 1984. ISSN 15582531.

47 LIPSITZ, L. A. et al. Spectral characteristics of heart rate variability before and during postural tilt. Relations to aging and risk of syncope. Circulation, v. 81, n. 6, p. 1803-1810, 1990. ISSN 00097322.

48 ROBERT, D.; SCOTT, G. C. Clinical Conference * Hearing Impairment in Elderly Persons.

49 PINCUS, S. Approximate entropy (ApEn) as a complexity measure. Chaos, v. 5, n. 1, p. 110-117, 1995. ISSN 10541500.

50 KAPLAN, D. T. et al. Aging and the complexity of cardiovascular dynamics. Biophysical journal, Elsevier, v. 59, n. 4, p. 945-949, 1991.

51 ROLE, T. H. E.; IN, E.; SENESCENCE, B. H=f+ts. p. 342-349, 1966.

52 SHAnnOn, C. E. A Mathematical Theory of Communication. Bell System Technical Journal, v. 27, n. 4, p. 623-656, 1948. ISSN 15387305.

53 PINCUS, S. M.; GLADSTONE, I. M.; EHRENKRANZ, R. A. A regularity statistic for medical data analysis. Journal of Clinical Monitoring, v. 7, n. 4, p. 335-345, 1991. ISSN 07481977.

54 BILLMAN, G. E. et al. An introduction to heart rate variability: Methodological considerations and clinical applications. Frontiers in Physiology, v. 6, n. FEB, 2015. ISSN $1664042 \mathrm{X}$.

55 BIGGER, J. T. The Predictive Value of RR Variability and Baroreflex Sensitivity in Coronary Heart Disease. Cardiac Electrophysiology Review, v. 1, n. 1-2, p. 198-204, 1997. ISSN 13852264.

56 De Jong, M. M. J.; RANDALL, D. C. Heart rate variability analysis in the assessment of autonomic function in heart failure. Journal of Cardiovascular Nursing, v. 20, n. 3, p. 186-195, 2005. ISSN 15505049.

57 THAYER, J. F.; YAMAMOTO, S. S.; BROSSCHOT, J. F. The relationship of autonomic imbalance, heart rate variability and cardiovascular disease risk factors. International Journal of Cardiology, v. 141, n. 2, p. 122-131, 2010. ISSN 01675273.

58 TAYLOR, J. A.; STUDINGER, P. Counterpoint: cardiovascular variability is not an index of autonomic control of the circulation. Journal of applied physiology (Bethesda, Md. : 1985), v. 101, n. 2, p. 676-682, 2006. ISSN 87507587.

59 KOLMOGOROV, A. N. A new metric invariant of transient dynamical systems and automorphisms in lebesgue spaces. In: Dokl. Akad. Nauk SSSR (NS). [S.l.: s.n.], 1958. v. 119, n. $861-864$, p. 2. 


\section{Referências}

60 POWELL, G. E.; PERCIVAL, I. C. A spectral entropy method for distinguishing regular and irregular motion of Hamiltonian systems. Journal of Physics A: General Physics, v. 12, n. 11, p. 2053-2071, 1979. ISSN 03054470.

61 ROBERTS, S. J.; PENNY, W.; REZEK, I. Temporal and spatial complexity measures for electroencephalogram based brain-computer interfacing. Medical and Biological Engineering and Computing, v. 37, n. 1, p. 93-98, 1999. ISSN 01400118.

62 ROSSO, O. A. et al. Wavelet entropy: A new tool for analysis of short duration brain electrical signals. Journal of Neuroscience Methods, v. 105, n. 1, p. 65-75, 2001. ISSN 01650270 .

63 BANDT, C.; POMPE, B. Permutation Entropy: A Natural Complexity Measure for Time Series. Physical Review Letters, v. 88, n. 17, p. 4, 2002. ISSN 10797114.

64 THURAISINGHAM, R. A.; GOTTWALD, G. A. On multiscale entropy analysis for physiological data. Physica A: Statistical Mechanics and its Applications, v. 366, p. 323-332, 2006. ISSN 03784371.

65 SINAI, Y. G. On the notion of entropy of a dynamical system. In: Dokl. Akad. Nauk. SSSR. [S.l.: s.n.], 1959. v. 124, p. 768.

66 LATORA, V.; BARANGER, M. Kolmogorov-sinai entropy rate versus physical entropy. Physical Review Letters, v. 82, n. 3, p. 520-523, 1999. ISSN 10797114.

67 Doyne Farmer, J. Chaotic attractors of an infinite-dimensional dynamical system. Physica D: Nonlinear Phenomena, v. 4, n. 3, p. 366-393, 1982. ISSN 01672789.

68 GRASSBERGER, P.; PROCACCIA, I. Estimation of the kolmogorov entropy from a chaotic signal. Physical review A, APS, v. 28, n. 4, p. 2591, 1983.

69 GOMEZ, I. et al. A Semiclassical Condition for Chaos Based on Pesin Theorem. International Journal of Theoretical Physics, v. 54, n. 7, p. 2192-2203, 2015. ISSN 15729575.

70 HAAKE, F.; WIEDEMANN, H.; ŻYCZKOWSKI, K. Lyapunov exponents from quantum dynamics. Annalen der Physik, v. 504, n. 7, p. 531-539, 1992. ISSN 15213889.

71 PESIN, Y. B. Characteristic lyapunov exponents and smooth ergodic theory. Uspekhi Matematicheskikh Nauk, Russian Academy of Sciences, Steklov Mathematical Institute of Russian ..., v. 32, n. 4, p. 55-112, 1977.

72 LICHTENBERG, A. J.; LIEBERMAN, M. A. Regular and chaotic dynamics. [S.1.]: Springer Science \& Business Media, 2013. v. 38.

73 DOWNAROWICZ, T. Entropy in dynamical systems. Entropy in Dynamical Systems, p. 1-365, 2011.

74 PINCUS, S. M.; GOLDBERGER, A. L. Physiological time-series analysis: What does regularity quantify? American Journal of Physiology - Heart and Circulatory Physiology, v. 266, n. 4 35-4, 1994. ISSN 00029513.

75 ECKMANN, J.-P.; RUELLE, D. Ergodic theory of chaos and strange attractors. The theory of chaotic attractors, Springer, p. 273-312, 1985. 
76 LAKE, D. E. et al. Sample entropy analysis of neonatal heart rate variability. American Journal of Physiology-Regulatory, Integrative and Comparative Physiology, American Physiological Society Bethesda, MD, v. 283, n. 3, p. R789-R797, 2002.

77 LIU, C. et al. Comparison of different threshold values $\mathrm{r}$ for approximate entropy: Application to investigate the heart rate variability between heart failure and healthy control groups. Physiological Measurement, v. 32, n. 2, p. 167-180, 2011. ISSN 09673334.

78 RAMDANI, S. et al. On the use of sample entropy to analyze human postural sway data. v. 31, n. 8, p. 1023-1031, 2009. ISSN 13504533.

79 HAYANO, J. Yamasaki f, sakata s, okada a, mukai s, and fujinami t. Spectral characteristics of ventricular response to atrial fibrillation. Am J Physiol Heart Circ Physiol, v. 273, p. H2811-H2816, 1997.

80 ZENG, W.; GLASS, L. Statistical properties of heartbeat intervals during atrial fibrillation. Physical Review E, APS, v. 54, n. 2, p. 1779, 1996.

81 BALOCCHI, R. et al. Methodology and clinical applications of blood pressure and heart rate analysis. Ios Press Inc., 1999.

82 NIU, H.; WANG, J. Quantifying complexity of financial short-term time series by composite multiscale entropy measure. Communications in Nonlinear Science and Numerical Simulation, Elsevier B.V., v. 22, n. 1-3, p. 375-382, 2015. ISSN 10075704. Disponível em: <http://dx.doi.org/10.1016/j.cnsns.2014.08.038>.

83 CHEN, W. et al. Measuring complexity using fuzzyen, apen, and sampen. Medical Engineering and Physics, Elsevier, v. 31, n. 1, p. 61-68, 2009.

84 ZHENG, J.-D. et al. Multiscale fuzzy entropy and its application in rolling bearing fault diagnosis. J. Vib. Eng, v. 27, p. 145-151, 2014.

85 ZHENG, J. et al. A rolling bearing fault diagnosis method based on multi-scale fuzzy entropy and variable predictive model-based class discrimination. Mechanism and Machine Theory, Elsevier B.V., v. 78, p. 187-200, 2014. ISSN 0094114X. Disponível em: <http://dx.doi.org/10.1016/j.mechmachtheory.2014.03.014>.

86 ANGELINI, L. et al. Multiscale analysis of short term heart beat interval, arterial blood pressure, and instantaneous lung volume time series. Artificial Intelligence in Medicine, v. 41, n. 3, p. 237-250, 2007. ISSN 09333657.

87 AZAMI, H.; ESCUDERO, J. Improved multiscale permutation entropy for biomedical signal analysis: Interpretation and application to electroencephalogram recordings. Biomedical Signal Processing and Control, Elsevier Ltd, v. 23, p. 28-41, 2016. ISSN 17468108. Disponível em: <http://dx.doi.org/10.1016/j.bspc.2015.08.004>.

88 SILVA, L. et al. The role of sympathetic and vagal cardiac control on complexity of heart rate dynamics. American Journal of Physiology, Heart and Circulatory Physiology, v. 312, n. 3, p. H469-H477, 2017.

89 GOLDBERGER, A. et al. Physiobank, physiotoolkit, and physionet: Components of a new research resource for complex physiologic signals. Circulation [Online], v. 23, n. 101, p. e215-e220, 2000. 


\section{Referências}

90 FAINI, A.; CASTIGLIONI, P. Comment on " Modified multiscale fuzzy entropy : A robust method for short-term Comment on " Modified multiscale fuzzy entropy : A robust method for short-term physiologic. AIP Publishing LLC, v. 083135, n. October 2020, 2021.

91 BORIN, A. M. S.; SILVA, L. E. V.; MURTA, L. O. Response to "comment on "modified multiscale fuzzy entropy: A robust method for short-term physiologic signals", [chaos 30, 083135 (2020)]. Chaos: An Interdisciplinary Journal of Nonlinear Science, v. 31, n. 1, p. 018102, 2021. Disponível em: <https://doi.org/10.1063/5.0040708>.

92 VALENCIA, J. F. et al. Refined multiscale entropy: Application to 24-h holter recordings of heart period variability in healthy and aortic stenosis subjects. IEEE Transactions on Biomedical Engineering, v. 56, n. 9, p. 2202-2213, 2009. ISSN 00189294.

93 SILVA, L. E. V. et al. Multiscale entropy analysis of heart rate variability in heart failure, hypertensive, and sinoaortic-denervated rats: Classical and refined approaches. American Journal of Physiology - Regulatory Integrative and Comparative Physiology, v. 311, n. 1, p. R150-R156, 2016. ISSN 15221490.

94 PENG, C.-K.; COSTA, M.; GOLDBERGER, A. L. Adaptive data analysis of complex fluctuations in physiologic time series. Advances in Adaptive Data Analysis, v. 01, n. 01, p. 61-70, 2009.

95 MAYER, C. et al. The effect of threshold values and weighting factors on the association between entropy measures and mortality after myocardial infarction in the Cardiac Arrhythmia suppression trial (CAST). Entropy, v. 18, n. 4, 2016. ISSN 10994300.

96 AZAMI, H. et al. Fuzzy Entropy Metrics for the Analysis of Biomedical Signals: Assessment and Comparison. IEEE Access, v. 7, p. 104833-104847, 2019. ISSN 2169-3536. 

Apêndices 



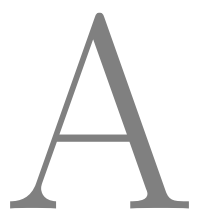

Artigo: "Modified multiscale fuzzy entropy: A robust method for short-term physiologic signals" https://doi.org/10.1063/5.0010330 


\section{Modified multiscale fuzzy entropy: A robust method for short-term physiologic signals}

Cite as: Chaos 30, 083135 (2020); https://doi.org/10.1063/5.0010330

Submitted: 15 April 2020 . Accepted: 03 August 2020 . Published Online: 17 August 2020

Airton Monte Serrat Borin (D), Luiz Eduardo Virgilio Silva (D), and Luiz Otavio Murta (iD)

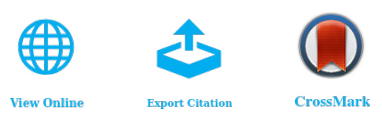

\section{ARTICLES YOU MAY BE INTERESTED IN}

Intermittent route to generalized synchronization in bidirectionally coupled chaotic oscillators Chaos: An Interdisciplinary Journal of Nonlinear Science 30, 083133 (2020); https:// doi.org/10.1063/5.0007156

Impact of number of stimulation sites on long-lasting desynchronization effects of coordinated reset stimulation

Chaos: An Interdisciplinary Journal of Nonlinear Science 30, 083134 (2020); https:// doi.org/10.1063/5.0015196

Order-indeterminant event-based maps for learning a beat

Chaos: An Interdisciplinary Journal of Nonlinear Science 30, 083138 (2020); https:// doi.org/10.1063/5.0013771

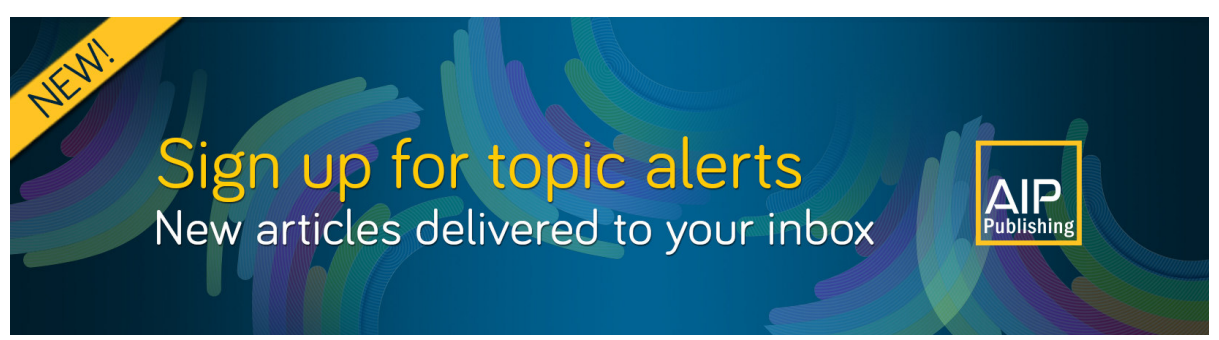




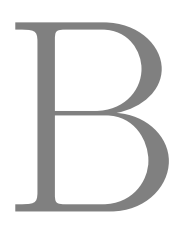

Artigo: "Response to "Comment on 'Modified multiscale fuzzy entropy: A robust method for, short-term physiologic signals"

https://doi.org/10.1063/5.0040708 